\title{
Investigation of glycolysis in Bacillus subtilis
}

\author{
Dissertation \\ for the award of the degree \\ „Doctor rerum naturalium“ (Dr. rer. nat.) \\ Division of Mathematics and Natural Sciences \\ of the Georg-August-Universität Göttingen
}

\author{
submitted by \\ Nico Pietack \\ from Frankfurt (Oder)
}

Göttingen 2010 
Supervisor: Prof. Dr. Jörg Stülke

(Institute for Microbiology and Genetics / Department of General Microbiology / University Göttingen)

Members of the thesis committee:

\section{Prof. Dr. Ralf Ficner}

(Institute for Microbiology and Genetics / Department of Molecular Structural Biology / University Göttingen)

\section{Dr. Ingo Heilmann}

(Albrecht von Haller Institute for Plant Sciences / Department of Plant Biochemistry / University Göttingen)

Day of oral examination: 29.04.2010 
I hereby declare that the doctoral thesis entitled, "Investigation of Glycolysis in Bacillus subtilis" has been written independently and with no other sources and aids than quoted.

Nico Pietack 
Die beste und sicherste Tarnung ist immer noch die blanke und nackte Wahrheit. Die glaubt niemand!

(Max Frisch) 


\section{Content}

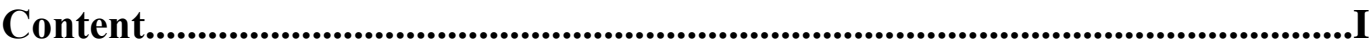

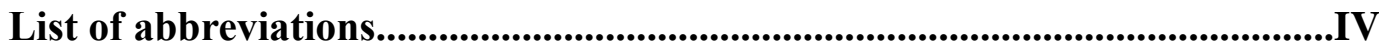

List of publications.........................................................................................................VII

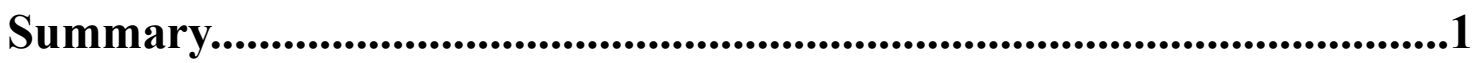

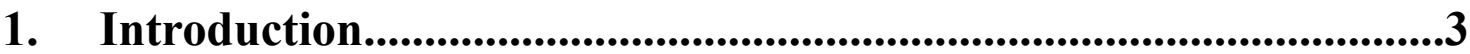

1.1. The Gram-positive model organism $B$. subtilis..............................................3

1.2. Central carbon metabolism in B. subtilis...............................................4

1.2.1. Carbon sources and uptake mechanisms...........................................5

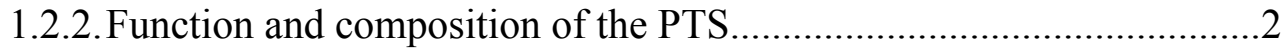

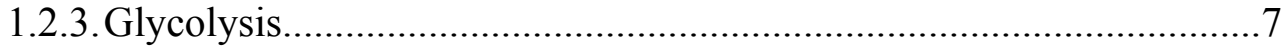

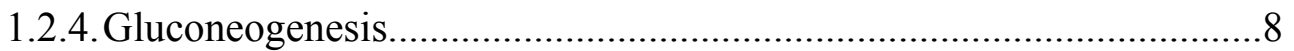

1.2.5. Main routes of carbon utilization in B. subtilis................................10

1.3. Posttranslational modifications............................................................10

1.3.1.Protein phosphorylation in bacteria..................................................10

1.3.2. Two-component regulatory systems................................................ 12

1.3.3. Protein phosphorylation on serine/ threonine and tyrosine .................12

1.4. Essential genes and metabolic skills......................................................14

1.4.1. Minimal genome and essential processes..........................................14

1.4.2. Specific requirements and versatile adaptation.................................15

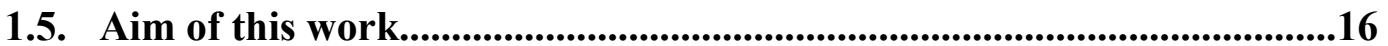

2. Materials and Methods.........................................................................17

2.1. Microbiological technique......................................................................17 
2.1.1. Bacterial strains and plasmids

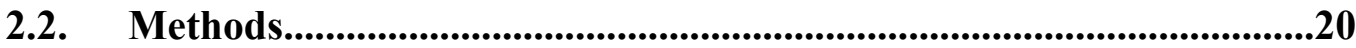

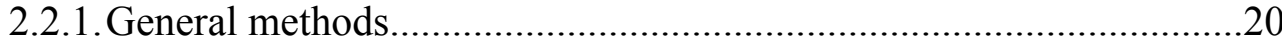

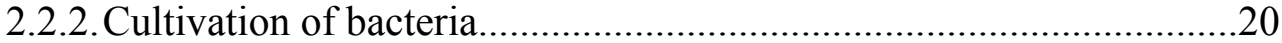

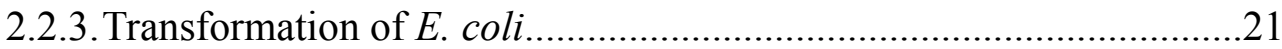

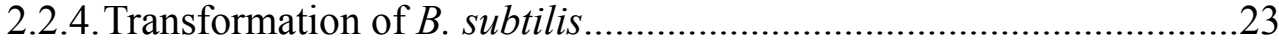

2.2.5.Preparation and detection of DNA.................................................24

2.2.6.Preparation and analysis of proteins.................................................32

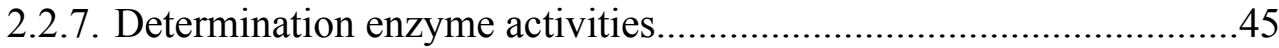

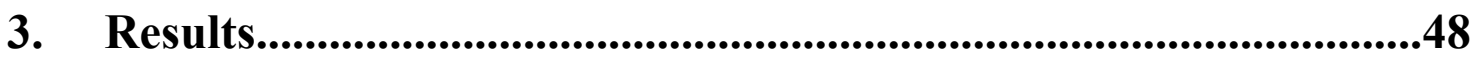

3.1. Construction and analysis of multiple Ser/ Thr kinase mutants.......48

3.1.1. Phosphoproteome analysis of kinase mutants.................................48

3.1.2. Phenotype of a triple kinase mutant................................................49

3.2. Investigation of conserved GTPases....................................................50

3.3. Analysis of the phosphorylation of HPr...............................................52

3.4. Investigation of essential glycolytic genes in $B$. subtilis.....................54

3.4.1. Conditions for the construction of mutants of glycolytic genes.........54

3.4.2. Morphological phenotype of glycolytic mutants...............................58

3.4.3. Growth of glycolytic mutants on different carbon sources................60

3.4.4. Elucidation of growth of a gapA mutant on glucose........................63

3.5. Phosphorylation of glycolytic enzymes...............................................67

3.5.1. ATP dependent phosphorylation events in crude extracts.................67

3.5.2. Autophosphorylation of the phosphoglycerate mutase.......................68

3.5.3. Significance of phosphorylation of phosphoglycerate mutase...........69

3.5.4. Relevance of phosphorylation of triose phosphate isomerase............70

3.5.5. Identification of phosphorylation sites of the pyruvate kinase...........72

3.6. Conservation of autophosphorylation of phosphosugar mutases.......74

3.6.1. Autophosphorylation of GlmM from B. subtilis and ManB from Mycoplasma pneumoniae. 
3.6.2. Importance of the conserved Ser-100 of GlmM for the viability of $B$. subtilis.

4. Discussion 79

4.1. Mutants of essential glycolytic genes. .79

4.2. Protein phosphorylation in $B$. subtilis: Of conservation and coincidence.

4.3. Autophosphorylation: The answer for kinase independent protein phosphorylation?............................................................................89

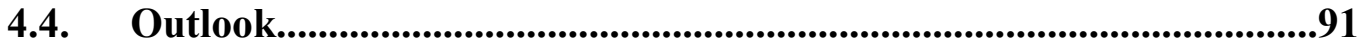

5. References...................................................................................................92

6. Appendix........................................................................................111

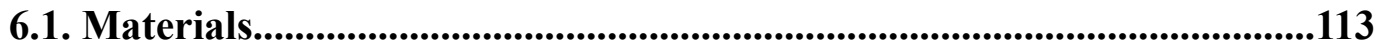

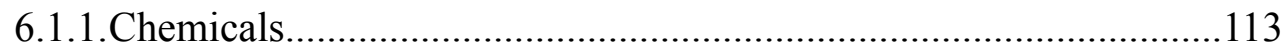

6.1.2.Auxiliary material..................................................................114

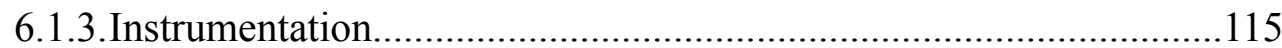

6.1.4.Commercial systems / software....................................................116

6.2. Oligonucleotides...........................................................................................117

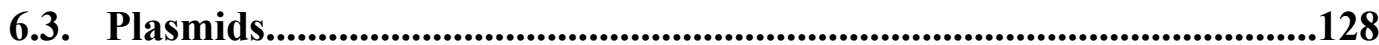

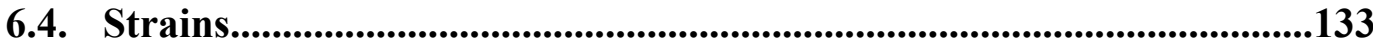

6.5. Construction of mutant...........................................................................137

7. Danksagung................................................................................138

8. Curriculum vitae....................................................................................140 


\section{List of abbreviations}

\begin{tabular}{|c|c|}
\hline$\%(\mathrm{v} / \mathrm{v})$ & \% (volume/volume) \\
\hline$\%(\mathrm{w} / \mathrm{v})$ & $\%$ (weight/volume) \\
\hline Amp & ampicillin \\
\hline APS & ammoniumperoxodisulfat \\
\hline ATP & adenosine triphosphate \\
\hline BSA & bovine serum albumin \\
\hline $\mathrm{C}$ & carbon \\
\hline CCR & carbon catabolite repression \\
\hline DMSO & dimethylsulfoxide \\
\hline DNA & desoxyribonucleic acid \\
\hline dNTP & desoxyribonucleic triphosphate \\
\hline DTT & dithiothreitol \\
\hline EI & enzyme I \\
\hline EII & enzyme II \\
\hline EDTA & ethylenediaminetetra acetic acid \\
\hline et al. & et alia \\
\hline $\mathrm{H}_{2} \mathrm{O}$ deion. & deionized water \\
\hline IPTG & isopropyl- $\beta$-D-thiogalactopyranoside \\
\hline LB & Luria Bertani (medium) \\
\hline LFH & long flanking homology \\
\hline MES & 2-(N-morpholino)ethanesulfonic acid \\
\hline $\mathrm{mM}$ & millimolar \\
\hline $\mathrm{NAD}^{+} / \mathrm{NADH}_{2}$ & $\beta$-nicotinamide adenine dinucleotide \\
\hline $\mathrm{NADP}^{+} /$ & $\beta$-nicotinamide adenine dinucleotide phosphat \\
\hline $\begin{array}{l}\mathrm{NADPH}_{2} \\
\mathrm{Ni}^{2+} \text {-NTA }\end{array}$ & nickel-nitrilotri acid \\
\hline OD & optical density \\
\hline PAGE & polyacrylamide gel electrophoresis \\
\hline PCR & polymerase chain reaction \\
\hline $\mathrm{pH}$ & power of hydrogen \\
\hline PTS & phosphoenolpyruvate: sugar phosphotransferase system \\
\hline RT & room temperature \\
\hline SDS & sodium dodecyl sulfate \\
\hline SP & sporulation medium \\
\hline Tab. & table \\
\hline
\end{tabular}




$\begin{array}{ll}\text { TCC } & \text { tricarboxylic acid cycle } \\ \text { TEMED } & \mathrm{N}, \mathrm{N}^{\prime} \mathrm{N}^{\prime}, \mathrm{N}^{\prime} \text {-tetramethylethylendiamine } \\ \text { Tris } & \text { tris-(hydroxymethyl)-aminomethane } \\ \mathrm{U} & \text { units } \\ \text { WT } & \text { wild type }\end{array}$

\section{Enzyme Gene}

Eno eno enolase

FbaA fbaA fructose-1,6-bisphosphate aldolase

GapDH gapA glyceraldehyde-3-phosphate dehydrogenase

GapDH gapB glyceraldehyde-3-phosphate dehydrogenase

PfkA pfkA phosphofructokinase

Pgi pgi glucosephosphate isomerase

Pgk pgk phosphoglycerate kinase

Pgm pgm phosphoglycerate mutase

Pyk pykA pyruvate kinase

Tpi tpiA triosephosphate isomerase

\section{Glycolytic intermediates}

G6P glucose-6-phosphate

F6P fructose-6-phosphate

2PG 2-phosphoglycerate

3PG 3-phosphoglycerate

1,3PG 1,3-bisphosphoglycerate

DHAP dihydroxyacetone phosphate

FBP fructose-1,6-bisphosphate

GAP glyceraldehyde-3-phosphate

Glc glucose

PEP phosphoenolpyruvate

PYR pyruvate 
Units

${ }^{\circ} \mathrm{C}$

A

bp

$\mathrm{Ci}$

cpm

$\mathrm{Da}$

$\mathrm{g}$

$\mathrm{h}$

1

M

$\min$

sec

rpm

$\mathrm{V}$

W degrees Celsius

Ampere

base pair

Curie

counts per minute

Dalton

gram

hour

litre

molar (mol/1)

minute

second

rounds per minute

Volt

Watt

\section{Prefixes}

$\begin{array}{lll}\mathrm{k} & \text { kilo } & 10^{3} \\ \mathrm{~m} & \text { milli } & 10^{-3} \\ \mu & \text { micro } & 10^{-6} \\ \mathrm{n} & \text { nano } & 10^{-9}\end{array}$

\section{Nucleotides}

A

C

adenine

cytosine

G

guanine

$\mathrm{T}$

thymine

U

uracile

Amino acids- nomenclatur: (IUPAC-IUB 1969)

$\begin{array}{llllll}\text { A } & \text { Ala } & \text { alanine } & \text { M } & \text { Met } & \text { methionine } \\ \text { C } & \text { Cys } & \text { cysteine } & \text { N } & \text { Asn } & \text { asparagine } \\ \text { D } & \text { Asp } & \text { aspartate } & \text { P } & \text { Pro } & \text { proline } \\ \text { E } & \text { Glu } & \text { glutamate } & \text { Q } & \text { Gln } & \text { glutamine } \\ \text { F } & \text { Phe } & \text { phenylalanine } & \text { R } & \text { Arg } & \text { arginine } \\ \text { G } & \text { Gly } & \text { glycine } & \text { S } & \text { Ser } & \text { serine } \\ \text { H } & \text { His } & \text { histidine } & \text { T } & \text { Thr } & \text { threonine } \\ \text { I } & \text { Ile } & \text { isoleucine } & \text { T } & \text { Tyr } & \text { tyrosine } \\ \text { K } & \text { Lys } & \text { lysine } & \text { V } & \text { Val } & \text { valine } \\ \text { L } & \text { Leu } & \text { leucine } & \text { W } & \text { Trp } & \text { tryptophan }\end{array}$




\section{List of publications}

Pietack, N., Becher, D., Hecker, M., Commichau F. M., Stülke, J. 2010. In vitro phosphorylation of key metabolic enzymes from Bacillus subtilis: PrkC phosphorylates enzymes from different branches of basic metabolism. Journal of Molecular Microbiology and Biotechnology.18 (3):129-140.

Schmidl, S. R., Gronau, K., Pietack, N., Hecker, M., Becher, D., Stülke, J. 2010. The phosphoproteome of the minimal bacterium Mycoplasma pneumoniae: Analysis of the complete known Ser/ Thr kinome suggests the existence of novel kinases. Molecular \& CellularProteomics, in press

Lehnik-Habrink, M., Pförtner, H., Pietack, N., Herzberg, C., Stülke, J., 2010. Identification of CshA as the major RNA helicase in the multi-protein complex. in revision 


\section{Summary}

Bacillus subtilis is a model organism for Gram-positive bacteria and object for biotechnological applications. The extensive investigation of this bacterium makes it one of the best studied prokaryotes in terms of molecular and cell biology. However, a lot of issues are still open for the complete comprehension of this bacterium. The functions of various genes must be elucidated, as well as the role of posttranslational modifications. Among the posttranslation modifications the phosphorylation of proteins has a great regulatory potential. Recent studies revealed, that the phosphorylation of proteins on serine, threonine and tyrosine residues is widespread among bacteria, including Bacillus subtilis.

The aim of this work was to investigate the origin and function of phosphorylation events on serine, threonine and tyrosine residues in $B$. subtilis. For this purpose, multiple kinase mutants were constructed and their phosphoproteomes were analysed. However, the phosphoproteome of these mutants remained unchanged. Hence, it was assumed that unknown kinases or other mechanism of phosphorylation must be responsible. Several approaches revealed that certain proteins are autophosphorylated. The conserved GTP-binding proteins Obg and YdiB were found as autophosphorylated in the presence of their substrates GTP and ATP, respectively. Furthermore, the phosphosugar mutases phosphoglycerate mutase (Pgm) and phosphoglucosamine mutase $(\mathrm{GlmM})$ are also autophosphorylated on conserved serine residues. The autophosphorylation of these residues is part of their enzymatic activity and thus kinase independent. These results indicate that apparently not all phosphorylation events in B. subtilis are kinase dependent. However, completely new kinases can not be excluded, but are obviously not responsible for the entirety of phosphorylation events in B. subtilis. Hence, it must be summarized that autophosphosphorylation of proteins can occur during interaction with energy rich phosphate carriers and it also can be part of enzymatic activity.

In $B$. subtilis, nearly all enzymes of glycolysis were found to be phosphorylated. In addition, previous studies described all genes that code for glycolytic enzymes as 
essential. However, in this work it was discovered that each glycolytic gene can be deleted and that even strains with combinations of mutations are still viable. Growth tests revealed, that single mutants of glycolytic genes are able to grow on minimal medium with glucose and malate. Moreover, the phosphofructokinase $(\triangle p f k A)$ and glyceraldehyde-3-phosphate dehydrogenase mutant $(\triangle g a p A)$ grow with glucose as sole carbon source.

For long time it was supposed that most of the glycolytic genes were essential for an unknown reason. This is the first time, that deletion mutants were constructed for each individual glycolytic gene of $B$. subtilis. Glycolytic mutants are a good basis for further studies in B. subtilis. 


\section{Introduction}

Bacteria are a large group of unicellular microorganisms. Their metabolic diversity and their ability to adapt to nearly every habitat makes them an interesting and valuable source for science and biotechnological applications. Bacteria are distributed from the earth crust and hydrothermal vents in deep sea to the glaciers of antarctica. Living under these extreme conditions requires sophisticated adaptation mechanisms. All cellular and metabolic functions have to be tightly regulated to cope with these challenging environmental conditions. However, the cultivation of bacteria from extreme habitats is difficult and time-consuming. Therefore, the knowledge of basic biochemical and genetic processes must be achieved by studying model organisms like Escherichia coli or Bacillus subtilis. Furthermore, bacteria are also the main cause of infectious diseases worldwide. Working with pathogenic bacteria requires complex safety regulation and remains still risky. This disadvantage can be circumvented by studying non-pathogenic relatives of pathogenic bacteria. For example, the knowledge about the regulation of the basic metabolism gives on one hand the opportunities to modulate the metabolism for biotechnological demands. On the other hand, new targets for drugs against multi-resistant bacteria could be raised. This work focusses on glycolysis as one of the central metabolic pathways.

\subsection{The Gram-positive model organism B. subtilis}

B. subtilis is a Gram-positive rod-shaped soil bacterium with low GC-content. The natural habitat is the upper soil (rhizosphere). Thus, it is subject to rapidly changing environmental conditions. The availability of water, osmolarity, oxygen and nutrient supply and fluctuations in temperature are just a few examples that require elaborate adaptation mechanisms. Therefore, B. subtilis possesses different strategies that guarantee the survival under changing conditions. B. subtilis and other aerobic Grampositives can adapt to stress condition, like energy depletion, cold and environmental shock by triggering the general stress response (Hecker et al., 2007). Furthermore, 
during starvation of carbon and nitrogen sources, growing cultures of B. subtilis are able to form dormant, heat- and stress resistant endospores (Losick et al., 1986). Various pathogens are able to form endospores, too. For example Bacillus anthracis and Clostridium botulinum as important toxin producers. Therefore B. subtilis is a interesting model for the investigation of cell differentiation and division processes (Errington, 2003). In the rhizosphere, B. subtilis utilises different polymers as energy and carbon source. For their depolymerization several classes of enzymes are secreted. These skills, make B. subtilis an important source for biotechnological applications. Furthermore, it is used as workhorse for the production of vitamins and enzymes. As a non-pathogenic bacterium it is classified as GRAS-organism (GRAS = general recognized as safe) and can therefore be cultivated without extensive safety regulations. In addition, the natural competence in combination with a fully annotated genome make B. subtilis a meaningful toolbox for molecular biology (Kunst et al., 1997; Barbe et al., 2009).

\subsection{Central carbon metabolism in $B$. subtilis}

The central carbon metabolism in B. subtilis consists of glycolysis, gluconeogenesis, the pentose phosphate pathway and the citric acid cycle (Sauer \& Eikmann, 2005). The main function of these metabolic pathways are the supply of energy and essential intermediates. Free energy that is released in metabolic processes is converted to high energy compounds, like ATP and reduction equivalents like $\mathrm{NAD}(\mathrm{P}) \mathrm{H}_{2}$. Reduction equivalents are further necessary for anabolic enzymatic reactions. These central metabolic pathways are conserved in most organisms. Some pathogens display specific adaptation to their nutrition rich environment. For example Mycoplasma exhibits a reduced genome, but still requires the glycolytic pathway as the only source for energy generation (Himmelreich et al., 1996). Furthermore, nitrogen metabolism is of great importance for the production of amino acids. The central carbon metabolism generates carbon networks. These precursors are further converted in addition to a amino group 
donor. Amino groups are mainly provided by the universal amino acids glutamate and glutamine.

\subsubsection{Carbon sources and uptake mechanisms}

Plants are the principle suppliers of biomass in the rhizosphere. This biomass provides polysaccharides like cellulose as the main nutrition source for Bacillus. These complex compounds must be broken down before transported into the cell. Therefore, B. subtilis secretes several enzymes to degrade the polymers, among them amylases, glucanases, lichenases, levanases (Stülke \& Hillen, 2000).

Different mechanisms are used for the sugar transport across the membrane. Uptake occurs by facilitated diffusion, secondary transporters, ABC-transporters (ㅁTP- $\underline{\text { binding }}$ cassette) and the PTS- system (phosphoenolpyruvate: phosphotransferase system) (Higgins, 1992; Postma et al., 1993).

\subsubsection{Function and composition of the PTS}

In bacteria the uptake of sugars occurs primarily by the PTS, resulting in the phosphorylation of monosaccharide or disaccharides. This modification produces a charged phosphosugar that cannot enter the membrane by diffusion. The trapped sugar is immediately converted in glycolysis. Besides its role in sugar uptake, the PTS has a function in signal transduction. In general the PTS consists of three basic components. These components are the enzyme I (EI), HPr and the enzyme II (EII). In B. subtilis the glucose specific enzyme II is organized in three domains. One of them is membrane associated (EIIC), whereas two are localized in the cytoplasm (EIIA and EIIB). The PTS dependent sugar uptake occurs via EIIC, where the sugar becomes phosphorylated. An energy rich intermediate of the glycolysis, phosphoenolpyruvate (PEP), serves as phosphate donor. The phosphate transfer from PEP to the sugar occurs through a phosphorylation cascade from EI to HPr-His15 and EIIA, EIIB (Fig. 1.1.). The general components of the PTS are encoded in the ptsGHI-operon that is glucose inducible 
(Stülke et al., 1997). The HPr protein is the key element in the sugar uptake system. It can be phosphorylated by the ATP dependent HPr kinase at Ser-46 (Deutscher \& Saier, 1983; Galinier et al., 1998; Reizer et al., 1998). The serine phosphorylation facilitates the binding of the transcriptional regulator $\mathrm{CcpA}$ (catabolite control protein $\underline{\mathrm{A}}$ ) (Schumacher et al., 2004). This complex regulates the expression of genes for the utilization of alternative carbon sources and is therefore important for carbon catabolite repression (Deutscher, 2008; Görke \& Stülke, 2008; Fujita, 2009). In addition, a different phosphorylation site of HPr was identified at Ser-12 (Macek et al., 2007). However, the biological relevance of this phosphorylation event is unknown.

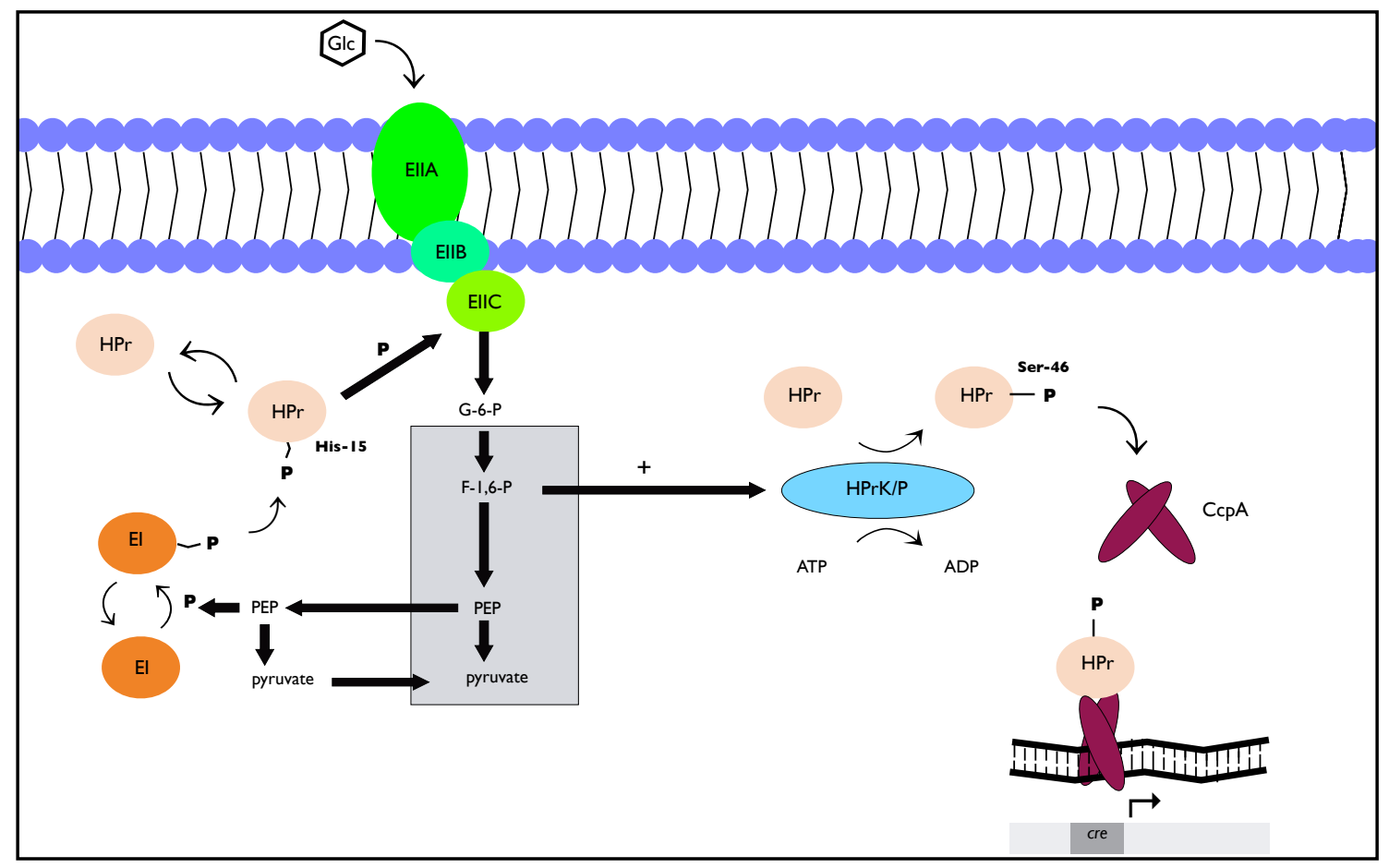

Figure 1.: Glucose transport via PTS and carbon catabolite repression in $B$. subtilis. The phosphate is transfered from PEP via EI and HPr protein (His-15), and EIIA and EIIB to the incoming sugar. The glucose uptake is mediated by the membrane spanning EIIC. In the presence of glucose HPr is phosphorylated by the HPrK/P on Ser-46. Serine phosphorylated HPr forms a complex with CcpA. This complex bind cre sequences of the DNA and thereby represses the transcription of catabolic operons. $\mathrm{CM}=$ cytoplasmatic membrane; cre $=$ catabolite responsive elements. 


\subsubsection{Glycolysis}

Glycolysis is a central metabolic pathway in nearly all organisms. Its function is the generation of ATP by substrate level phosphorylation and the production reduction equivalents. Furthermore it provides essential precursors for the amino acids- and cell wall biosynthesis. B. subtilis encodes all enzymes for the entire glycolysis (Ludwig et al., 2002).

Glucose is phosphorylated immediately when entering the cell by the PTS. Unphosphorylated hexoses must be phosphorylated by the ATP-dependent glucose kinase (Skarlatos \& Dahl, 1998). Rearrangement of glucose-6-phosphate to fructose-6-phosphate is catalyzed by phosphoglucose isomerase encoded by pgi. Fructose-6-phosphate is then phosphorylated in a irreversible, ATP-dependent reaction by the phosphofructokinase $(p f k A)$. The resulting fructose-1,6-diphosphate (FBP) is an important intermediate that indicates the metabolic status of the cell. It also acts as inducer and cofactor in regulatory processes (Jault et al., 2000; Zorilla et al., 2006). The FBP hexose ring is split by the fructose-1,6-diphosphate aldolase $(f b a A)$ into two triose phosphates, dihydroxyacetone phosphate (DHAP) and glyceraldehyde-3-phosphate (G-3-P). DHAP is rapidly interconverted to G-3-P by the triosephosphate isomerase (tpiA). The pay off phase in glycolysis starts with the oxidation of G-3-P to 1,3-bisphosphoglycerate by the glycolytic dehydrogenase (gapA), and reduction of NAD. In the reaction catalyzed by phosphoglycerate kinase (pgk) one molecule of ATP is obtained. 3-Phosphoglycerate (3-PG) is converted to 2-PG by the phosphoglycerate mutase (pgm), and further to PEP by enolase (eno). The pyruvate kinase (pyk) catalyses the final reaction in glycolysis, from PEP to pyruvate with the gain of one ATP. The reactions catalyzed by phosphofructokinase and the pyruvate kinase are irreversible. Interestingly, both genes are encoded in one operon. In the presence of glucose, the expression the pfkA-pyk-operon is induced twofold (Ludwig et al., 2001). The monocistronic $p g i$ and $f b a A$ genes are constitutively expressed. The remaining genes for the lower part of glycolysis are coded in the hexacistronic gap operon. This operon codes also for the own specific regulator ( $\operatorname{cggR}$ ) and the genes gapA, pgk, tpiA, pgm and 
eno (Fillinger et al., 2000). The expression of the operon is repressed by CggR in the absence of glucose. A second promoter downstream of gapA guarantees the expression of the downstream genes, that are necessary for both glycolysis and gluconeogenesis.

\subsubsection{Gluconeogenesis}

Glycolysis provides energy, but more importantly metabolites for anabolic reactions. These metabolites are needed for amino acid and peptidoglycan biosynthesis. Three reactions in glycolysis are irreversible and must therefore be bypassed. Gluconeogenesis is mainly fed by the products of PEP carboxykinase and malic enzymes. PEP can be generated from oxaloacetate by the PEP carboxykinase (pckA) (Tännler et al., 2008). Malic enzymes, especially YtsJ, convert malate to pyruvate (Lerondel et al., 2008). The gained PEP is further converted by the reversible reactions of enolase, phosphoglycerate mutase and phosphoglycerate kinase to 1,3-bisphosphoglycerate. Conversion of 1,3-bisphosphoglycerate to glyceraldehyde-3-phosphate is catalyzed by the gluconegenetic glyceraldehyde-3-phosphate dehydrogenase (gapB). The reversible reaction of aldolase $(f b a A)$ produces fructose-1,6-bisphosphate. The irreversible activity of the phosphosphofructokinase is bypassed by fructose-1,6-bisphosphatase $(f b p A)$. Interestingly, Fujita and Freese have shown that the phosphatase activity is not strictly required for growth on gluconeogenetic substrates (Fujita \& Freese, 1981). Recently, GlpX was described to be also active as fructose-1,6-bisphosphatase. A double mutant lacking both fructose-1,6-bisphosphatases (FbpA and GlpX) was unable to grow on gluconeogenetic carbon sources (Jules et al., 2009). The last reaction resulting in glucose-6-phosphate is reversible and catalyzed by phosphoglucose isomerase. Glucose-6-phosphate is an important precursor for the synthesis of polysaccharides. These polysaccharides are the basis for the peptidoglycan synthesis and therefore essential for cell wall synthesis. The enzymes PckA ( $p c k A)$ and GapB (gapB) catalyse the irreversible and therefore essential reactions at junctions of glycolysis and gluconeogenesis. Their expression isrepressed during growth on glycolytic substrates by the transcriptional regulator CcpN (Servant et al., 2005). 


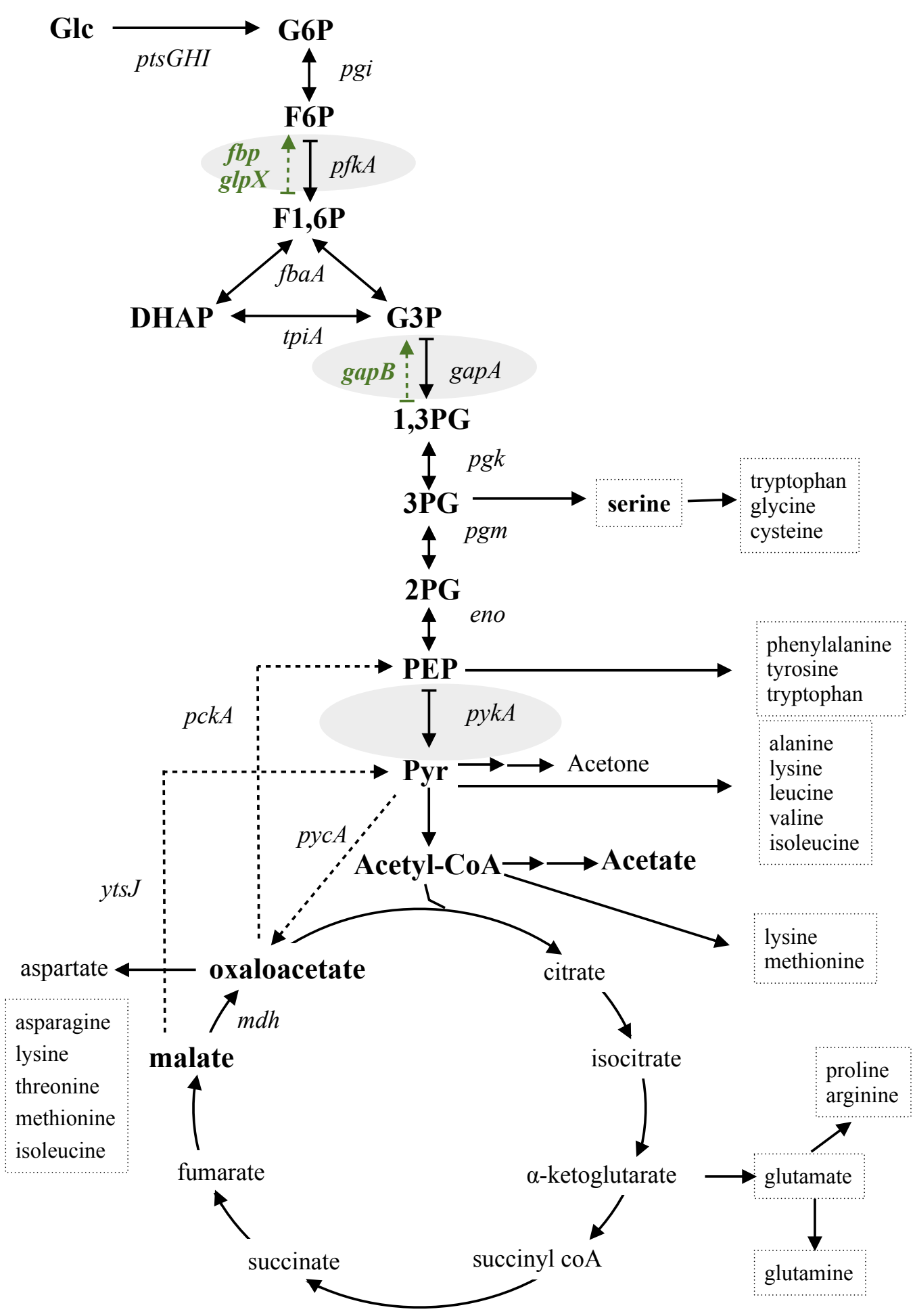

Figure 2.: Central carbon metabolism in B. subtilis. Intermediates of the main reactions in glycolysis and gluconeogenesis are highlighted in bold letters. Irreversible reactions in glycolysis are marked in grey. Reaction in gluconeogenesis are indicated with dashed lines. Connection between carbon metabolism and amino acids biosynthesis is indicated in dotted boxes. 


\subsubsection{Main routes of carbon utilization in $B$. subtilis}

Bacteria evolved different pathways for the utilization of glucose. The anaerobic lactic acid bacteria metabolize glucose through homo- and heterofermentative metabolism. Homofermentative bacteria utilize glucose via glycolysis. Heterofermentative bacteria do not have an aldolase, therefore they can not utilize glucose via glycolysis. However, they can utilize glucose via the phosphoketolase pathway. When B. subtilis is grown aerobically on glucose, the main carbon flow passes glycolysis. About $40 \%$ of the carbon enters the pentose phosphate pathway (Furer et al., 2004; Kleijn et al., 2010). Only half of carbon passes the citric acid cycle. Most of the sugar is excreted by overflow metabolism. The main product of overflow metabolism in B. subtilis is acetic acid. Surprisingly, during growth on malate just $10 \%$ of the carbon is converted in gluconeogenesis, while excretion in overflow metabolism remained unchanged.

\subsection{Posttranslational modifications}

The posttranslation modification of proteins is an important mechanism for the regulation of cellular processes. Different kinds of protein modification have been described so far. The main types are acetylation, adenylation, glycosylation, methylation and phosphorylation (Amaro \& Jerez, 1984; Merrick \& Edwards, 1995; Cozzone, 1998; Abu-Qarn et al., 2008; Wang et al., 2010). These modifications occur at different amino acids residues of proteins that are related to different functional groups in the cell, like carbon metabolism and protein synthesis etc. Furthermore, phosphorylation of proteins plays an important role in the regulation of enzymatic activities.

\subsubsection{Protein phosphorylation in bacteria}

Reversible protein phosphorylation is an important mechanism of posttranslational modification. In B. subtilis, about $5 \%$ of all proteins are subject to phosphorylation. In general the phosphorylation of proteins is catalyzed by protein kinases that use ATP as 
phosphate donor for the phosphorylation of specific amino acid residues. The dephosphorylation is catalyzed by phosphatases that remove the phosphate group. In 1978 the first phosphorylation of proteins on Ser- and Thr residues in bacteria was described (Wang \& Koshland, 1978). Moreover, studies in E. coli revealed that phosphorylation of the isocitrate dehydrogenase on a Ser-residue regulates the carbon flow between citric acid cycle and glyoxylate pathway (Garnak \& Reeves, 1979). However, it was long time assumed that phosphorylation of proteins is specific for eukaryotes and protein phosphorylation in bacteria is limited to the PTS and twocomponent regulatory systems (Deutscher \& Saier, 2005).

In the last decades protein phosphorylation turned into focus of scientific research. The progress in the development of methods for analysis of phosphorylation events allows a rapid and sensitive investigation of phosphoproteomes. Phosphoproteome analysis in B. subtilis identified around 80 proteins phosphorylated on Ser/ Thr and Tyr residues (Levine et al., 2006 Macek et al., 2007; Eymann et al., 2007). However, the function and the origin of these phosphorylation events is mostly unknown. Further phosphoproteome studies were performed in Campylobacter jejuni, Echerichia coli, Klebsiella pneumoniae, Lactococcus lactis, Mycoplasma pneumoniae, Pseudomonas aeruginosa and Streptococcus pneumoniae ( Li et al., 2007; Voisin et al., 2007; Macek et al., 2008; Ravichandran et al., 2008; Soufi et al., 2008; Sun et al., 2010; Schmidl et al., 2010). These studies revealed that phosphorylation on Ser-/ Thr and Tyr residues is wide spread among Gram-positive and Gram-negative bacteria and is therefore not specific for eukaryotes. In addition, conserved phosphoproteins were identified in all investigated species.

In general protein phosphorylations in bacteria can be summarized in three groups. First, phosphorylation of proteins during the sugar uptake by PTS; second, signal transduction by two-componenent sytems; third, phosphorylation of proteins on Ser-/Thr- and Tyr residues that is involved in a variety of cellular processes. 


\subsubsection{Two-component regulatory systems}

Two-component regulatory systems are wide spread among bacteria and are important for sensing of and reacting to environmental changes. They consist of a membrane associated sensor kinase and a response regulator. The sensor kinase responds to specific stimuli with ATP-dependent autophosphorylation on a His-residue. The phosphate group is further passed to an aspartate residue of the cognate response regulator. The response regulator binds specific DNA-sequences and thereby regulates the expression of certain genes. B. subtilis possesses 36 histidine kinases and 34 response regulators, that are part of two-component regulatory systems (Fabret et al., 1999). Two-component systems are involved in regulation of diverse cellular processes for example, the development of competence, spore formation, citrate uptake and peptidoglycan synthesis (Dubnau, 1991; Trach et al., 1991; Yamamoto et al., 2000; Bisicchia et al., 2010).

\subsubsection{Protein phosphorylation on serine/ threonine and tyrosine}

In $B$. subtilis about 80 proteins were found to be phosphorylated on Ser-/ Thr-and Tyrresidues. Only a few of these phosphorylation events are well understood. Interestingly, nearly all glycolytic enzymes were identified as phosphorylated on Ser-/Thr- and partially Tyr-residues.

Protein phosphorylations on Ser/Thr and Tyr residues are the basis of differential regulatory mechanisms like the regulation of gene expression, regulation of enzymatic activities and they also may regulate protein-protein interactions. Studies in B. subtilis revealed that regulatory protein phosphorylation takes place in carbon catabolite repression, general stress response, peptidoglycan synthesis, replication and many more. Well studied examples for protein phosphorylation are Crh and HPr. These proteins are phosphorylated under certain conditions by the ATP-dependent HPr-kinase on Ser-46. The activity of the HPr kinase is stimulated by ATP and FBP. The phosphorylated forms 
of $\mathrm{Crh}$ and $\mathrm{HPr}$ act as co-factors for the transcriptional regulator CcpA, that mediates carbon catabolite repression (Brückner \& Titgemeyer 2002; Stülke \& Hillen, 1999).

Besides, the activity of sigma factors is regulated by protein phosphorylation. The sigma factor $\mathrm{B}(\mathrm{SigB})$ is responsible for the transcription of genes under different stress conditions. SigB is regulated by a partner switching mechanism that is dependent on the phosphorylation status of the participating proteins (on serine and threonine) (Alper et al., 1996; Xiaofeng et al., 1996). Under standard growth conditions, SigB is sequestered by an anti-sigma factor that phosphorylates the anti-anti-sigma factor. The phosphorylated anti-anti-sigma factor is inactive. Under stress conditions different activation routes result in the dephosphorylation of the anti-anti-sigma factor that now binds and inactivates the anti-sigma factor. The released SigB can now associate to the RNA polymerase and the transcription of the stress genes occurs.

B. subtilis possesses also a protein kinase that is similar to eukaryotic Ser-/Thr-kinases. Blast analysis revealed that the kinase domain of PrkC is conserved among bacteria. In B. subtilis PrkC is required for germination in response to muropeptides that were sensed by extracellular PASTA-domain (Shah et al., 2008). Different proteins were identified as phosphorylated by PrkC; among them elongation factors (EF-Tu and G), the ribosome associated GTPase CpgA and the potential stressosome component YezB and proteins of central carbon metabolism (Gaidenko et al., 2002; Absalon et al., 2009; Pietack et al., 2010).

In contrast to phosphorylations on serine and threonine, phosphorylation on tyrosine is rare. In B. subtilis two bacterial tyrosine kinases (BY-kinase) are described, PtkA and EpsB. However, EpsB is just a potential tyrosine kinase (Olivares-Illana et al., 2008). The UDP-glucose dehydrogenase (Ugd) is required for cell wall synthesis and its phosphorylation by PtkA is required for its enzymatic activity (Mijakovic et al., 2003; Petranovic et al., 2009 ). PtkA also phosphorylates single strand DNA binding proteins. Here the phosphorylation enhances the binding activity for DNA and is therefore required for efficient replication (Petranovic et al., 2007).

However, protein phosphorylation is not limited to His/Asp and Ser/Thr/Tyr. Recently it was shown that the transcription repressor for heat shock proteins, CtsR is 
phosphorylated by McsB on an arginine residue. The arginine phosphorylation prevents CtsR from binding DNA (Fuhrmann et al., 2009).

\subsection{Essential genes and metabolic skills}

In the recent years a large number of complete genomic sequences became available for bacteria that are adapted to diverse habitats. The available genomes data are basis for for the detailed investigation of cellular functions. The gained knowledge can be used for specific modification of bacterial metabolism. This opportunity is an important aspect of biotechnology and allows purposeful construction of metabolic pathways.

\subsubsection{Minimal genome and essential processes}

Organisms must have certain properties to be classified alive. They must be capable of reproduction and cellular development. Furthermore, they can respond to stimuli and maintain homeostasis. Related to these general qualities, every organism must have a set of genes for DNA and RNA metabolism, protein processing and folding, for cellular processes and energy and intermediary metabolism.

Comparative genomics revealed a high conservation of genes in bacteria. This conservation can be ascribed to horizontal gene transfer, that served as dominant force of prokaryotic evolution (Koonin et al., 2008). Therefore, genes-products that catalyze essential reactions in the cell, are more conserved then species specific genes. The smallest genome of a self-replicating organism was found in Mycoplasma genitalium. This Gram-positive pathogen possesses only 468 protein-coding genes (Fraser et al., 1995). These small genomes are typical for Mycoplasma species and are the product of degenerative evolution. Mycoplasma species are obligate parasites that require the supply of essential metabolites. They possess a complete glycolysis, however the pentose phosphate pathway is incomplete and the tricarboxylic acid cycle is missing (Himmelreich et al., 1996). Because of these metabolic restrictions, they need complex nutrition for growth. However, complex medium did not make glycolysis dispensable 
for their survival. In contrast to that, B. subtilis possesses a complete glycolysis, the pentose phosphate pathway and the tricarboxylic acid cycle. The genome of B. subtilis codes for around 4,100 protein-coding genes, from that 271 genes were described to be essential by single deletion (Kobayashi et al., 2003). However, bioinformatic analysis showed that around 2,000 genes are duplications. In contrast to that the M. genitalium genome with around 500 genes possesses only 90 duplications (Hannay et al., 2008).

\subsubsection{Specific requirements and versatile adaptation}

B. subtilis is a ubiquitous soil bacterium, that is exposed to rapidly changing environmental conditions and nutrition supply. Therefore, its genome contains specific genes for the utilization of various nutrients. The expression of genes enables the cell to grow on different carbon sources. As B. subtilis is not using all carbon sources at the same time, the expression of these genes has to be regulated to avoid futile expression. Thus, B. subtilis possesses different transcription regulators that coordinate the expression of genes for the efficient utilization of different carbon sources. However, metabolites of glycolysis serve as signals for the metabolic status of the cell. When $B$. subtilis is grown on glucose, FBP stimulates the phosphorylation of HPr and Crh that act as co-repressors for CcpA in carbon catabolite repression. CcpA regulates the transcription of around 300 genes by binding on cre-DNA sequences. In general the expression of genes involved in the overflow metabolism is activated by CcpA (Tobisch et al., 1999; Blencke et al., 2003).

Furthermore, the expression of glycolytic genes is regulated depending on the metabolic status. During growth under gluconeogenetic conditions, CggR represses the transcription of the gapA operon. However, under glycolytic condition the expression is derepressed. The derepression is also mediated by FBP (Doan \& Aymerich, 2003).

The gluconeogenetic genes $p c k A$ and gapB are also regulated on the transcriptional level by $\mathrm{CcpN}$, that represses their expression under glycolytic conditions (Servant et al., 2005). 


\subsection{Aim of this work}

The posttranslational modification of proteins is an ubiquitary mechanism to regulate cellular processes in all domains of life. Protein phosphorylation is one of the most important and best studied forms of modification. Phosphorylation on serine, threonine and tyrosine residues was long time assumed to be unique to eukaryotes. Recent studies indicated that this modification does also occur in bacteria. However, the origin and relevance of these phosphorylation events are unknown to great extent.

The aim of this work was to investigate protein phosphorylation events in B. subtilis. Therefore, the phosphoproteome of multiple kinase mutants was under investigation. 


\section{Materials and Methods}

\subsection{Microbiological techniques}

Materials: Chemicals, utilities, equipment, commercial systems, proteins, antibodies, enzymes and oligonucleotides are listed in the appendix.

\subsubsection{Bacterial strains and plasmids}

See appendix of this work, in chapter 6.

\section{Growth media}

Buffers, solutions and media were prepared with deionized water and autoclaved (20 min at $121^{\circ} \mathrm{C}$ and 2 bar). Thermolabile substances were dissolved and sterilized by filtration. Solutions are related to water, other solvents are indicated.

\section{Bacterial growth media and optional additives}

B. subtilis was grown in C-minimal medium, supplemented with specific additives as indicated. C- minimal medium was supplemented with glucose (Glc) and malate $(0.5 \% \mathrm{w} / \mathrm{v})$. CSE-Glc minimal medium contains beside glucose, sodium succinate (S) (final concentration $8 \mathrm{~g} / \mathrm{l}$ ) and potassium glutamate (E) (final concentration $6 \mathrm{~g} / \mathrm{l}$ ). Further variations of carbon sources are indicated. Basic media were supplemented with agar $(16 \mathrm{~g} / \mathrm{l})$ for solidification.

\begin{tabular}{|c|c|c|}
\hline \multirow[t]{3}{*}{ 5x C salts (1 1) } & $\mathrm{KH}_{2} \mathrm{PO}_{4}$ & $20 \mathrm{~g}$ \\
\hline & $\mathrm{K}_{2} \mathrm{HPO}_{4} \times 3 \mathrm{H}_{2} \mathrm{O}$ & $80 \mathrm{~g}$ \\
\hline & $\left(\mathrm{NH}_{4}\right)_{2} \mathrm{SO}_{4}$ & $16.5 \mathrm{~g}$ \\
\hline
\end{tabular}




\begin{tabular}{|c|c|c|}
\hline \multirow[t]{2}{*}{ III salts $\left(\begin{array}{lll}1 & 1\end{array}\right)$} & $\mathrm{MnSO}_{4} \times 3 \mathrm{H}_{2} \mathrm{O}$ & $0.232 \mathrm{~g}$ \\
\hline & $\mathrm{MgSO}_{4} \times 7 \mathrm{H}_{2} \mathrm{O}$ & $12.3 \mathrm{~g}$ \\
\hline \multirow{3}{*}{$\begin{array}{l}\text { 10x MN medium } \\
\text { (11) }\end{array}$} & $\mathrm{K}_{2} \mathrm{HPO}_{4} \times 3 \mathrm{H}_{2} \mathrm{O}$ & $136 \mathrm{~g}$ \\
\hline & $\mathrm{KH}_{2} \mathrm{PO}_{4}$ & $60 \mathrm{~g}$ \\
\hline & Sodium citrate $\mathrm{x} 2 \mathrm{H}_{2} \mathrm{O}$ & $10 \mathrm{~g}$ \\
\hline \multirow{5}{*}{$\begin{array}{l}\text { 1x C minimal medium } \\
(100 \mathrm{ml})\end{array}$} & $5 \times \mathrm{C}$ salts & $20 \mathrm{ml}$ \\
\hline & Tryptophan $\left(5 \mathrm{mg} \mathrm{ml}^{-1}\right)$ & $1 \mathrm{ml}$ \\
\hline & Ammonium iron citrate $\left(2.2 \mathrm{mg} \mathrm{ml}^{-1}\right)$ & $1 \mathrm{ml}$ \\
\hline & III`salts & $1 \mathrm{ml}$ \\
\hline & $\mathrm{H}_{2} \mathrm{O}_{\text {deion }}$ & ad $100 \mathrm{ml}$ \\
\hline \multirow{7}{*}{$\begin{array}{l}\text { 1x CSE medium } \\
(100 \mathrm{ml})\end{array}$} & $5 \times \mathrm{C}$ salts & $20 \mathrm{ml}$ \\
\hline & Tryptophan (5 mg ml-1) & $1 \mathrm{ml}$ \\
\hline & Ammonium iron citrate $\left(2.2 \mathrm{mg} \mathrm{ml}^{-1}\right)$ & $1 \mathrm{ml}$ \\
\hline & III`salts & $1 \mathrm{ml}$ \\
\hline & Potassium glutamate $(40 \%)$ & $2 \mathrm{ml}$ \\
\hline & Sodium succinate $(30 \%)$ & $2 \mathrm{ml}$ \\
\hline & $\mathrm{H}_{2} \mathrm{O}_{\text {deion }}$ & ad $100 \mathrm{ml}$ \\
\hline \multirow{8}{*}{$\begin{array}{l}\text { SP medium } \\
\left(\begin{array}{ll}1 & 1\end{array}\right)\end{array}$} & Nutrient Broth & $0.8 \mathrm{~g}$ \\
\hline & $\mathrm{MgSO}_{4} \times 7 \mathrm{H}_{2} \mathrm{O}$ & $0.25 \mathrm{~g}$ \\
\hline & $\mathrm{KCl}$ & $1.0 \mathrm{~g}$ \\
\hline & $\mathrm{H}_{2} \mathrm{O}_{\text {deion }}$ & ad 11 \\
\hline & autoclave, after cooling down addition of: & \\
\hline & $\mathrm{CaCl}_{2}(0.5 \mathrm{M})$ & $1 \mathrm{ml}$ \\
\hline & $\mathrm{MnCl}_{2}(10 \mathrm{mM})$ & $1 \mathrm{ml}$ \\
\hline & Ammonium iron citrate $\left(2.2 \mathrm{mg} \mathrm{ml}^{-1}\right)$ & $2 \mathrm{ml}$ \\
\hline \multirow{5}{*}{$\begin{array}{l}\text { MNGE medium } \\
(10 \mathrm{ml})\end{array}$} & $1 \times \mathrm{MN}$ medium & $8.77 \mathrm{ml}$ \\
\hline & Glucose $(20 \%)$ & $1 \mathrm{ml}$ \\
\hline & Potassium glutamate $(40 \%)$ & $50 \mu 1$ \\
\hline & Ammonium iron citrate $\left(2.2 \mathrm{mg} \mathrm{ml}^{-1}\right)$ & $50 \mu 1$ \\
\hline & Tryptophan $\left(5 \mathrm{mg} \mathrm{ml}^{-1}\right)$ & $100 \mu 1$ \\
\hline
\end{tabular}




$$
\begin{array}{lr}
\mathrm{MgSO}_{4} \times 7 \mathrm{H}_{2} \mathrm{O}(1 \mathrm{M}) & 30 \mu \mathrm{l} \\
+/-\quad \mathrm{CAA}(10 \%) & 100 \mu \mathrm{l}
\end{array}
$$

X-Gal Stock solution: $40 \mathrm{mg} / \mathrm{ml} \mathrm{X-Gal} \mathrm{in} \mathrm{DMF,} \mathrm{final} \mathrm{concentration}$ $40 \mu \mathrm{g} / \mathrm{ml}$ in medium.

\section{Antibiotics}

Antibiotics were prepared as 1000-fold concentrated stock solutions. Ampicillin, spectinomycin, lincomycin and kanamycin were dissolved in deion. water, chloramphenicol, erythromycin and tetracycline in $70 \%$ ethanol. All solutions were sterile filtrated and stored at $-20^{\circ} \mathrm{C}$. Autoclaved medium was chilled down to approximately $50^{\circ} \mathrm{C}$, and antibiotics were added to their final concentration. For light sensitive additives such as tetracycline, incubation occurred in the dark.

Selection concentration for $\boldsymbol{E}$. coli

Ampicillin $100 \mu \mathrm{g} \mathrm{ml}^{-1}$

Spectinomycin $100 \mu \mathrm{g} \mathrm{ml}^{-1}$

Kanamycin $50 \mu \mathrm{g} \mathrm{ml}^{-1}$

Selection concentration for $\boldsymbol{B}$. subtilis

Chloramphenicol $5 \mu \mathrm{g} \mathrm{ml} \mathrm{l}^{-1}$

Erythromycin $2 \mu \mathrm{g} \mathrm{ml}^{-1}$

Kanamycin $5 \mu \mathrm{g} \mathrm{ml}^{-1}$

Lincomycin $25 \mu \mathrm{g} \mathrm{ml}^{-1}$

Spectinomycin $100 \mu \mathrm{g} \mathrm{ml}^{-1}$

Tetracycline $10 \mu \mathrm{g} \mathrm{ml}^{-1}$

${ }^{1}$ For selection on erm $C$ a mixture of erythromycin and lincomycin was used in their respective concentration, see above. 


\subsection{Methods}

\subsubsection{General methods}

Some general methods used in this work that are described in the literature are listed in table 3.1 .

\begin{tabular}{ll} 
Method & Reference \\
\hline Absorption measurement & Sambrook et al., 1989 \\
Ethidiumbromide staining & Sambrook et al., 1989 \\
Precipitation of nucleic acids & Sambrook et al., 1989 \\
Gel electrophoresis of DNA & Sambrook et al., 1989 \\
Plasmid preparation from $E$. coli & Sambrook et al., 1989 \\
Ligation of DNA fragments & Sambrook et al., 1989 \\
Determination of protein amounts & Bradford, 1976 \\
Gel electrophoresis of proteins (denaturating) & Laemmli, 1970 \\
Sequencing according to the chain termination method & Sanger et al., 1977 \\
\hline
\end{tabular}

Tab. 3.1. General methods

\subsubsection{Cultivation of bacteria}

Unless otherwise stated, E. coli was grown in LB medium at $37^{\circ} \mathrm{C}$ and $200 \mathrm{rpm}$ in tubes and flasks. B. subtilis was grown in LB medium, CSE, C-Glc, malate and MNGE medium at $37^{\circ} \mathrm{C}$ or $28^{\circ} \mathrm{C}$ in tubes and Erlenmeyer flasks. Fresh colonies from plates were used for inoculation. Furthermore, overnight liquid cultures were used. Growth was measured at a wavelength of $600 \mathrm{~nm}$. For the calculation of the generation time the optical density of cultures in the logarithmic growth phase was used. The generation time (g) was calculated with the following formula: 


$$
\begin{array}{cl}
\mathrm{g}=\frac{\lg 2 \mathrm{x}\left(\mathrm{t}_{2}-\mathrm{t}_{1}\right)}{\log \mathrm{K}_{2}-\log \mathrm{K}_{1}} & \\
\mathrm{~g}=\text { generation time }(\mathrm{min}) & \\
\mathrm{t}_{1}=\text { time point } 1(\mathrm{~min}) & \mathrm{K}_{1}=\mathrm{OD}_{600} \text { at time point } 1 \\
\mathrm{t}_{2}=\text { time point } 2(\mathrm{~min}) & \mathrm{K}_{2}=\mathrm{OD}_{600} \text { at time point } 2
\end{array}
$$

\section{Storage of bacteria}

E. coli was kept on LB medium agar plates up to 4 weeks at $4{ }^{\circ} \mathrm{C}$. For long-term storage glycerol or DMSO cultures were established. B. subtilis was cultured on LB medium agar plates not longer than 3 days. SP agar plates and tubes were used for the long-term storage of $B$. subtilis. Strains that require glucose or malate were stored in cryo cultures. For the storage of bacteria in glycerol, $900 \mu \mathrm{l}$ of a fresh overnight culture was gently mixed with $600 \mu \mathrm{l}$ of $50 \%$ glycerol (final concentration of $33.3 \%$ (w/v) glycerol). DMSO cultures were prepared with $900 \mu 1$ of a fresh overnight culture mixed with 100 $\mu 1$ of DMSO (100\%). Stocks were frozen and stored at $-70^{\circ} \mathrm{C}$.

\subsubsection{Transformation of $E$. coli}

\section{Preparation of competent cells by the $\mathrm{RbCl}_{2}$ method}

A single colony of $E$. coli DH5 $\alpha$ was used to inoculate a LB overnight culture (4 ml). This culture was used to inoculate $500 \mathrm{ml}$ of LB medium in a dilution of 1 to 200. E. coli DH5 $\alpha$ was incubated at $37^{\circ} \mathrm{C}$ and $200 \mathrm{rpm}$ in baffled flasks for $4 \mathrm{~h}$. Cultures were cooled down by shaking in ice water for $10 \mathrm{~min}$. The cells were harvested by centrifugation (10 min; 3,000 rpm; $4^{\circ} \mathrm{C}$ ) and suspended in $20 \mathrm{ml}$ of ice-cold TfbI. After centrifugation $\left(10 \mathrm{~min} ; 3,000 \mathrm{rpm} ; 4^{\circ} \mathrm{C}\right)$, the cells were suspended in $4 \mathrm{ml}$ of ice-cold TfbII. Aliquots of $200 \mu 1$ were frozen in liquid nitrogen and stored at $-70^{\circ}$ C. E. coli was transformed by the heat shock method. 


\begin{tabular}{ccc}
\hline & Final concentration & $\mathrm{g} / 100 \mathrm{ml}$ \\
K-Acetate & $30 \mathrm{mM}$ & 0.29 \\
$\mathrm{MnCl}_{2}$ & $50 \mathrm{mM}$ & 0.99 \\
$\mathrm{RbCl}_{2}$ & $100 \mathrm{mM}$ & 1.21 \\
$\mathrm{CaCl}_{2}$ & $10 \mathrm{mM}$ & 0.147 \\
$\mathrm{Glycerol}$ & $15 \%$ & $(30 \mathrm{ml})$ \\
\hline
\end{tabular}

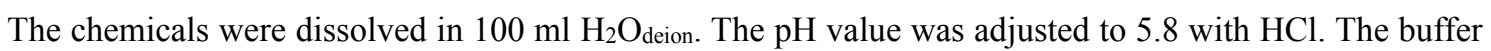
was sterile filtrated and stored on ice.

TfbII- Buffer

\begin{tabular}{ccc}
\hline & Final concentration & $\mathrm{g} / 100 \mathrm{ml}$ \\
MOPS & $10 \mathrm{mM}$ & 0.21 \\
$\mathrm{CaCl}_{2}$ & $75 \mathrm{mM}$ & 1.1 \\
$\mathrm{RbCl}_{2}$ & $10 \mathrm{mM}$ & 0.121 \\
Glycerol & $15 \%$ & $(30 \mathrm{ml})$ \\
\hline
\end{tabular}

The chemicals were dissolved in $100 \mathrm{ml} \mathrm{H}_{2} \mathrm{O}_{\text {deion. The }} \mathrm{pH}$ value was adjusted to 6.8 with $\mathrm{NaOH}$. The buffer was sterile filtrated and stored on ice.

Competent cells were thawed on ice, and 10-100 ng DNA were added to $200 \mu 1$ cells. The suspension was mixed and incubated on ice for 30 minutes. The heat shock was performed at $42^{\circ} \mathrm{C}$ for 90 seconds. Afterwards, the samples were incubated for 5 minutes on ice. After addition of $600 \mu \mathrm{LB}$ medium, the samples were incubated 60 minutes at $37^{\circ} \mathrm{C}$ for (with shaking). One hundred microlitres and the concentrated rest were plated on LB selection plates (with ampicillin, spectinomycin and kanamycin, respectively). 


\subsubsection{Transformation of $B$. subtilis}

\section{Preparation of competent cells}

Ten millilitres of MNGE medium containing 1\% CAA were inoculated with an overnight culture of $B$. subtilis to an optical density of $\sim 0.1$. This culture was grown at $37^{\circ} \mathrm{C}$ with aeration until $\mathrm{OD}_{600}$ of $\sim 1.3$ was reached. Then the culture was diluted with $10 \mathrm{ml}$ MNGE medium without CAA and incubated again for one hour. After the incubation step, the cells were harvested by centrifugation ( $5 \mathrm{~min} ; 5,000 \mathrm{rpm}$; RT). The supernatant was retained in a sterile falcon tube. The pellet was resuspended in $1 / 8$ of the supernatant and supplemented with glycerol to a final concentration of $10 \%$. Aliquots of $300 \mu \mathrm{l}$ were frozen in liquid nitrogen and stored at $-70^{\circ} \mathrm{C}$.

\section{Transformation of competent cells}

Three hundred microlitres of aliquoted competent cells were thawed at $37^{\circ} \mathrm{C}$ and supplemented with $100 \mu 1$ of following solution:

$\begin{array}{ll}\mathrm{MN}(1 \mathrm{x}) & 1.7 \mathrm{ml} \\ \text { Glucose (20\%) } & 43 \mu \mathrm{l} \\ \mathrm{MgSO}_{4}(1 \mathrm{M}) & 34 \mu \mathrm{l}\end{array}$

400 microlitres of competent cells were incubated with $5 \mu \mathrm{g}$ DNA for 30 min at $37^{\circ} \mathrm{C}$ with shaking. Afterwards, $100 \mu \mathrm{l}$ of expression solution $(50 \mu \mathrm{l}$ yeast extract $(5 \%)$, $25 \mu \mathrm{l} \mathrm{CAA}(10 \%), 25 \mu \mathrm{l}$ deion. water and $5 \mu \mathrm{l}$ tryptophan $(5 \mathrm{mg} / \mathrm{ml}))$ was added and the samples were incubated at $37^{\circ} \mathrm{C}$ for one hour. The cell suspensions were spread onto SP or LB plates containing the appropriate antibiotics for selection. 


\subsubsection{Preparation and detection of DNA}

\section{Preparation of plasmid DNA from $E$. coli}

Plasmid DNA was prepared from E. coli carrying the desired plasmid. An overnight culture $(4 \mathrm{ml})$ with cells carrying the desired plasmid was harvested ( 2 min; 13,000 rpm). The plasmid DNA was isolated using the Mini Prep Kit (Macherey-Nagel, Düren, Germany) according to the manufacturer's instructions. Deion. water was used for elution of the DNA from the columns. All steps were performed at room temperature.

\section{Isolation of genomic DNA of $B$. subtilis}

Genomic DNA of B. subtilis was isolated using the DNeasy Tissue Kit (Qiagen, Hilden, Germany). B. subtilis was grown overnight in LB medium. Cells of $1.5 \mathrm{ml}$ culture volume were harvested ( $2 \mathrm{~min} ; 13,000 \mathrm{rpm}$; RT). The pellet was resuspended in $180 \mu \mathrm{l}$ lysis buffer and incubated at $37^{\circ} \mathrm{C}$ for $60 \mathrm{~min}$. The further steps for the isolation of the genomic DNA were performed according to the manufacturers instructions.

\section{Solutions for isolation of genomic DNA}

\begin{tabular}{lll}
\hline Lysis buffer & Lysozyme & $50 \mathrm{mg}$ \\
Tris-HCl pH $8.0(1 \mathrm{M})$ & $50 \mu \mathrm{l}$ \\
EDTA pH $8.0(0.5 \mathrm{M})$ & $10 \mu \mathrm{l}$ \\
$\mathrm{H}_{2} \mathrm{O}_{\text {deion }}$ & $2.5 \mathrm{ml}$ \\
\hline
\end{tabular}

\section{Agarose gel electrophoresis}

For analytical and preparative separation of DNA fragments, agarose gels containing 1 to $2 \%(\mathrm{w} / \mathrm{v})$ agarose (according to the expected fragment size) in TAE buffer were prepared. The DNA samples were mixed with $5 \mathrm{x}$ DNA loading dye to facilitate loading and to indicate the migration of the samples in the gel. A voltage of $80-120 \mathrm{~V}$ was 
applied until the color marker reached the last third of the gel. DNA fragments migrate towards the anode with a velocity that is proportional to the negative logarithm of their length. After electrophoresis, gels were incubated in ethidium bromide solution for 5 min and briefly rinsed with $\mathrm{H}_{2} \mathrm{O}_{\text {deion. }}$. The DNA was detected and documented via its fluorescence under UV light $(\lambda=254 \mathrm{~nm})$. For the estimation of the size of the DNA fragments, the GeneRuler ${ }^{\mathrm{TM}}$ DNA Ladder Mix and $\lambda$-DNA marker were used. For the isolation of DNA fragments from preparative gels, the bands were visualized at a wavelength of $\lambda=365 \mathrm{~nm}$. The bands were cut out and led across a microcentrifuge tube. The purification of the DNA followed with the QIAquick PCR Purification Kit (250) (Qiagen, Hilden, Germany) according to the manufacturer's instructions.

\section{Solutions for agarose gel electrophoresis}

$1 \%$ Agarose gel

$1 \%(\mathrm{w} / \mathrm{v})$ Agarose in $1 \times \mathrm{TAE}$

$1 \%(\mathrm{w} / \mathrm{v})$

$50 \times$ TAE buffer

Tris

$242 \mathrm{~g}$

Tris-acetate

$57.1 \mathrm{ml}$

EDTA (0.5 M, pH 8.0)

$100 \mathrm{ml}$

$\mathrm{H}_{2} \mathrm{O}_{\text {deion }}$

ad $500 \mathrm{ml}$

5 x DNA loading dye

Glycerol

$5 \mathrm{ml}$

$\mathrm{H}_{2} \mathrm{O}_{\text {deion }}$

$4.5 \mathrm{ml}$

TAE $(50 \mathrm{x})$

$200 \mu 1$

Bromphenol blue

$0.01 \mathrm{~g}$

Xylencyanol

$0.01 \mathrm{~g}$

\section{Sequencing of DNA}

Sequencing was done based on the chain termination method (Sanger) with fluorescence labeled dideoxynucleotides. The sequencing reactions were conducted by SeqLab (Göttingen, Germany) and the Laboratorium für Genomanalyse $\left(\mathrm{G}_{2} \mathrm{~L}\right)$ of the Georg-August-University Göttingen. 


\section{Digestion of DNA}

The digestion of DNA with endonucleases was performed with buffers recommended by the manufacturer. Reaction buffers, concentration of enzymes and DNA as well as incubation temperatures were chosen according to the manufacturer's instructions. The digestion was allowed to proceed for up to $2 \mathrm{~h}$ and was, if possible, followed by heat inactivation of the restriction endonucleases $\left(20 \mathrm{~min} ; 65^{\circ} \mathrm{C}\right.$ or $\left.80^{\circ} \mathrm{C}\right)$. The DNA was purified using the PCR Purification Kit (Qiagen, Hilden, Germany) following the manufacturer's instructions.

\section{Dephosphorylation of DNA}

To avoid re-circularization of a previously digested DNA vector, the 5' phosphate groups of the linearized vector were removed prior to the ligation reaction. The dephosphorylation of the 5 -prime end of DNA fragments was performed with the FastAP (alkaline phosphatase) (Fermentas, Lithuania) with buffers supplied by the manufacturer. Approximately 3-10 ng/ $\mu \mathrm{l}$ DNA were mixed with $1 \mu \mathrm{l}$ FastAP (1U/ $\mu \mathrm{l})$ and incubated at $37^{\circ} \mathrm{C}$ for $30 \mathrm{~min}$. The FastAP was inactivated by boiling at $75^{\circ} \mathrm{C}$ for 10 $\min$.

\section{Ligation of DNA}

DNA fragments were ligated using T4-DNA ligase (Fermentas, Lithuania) with buffers supplied by the manufacturer. The ligation reaction contained 20 - $200 \mathrm{ng}$ of vector DNA and an excess of the DNA fragment (insert to vector molar ratio of 10:1 to 20:1). The reaction was started after addition of 5 U T4-DNA ligase in a final volume of $20 \mu 1$. The ligation occurred for $2 \mathrm{~h}$ at RT or overnight at $16^{\circ} \mathrm{C}$. 


\section{Polymerase chain reaction (PCR)}

DNA was amplified by PCR with specific oligonucleotide primers. For each DNA fragment of interest, primers were designed. For cloning of DNA fragments into plasmid vectors, recognition sequences for specific restriction endonucleases were added via primers at both ends of the amplified DNA fragments. Oligonucleotides were purchased from Eurofins MWG Operon (Ebersberg, Germany) and Sigma-Aldrich (Munich, Germany). All oligonucleotides used in this work are listed in the appendix. The PCR reactions were performed in a total volume of $50 \mu \mathrm{l}$. For check PCR the Taq polymerase (own purification) was used. The Taq polymerase is known to create one mismatch in 1,000 base pairs.

\begin{tabular}{lll} 
Reaction conditions for the Taq polymerase & \\
\hline template DNA & $2.5 \mu 1$ & $10 \mathrm{ng}$ plasmid DNA / \\
& & $200 \mathrm{ng}$ genomic DNA \\
& $5 \mu \mathrm{l}$ \\
10 x reaction buffer & $5 \mu \mathrm{l}$ \\
forward primer $(20 \mathrm{pmol})$ & $5 \mu \mathrm{l}$ \\
reverse primer $(20 \mathrm{pmol})$ & $2 \mu \mathrm{l}$ \\
dNTPs $12.5 \mathrm{mM}$ & $1 \mu \mathrm{l}(1 \mathrm{U})$ \\
Taq polymerase & $30.5 \mu \mathrm{l}$ \\
$\mathrm{H}_{2} 0_{\text {deion }}$ &
\end{tabular}

The sample was mixed and placed in a thermocycler with a preheated lid. After an initial DNA denaturation step, a cycle consisting of three steps including denaturation, primer annealing and primer elongation was performed for 30 times. The reaction was terminated after a final elongation step by cooling down to $15^{\circ} \mathrm{C}$. Time and temperature for denaturation, time of annealing and elongation temperature remained constant for each reaction. The annealing temperature $(\mathrm{Tm})$ was dependent on the length of the oligonucleotide and its $\mathrm{G}+\mathrm{C}$ content. It was calculated as follows: 
$\operatorname{Tm}\left[{ }^{\circ} \mathrm{C}\right]=69.3+0.41(\% \mathrm{G}+\mathrm{C})-650 / n$

$\% \mathrm{G}+\mathrm{C}$ represents the $\mathrm{G}+\mathrm{C}$ content in the primer; $n$ represents the number of nucleotides.

\begin{tabular}{lcc}
\multicolumn{3}{l}{ Standard program for the Taq polymerase } \\
\hline denaturation & $95^{\circ} \mathrm{C}$ & $300 \mathrm{~s}$ \\
denaturation & $95^{\circ} \mathrm{C}$ & $30 \mathrm{~s}$ \\
annealing & $\mathrm{Tm}\left[{ }^{\circ} \mathrm{C}\right] 1 /-10^{\circ} \mathrm{C}$ & $45 \mathrm{~s}$ \\
elongation & $72^{\circ} \mathrm{C}$ & $60 \mathrm{~s}$ per $1 \mathrm{~kb}$ \\
elongation & $72^{\circ} \mathrm{C}$ & $600 \mathrm{~s}$ \\
break & $15^{\circ} \mathrm{C}$ & $\infty$ \\
\hline
\end{tabular}

For cloning of PCR fragments, the Phusion ${ }^{\mathrm{TM}}$ polymerase (Finnzymes, Espoo, Finland) was used, because of its proofreading activity that avoids mistakes during amplification.

\begin{tabular}{lc}
${\text { Reaction conditions for the } \text { Phusion }^{\mathrm{TM}} \text { polymerase }}^{\text {template DNA }}$ & $2.5 \mu \mathrm{l}$ (10 ng plasmid DNA / \\
5 x reaction buffer & $10 \mu \mathrm{l}$ \\
forward primer (20 pmol) & $5 \mu \mathrm{l}$ \\
reverse primer (20 pmol) & $5 \mu \mathrm{l}$ \\
Phusion $^{\mathrm{TM}}$ dNTPs $12.5 \mathrm{mM}$ & $1 \mu \mathrm{l}$ \\
Phusion $^{\mathrm{TM}}$ polymerase & $0.5 \mu \mathrm{l}(1 \mathrm{U})$ \\
$\mathrm{H}_{2} \mathrm{O}_{\text {deion }}$ & $26 \mu \mathrm{l}$ \\
\hline
\end{tabular}

Standard program for the Phusion ${ }^{\mathrm{TM}}$ polymerase

$\left.\begin{array}{lcc}\hline \text { denaturation } & 98^{\circ} \mathrm{C} & 60 \mathrm{~s} \\ \text { denaturation } & 98^{\circ} \mathrm{C} & 10 \mathrm{~s} \\ \text { annealing } & \mathrm{Tm}\left[{ }^{\circ} \mathrm{C}\right] 1 /-10^{\circ} \mathrm{C} & 30 \mathrm{~s} \\ \text { elongation } & 72^{\circ} \mathrm{C} & 20 \mathrm{~s} \text { per } 1 \mathrm{~kb} \\ \text { break } & 15^{\circ} \mathrm{C} & \infty\end{array}\right\} 30 \mathrm{x}$




\section{Combined chain reaction $(\mathrm{CCR})$}

For site directed mutagenesis the combined chain reaction was used. The CCR is a PCR-based mutagenesis in which the mutagenic primers hybridize more strongly to the template then the flanking primer. The mutagenic primer is phosphorylated at its 5 'end, and is ligated to the $3^{\prime} \mathrm{OH}$-group of the extended upstream primer by the action of a thermostable DNA ligase. For the design of the mutagenic primer three guidelines were followed: First, the melting temperature of the mutagenic primer is $10^{\circ} \mathrm{C}$ above that of the external primers. Second, the number of mismatching nucleotides should be as low as possible. And third, the mutation must be localized in the middle of the primer.

\begin{tabular}{|c|c|}
\hline $\begin{array}{l}\text { Combined chain reaction (CCR): } \\
\text { Reaction conditions for the } A c c u z y m e^{\mathrm{TM}} \text { polymerase }\end{array}$ & \\
\hline plasmid DNA (200 ng) & $1 \mu 1$ \\
\hline $10 \times$ CCR buffer & $5 \mu 1$ \\
\hline forward primer (20 pmol) & $2 \mu 1$ \\
\hline reverse primer (20 pmol) & $2 \mu 1$ \\
\hline mutagenic primer (20 pmol) & $4 \mu 1$ \\
\hline dNTPs (12.5 mM) & $1 \mu 1$ \\
\hline bovine serum albumine $(10 \mathrm{mg} / \mathrm{ml})$ & $2 \mu 1$ \\
\hline Ampligase $\mathbb{R}$ & $3 \mu \mathrm{l}(15 \mathrm{U})$ \\
\hline Accuzyme ${ }^{\mathrm{TM}}$ polymerase & $1 \mu \mathrm{l}(2.5 \mathrm{U})$ \\
\hline $\mathrm{H}_{2} \mathrm{O}_{\text {deion }}$ & $24 \mu 1$ \\
\hline
\end{tabular}

The CCR reaction was perfomed with $2.5 \mathrm{U}$ of Accuzyme ${ }^{\mathrm{TM}}$ DNA polymerase (Bioline, Luckenwalde, Germany) and Ampligase ${ }^{\circledR}$ (Epicentre, Madison, USA) in CCR buffer (20 mM Tris- $\mathrm{HCl}$ [pH 8.5], $3 \mathrm{mM} \mathrm{MgCl}_{2}, 50 \mathrm{mM} \mathrm{KCl}, 0.5 \mathrm{mM} \mathrm{NAD}^{+}$and $0.4 \mathrm{mg} / \mathrm{ml}$ bovine serum albumin (BSA, New England BioLabs, Ipswich, USA)) in a total volume of $50 \mu 1$. 


\begin{tabular}{lcc} 
Standard program for CCR with Accuzyme $^{\mathrm{TM}}$ polymerase \\
\hline denaturation & $95^{\circ} \mathrm{C}$ & $300 \mathrm{~s}$ \\
denaturation & $95^{\circ} \mathrm{C}$ & $30 \mathrm{~s}$ \\
annealing & $57^{\circ} \mathrm{C}$ & $30 \mathrm{~s}$ \\
elongation & $65^{\circ} \mathrm{C}$ & $180 \mathrm{~s}$ per $1 \mathrm{~kb}$ \\
elongation & $65^{\circ} \mathrm{C}$ & $360 \mathrm{~s}$ \\
break & $15^{\circ} \mathrm{C}$ & $\infty$ \\
\hline
\end{tabular}

\section{Long flanking homology PCR (LFH-PCR)}

Deletion of a gene in $B$. subtilis was performed with the long flanking homology PCR (LFH-PCR) technique (Wach, 1996). For this purpose, genes that mediate resistance against chloramphenicol, erythromycin, kanamycin and spectinomycin were amplified from the plasmids pDG646, pDG780, pDG1726 and pGEM-cat, respectively (GueroutFleury et al., 1995). DNA fragments of about 1,000 bp flanking the target gene at its 5' and 3 ' ends were amplified. The 3' end of the upstream fragment as well as the 5' end of the downstream fragment extended into the target gene in a way that all expression signals of genes up- and downstream of the gene remained intact. The joining of the two fragments to the resistance cassette was performed in a second PCR. Joining was allowed by complementary sequences of $25 \mathrm{bp}$ that were attached to the single fragments by the respective primers. Thus, the $3^{`}$ end of the upstream fragment was linked with the 5 end of the resistance cassette and the 3 'end of the resistance with the 5 'end of the downstream fragment. For the LFH joining reaction, $150 \mathrm{ng}$ of the up- and downstream fragments and $300 \mathrm{ng}$ of the resistance cassette were used. The fused fragment was amplified by PCR using the forward primer of the upstream fragment and the reverse primer of the downstream fragment. The PCR product was purified using the QIAquick PCR Purification Kit (Qiagen; Hilden; Germany). B. subtilis was transformed with the purified PCR products and transformants were selected on plates. Clones were examined by check PCR for the integrity of the resistance cassette (see appendix). The DNA sequence of the flanking regions was verified by sequencing. 


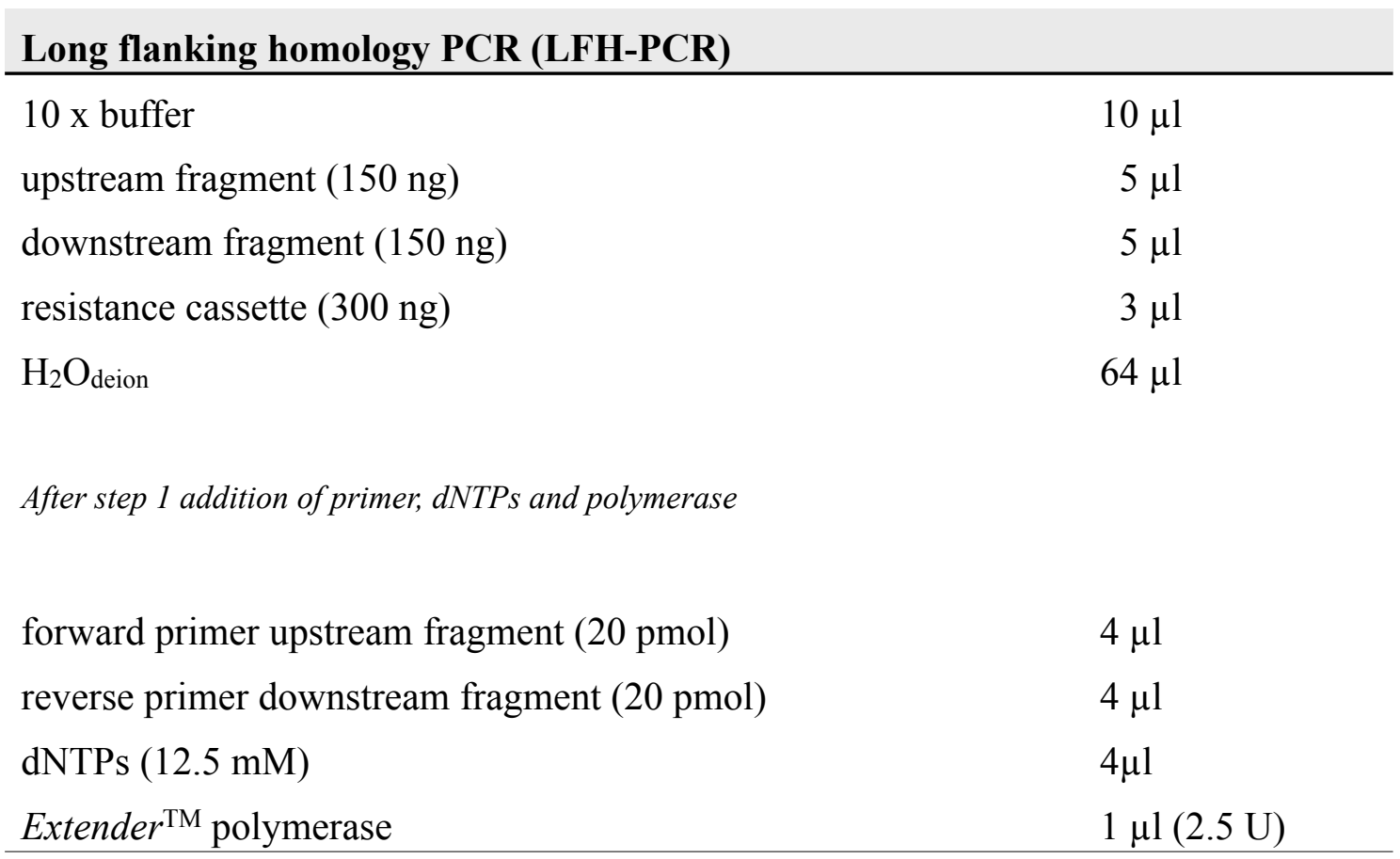

The up- and downstream fragments and the resistance cassette were first incubated to allow joining. Afterwards, the respective primer pair, dNTPs and Extender ${ }^{\mathrm{TM}}$ polymerase were added. In step 2 the joint PCR product was amplified using the flanking primer.

\section{LFH standard program for the Extender ${ }^{\mathrm{TM}}$ polymerase}

$\left.\begin{array}{cccc}\hline & \text { denaturation } & 94^{\circ} \mathrm{C} & 120 \mathrm{~s} \\ \text { 1. step } & 94^{\circ} \mathrm{C} & 20 \mathrm{~s} \\ & \text { annealing } & \mathrm{Tm}\left[{ }^{\circ} \mathrm{C}\right] 1 /-10^{\circ} \mathrm{C} & 45 \mathrm{~s} \\ & \text { elongation } & 68^{\circ} \mathrm{C} & 480 \mathrm{~s}\end{array}\right\} 10 \mathrm{x}$




\subsubsection{Preparation and analysis of proteins}

\section{Cell disruption by sonication}

Cells were harvested by centrifugation $\left(8,000 \mathrm{rpm} ; 10 \mathrm{~min} ; 4^{\circ} \mathrm{C}\right)$ and the supernatant was completely removed. The pellet was resuspended in the cell disruption buffer. The disruption was performed with a ultrasonic probe, three times with 20 intervals of 0.5 seconds. The samples were stored on ice during the whole process. The samples were centrifuged (30 $\mathrm{min} ; 13,000 \mathrm{rpm} ; 4^{\circ} \mathrm{C}$ ) to remove remaining membrane compounds.

\section{Cell disruption with the French press}

The prechilled bomb was filled with the cell suspension and the remaining air was squeezed out before the bomb was locked. After closing the release valve the bomb was placed in the French press and set under pressure. The disruption took place with a pressure of 1,400 bar and was performed three times.

\section{Cell disruption with One shot}

The cell disruption with the One Shot was in principle equal to the French press. Here, $6 \mathrm{ml}$ of the cell suspension were pipetted into the precooled cylinder and closed airtight. Internal pressure was established using the starter stick. The disruption of the cells was carried out at maximum pressure $(2,500 \mathrm{psi} ; 2$ to 3 passages $)$

\section{Discontinuous SDS polyacrylamide gel electrophoresis (SDS-PAGE)}

Proteins were analyzed by SDS-PAGE as described by Laemmli (1970). Protein samples were denatured by boiling in SDS loading dye at $95^{\circ} \mathrm{C}$ for $10 \mathrm{~min}$. The polyacrylamide concentration of the gels was chosen according to the expected proteins 
sizes varying from 12 to $16 \%(\mathrm{v} / \mathrm{v})$. Samples were loaded onto the prepared gel. Electrophoresis was performed at $120 \mathrm{~V}$ until the bromophenol blue had reached the lower end of the gel. During electrophoresis, proteins were first focused in the stacking gel and subsequently separated according to their molecular mass in the running gel. The self constructed protein marker Page King and the purchased Protein Molecular Weight Marker (Fermentas, Lithuania) were used as size standards. Gels were stained with Coomassie Brilliant Blue G-250 and destained until the protein bands were clearly visible. For analytic gels with small protein amounts silver staining was performed.

Solutions for SDS-PAGE

5 x SDS loading dye

Tris- $\mathrm{HCl} \mathrm{pH} 7.0$ (1 M)

$1.4 \mathrm{ml}$

Glycerol (100\%)

$3 \mathrm{ml}$

SDS (20\%)

$2 \mathrm{ml}$

$\beta$-Mercaptoethanol (100\%)

$1.6 \mathrm{ml}$

Bromphenol blue

$0.01 \mathrm{~g}$

$\mathrm{H}_{2} \mathrm{O}_{\text {deion }}$

$2 \mathrm{ml}$

$6 \%$ Stacking gel (v/v)

Acrylamide-Bisacrylamide (39:1) (40\%)

$0.75 \mathrm{ml}$

Tris-HCl pH 6.8 (1 M)

$0.65 \mathrm{ml}$

$\mathrm{H}_{2} \mathrm{O}_{\text {deion }}$

$5.35 \mathrm{ml}$

SDS $(20 \%)$

APS (10\%)

$200 \mu 1$

TEMED

$10 \mu 1$

12.5\% Running gel (v/v) Acrylamide-Bisacrylamide (39:1) (40\%)

$4,6 \mathrm{ml}$

Tris-HCl pH 8.8 (1 M)

$1.3 \mathrm{ml}$

$\mathrm{H}_{2} \mathrm{O}_{\text {deion }}$

$6.5 \mathrm{ml}$

SDS $(20 \%)$

$200 \mu 1$

APS (10\%)

$200 \mu 1$

TEMED

$12.5 \mu 1$ 


\begin{tabular}{llr} 
Electrophoresis buffer & Glycine & $1.92 \mathrm{M}$ \\
& Tris & $0.5 \mathrm{M}$ \\
& SDS & $1 \%$ \\
\hline
\end{tabular}

\section{Overexpression of proteins in $E$. coli}

An overnight culture of E. coli, carrying the relevant plasmid, was used to inoculate one litre of $\mathrm{LB}$ medium to $\mathrm{OD}_{600} \sim 0.1$. Cultures were grown with shaking at $16^{\circ} \mathrm{C}$ or $37^{\circ} \mathrm{C}$ until they had reached an optical density of 0.6-0.8. Expression of recombinant proteins was induced by the addition of isopropyl- $\beta$-D-thio-galactopyranoside (IPTG, final concentration: $1 \mathrm{mM}$ ) (PeqLab, Erlangen, Germany). The cultures were incubated for three hours. To test the expression, small aliquots (sample $[\mu 1]=100 / \mathrm{OD}_{600}$ ) were taken before and after the induction. The samples were boiled in SDS loading dye and analyzed on a SDS gel. The main culture was harvested by centrifugation (10 min; $\left.8,000 \mathrm{rpm} ; 4^{\circ} \mathrm{C}\right)$. After removing the supernatant the cells were washed in cold cell disruption buffer and the pellets were stored at $-20^{\circ} \mathrm{C}$.

\section{Purification of His6-tagged proteins}

For protein purification, the frozen pellets were resuspended in cold cell disruption buffer, and the cells were disrupted by at least 3 passages through the French pressure cell (Spectonic Unicam) at 1,000 psi. Cell debris and other insoluble material was removed by ultracentrifugation (Beckmann, L7-55) (60 min; 27,000 rpm; $\left.4^{\circ} \mathrm{C}\right)$. For purification of recombinant His6-tagged proteins the supernatant fraction was loaded onto a $4 \mathrm{ml}$ bed volume of $\mathrm{Ni}^{2+}$-NTA resin (Qiagen) in a Poly-Prep Chromatography Column (Biorad, Munich, Germany). The $\mathrm{Ni}^{2+}$-NTA resin had been pre-equilibrated with $10 \mathrm{ml}$ cell disruption buffer. After extensive washing with $20 \mathrm{ml}$ of cell disruption buffer containing $10 \mathrm{mM}$ imidazole (Roth, Karlsruhe, Germany) and $20 \mathrm{ml}$ with $20 \mathrm{mM}$ imidazole the His6-tagged proteins were eluted. The elution was performed in $10 \mathrm{ml}$ steps with cell disruption buffer containing an increasing concentration of imidazole 
(50 mM, $100 \mathrm{mM}, 200 \mathrm{mM}$, and $500 \mathrm{mM}$ ). To analyze the purification success, $15 \mu 1$ of each fraction was mixed with SDS loading dye and boiled at $95^{\circ} \mathrm{C}$ for 10 minutes. The samples were loaded onto a SDS gel and after electrophoresis stained with Coomassie brilliant blue. The relevant fractions were combined and dialyzed overnight. Protein concentration was determined using the Bio-rad dye-binding assay using Bovine serum albumin as the standard.

\section{Purification of Strep-tagged proteins}

Overexpression and cell disruption were performed as described above. The proteins were purified using $1 \mathrm{ml}$ Strep-Tactin Sepharose (IBA, Göttingen, Germany) loaded on a Poly-Prep Chromatography Column (Biorad, Munich, Germany). The matrix specifically binds a sequence of eight amino acids (WSHPQFEK). D-desthiobiotin was used to elute the bound proteins. The matrix was equilibrated with $5 \mathrm{ml}$ of buffer $\mathrm{W}$. Afterwards the column was loaded with $10 \mathrm{ml}$ of the crude extract. Washing steps were performed with $5 \mathrm{ml}$ buffer $\mathrm{W}$. The bound proteins were eluted with buffer $\mathrm{E}$ in 6 fractions of $500 \mu \mathrm{l}$. The fractions were analyzed by SDS-PAGE.

\section{Buffer for purification of Strep-tagged proteins}

\begin{tabular}{llr}
\hline Buffer W & Tris-HCl pH 8 & $100 \mathrm{mM}$ \\
& $\mathrm{NaCl}$ & $150 \mathrm{mM}$ \\
EDTA & $1 \mathrm{mM}$ \\
Buffer E & Tris-HCl pH 8 & $100 \mathrm{mM}$ \\
& $\mathrm{NaCl}$ & $150 \mathrm{mM}$ \\
& EDTA & $1 \mathrm{mM}$ \\
& D-desthiobiotin & $2.5 \mathrm{mM}$ \\
\hline
\end{tabular}




\section{Dialysis of proteins}

Proteins purified by $\mathrm{Ni}^{2+}$-NTA or Strep-Tactin Sepharose contain immidazole and D-desthiobiotin, respectively. These components can have negative effects on following experiments. Thus, the elution fractions were dialyzed against cell disruption buffer supplemented with $1 \mathrm{mM}$ desthiothreitol (DTT) in a dialysis tube. The exclusion size of the dialysis tube was half the size of the protein. Protein solution was dialyzed against buffer, in relation 1 to 1000 .

\section{Purification of Taq DNA polymerase}

The modified DNA polymerase of Thermus thermophilus was overexpressed in E. coli (Nadicom E. coli stock 147). Therefor, $4 \mathrm{ml}$ of a LB $_{\text {Amp preculture was inoculated with }}$ one colony of this strain and incubated at $37^{\circ} \mathrm{C}$ overnight. The preculture was used to inoculate $100 \mathrm{ml} \mathrm{LB}$ Amp medium, that was incubated at $37^{\circ} \mathrm{C}$ with shaking. At an $\mathrm{OD}_{600}$ of 0.3 the culture was supplemented with IPTG $(500 \mathrm{mM})$ and incubated at $37^{\circ} \mathrm{C}$ for $24 \mathrm{~h}$ with shaking. Cells were harvested by centrifugation $\left(15 \mathrm{~min} ; 5,000 \mathrm{rpm} ; 4^{\circ} \mathrm{C}\right)$ in two falcon tubes. The supernatant was refused and the pellets were resuspended in buffer A and pooled. The suspension was supplemented with $12 \mathrm{mg}$ lysozyme and incubated with shaking at room temperature for $15 \mathrm{~min}$. Addition of $3 \mathrm{ml}$ buffer B followed with reversion. The solutions were divided into $2(2 \mathrm{ml})$ centrifuge cups and incubated at $75^{\circ} \mathrm{C}$ for $1 \mathrm{~h}$ under smooth shaking. Afterwards, the solutions were centrifuged $(13,000 \mathrm{rpm} ; 10 \mathrm{~min} ; \mathrm{RT})$ and the supernatant was pipetted in new centrifuge cups. The success of the overexpression of the DNA polymerase was tested by PCR. For this purpose, $40 \mu 1$ of the suspensions was mixed with $40 \mu 1$ of storage buffer and $40 \mu 1$ glycerol. Test PCR's were performed with selected primer pairs for the amplification of $B$. subtilis genes from 0.5 to $2.1 \mathrm{~kb}$. After confirmation of DNA polymerase activity, dialysis was prepared. Approx. $10 \mathrm{~cm}$ dialysis tube was shortly boiled with $2 \mathrm{mM}$ EDTA in a microwave. The polymerase solution was filled in the dialyze tube and closed with clips. Dialysis occurred in $500 \mathrm{ml}$ storage buffer for $12 \mathrm{~h}$ 
under light stirring. Altogether, dialysis was proceeds two times and the solution was tested again on polymerase activity. Then, 10-fold storage buffer was added to a final dilution of 1:10. DNase solution was added and incubated at $37^{\circ} \mathrm{C}$ for $30 \mathrm{~min}$. Afterwards, DNase was inactivated by boiling at $80^{\circ} \mathrm{C}$ for $10 \mathrm{~min}$. The solution was dialyzed again two times. Taq-DNA polymerase solution was aliquoted (50 $\mu 1$ polymerase solution $+50 \mu$ glycerol $100 \%$ ) and tested once again before stored at $-20^{\circ} \mathrm{C}$.

Primer combinations for test PCR

\section{Primer}

NP74 / NP75

NP70 / NP71

NP78 / NP79

NP 94 / NP95

\section{expected size}

$500 \mathrm{bp}$

$903 \mathrm{bp}$

$1208 \mathrm{bp}$

$2115 \mathrm{bp}$

\section{gene}

$y d i B$

era

yphC

pnpA

\section{Solutions for Taq-DNA polymerase purification}

\begin{tabular}{llr}
\hline Buffer A & Tris & $50 \mathrm{mM}$ \\
Glucose & $20 \mathrm{mM}$ \\
EDTA (stock solution $100 \mathrm{mM})$ & $1 \mathrm{mM}$ \\
Buffer B & Tris & $10 \mathrm{mM}$ \\
KCl & $50 \mathrm{mM}$ \\
EDTA & $1 \mathrm{mM}$ \\
Tween 20 & $5 \%$ \\
& Tris & $50 \mathrm{mM}$ \\
NaCl & $100 \mathrm{mM}$ \\
EDTA & $0.1 \mathrm{mM}$ \\
& DTT & $0.5 \mathrm{mM}$ \\
Triton X100 & $1 \%$ \\
PMSF & spatula point
\end{tabular}




\begin{tabular}{|c|c|c|}
\hline $10 \times$ DNase storage buffer & Tris-HCl & $1.75 \mathrm{~g}$ \\
\hline \multirow[t]{4}{*}{$\mathrm{pH} 7.5$} & $\mathrm{CaCl}_{2} \times 2 \mathrm{H}_{2} \mathrm{O}$ & $1.47 \mathrm{~g}$ \\
\hline & $\mathrm{MgCl}_{2} \times 7 \mathrm{H}_{2} \mathrm{O}$ & $2.03 \mathrm{~g}$ \\
\hline & Glycerol & $50 \mathrm{ml}$ \\
\hline & $\mathrm{H}_{2} \mathrm{O}_{\text {deion }}$ & ad $100 \mathrm{ml}$ \\
\hline \multirow{4}{*}{$\begin{array}{l}10 \times \text { Reaction-buffer DNase } \\
\mathrm{pH} 8.8\end{array}$} & Tris-HCl & $100 \mathrm{mM}$ \\
\hline & $\mathrm{KCl}$ & $500 \mathrm{mM}$ \\
\hline & $\mathrm{MgCl}_{2}$ & $15 \mathrm{mM}$ \\
\hline & Nonidet P40 & $8 \%$ \\
\hline \multirow[t]{2}{*}{ DNase solution } & DNase & $70 \mathrm{mg}$ \\
\hline & Storage buffer & $1 \mathrm{ml}$ \\
\hline
\end{tabular}

\section{Preparation of a protein marker (unstained)}

A protein marker was prepared using existing purified proteins of good purity. These proteins were purified using the appropriate affinity tag (Tab. 3.2.). The protein solution was mixed with storage buffer to a final protein concentration of $0.2 \mu \mathrm{g} / \mu \mathrm{l}$. The marker was stored at $-20^{\circ} \mathrm{C}$.

\begin{tabular}{cccccc} 
Protein & kDa & Plasmid & Affinity-Tag & Vector / Strain & Cloning \\
\hline PnpA & 77 & pGP838 & His 6 & pWH844 / DH5 $\alpha$ & NP94 / NP95 \\
Obg & 48 & pGP843 & His6 & pWH844 / DH5 $\alpha$ & NP72 / NP73 \\
LDH M.p. & 35 & pGP369 & His6 & pWH844 / DH5 & SH52 / SH55 \\
TpiA & 27 & pGP394 & His6 & pWH844 / DH5 $\alpha$ & EW5 / NP92 \\
YwjH & 23 & pGP819 & Strep & pGP172 / BL21 & NP11 / NP12 \\
HPr & 9 & pAG2 & His6 & pQE30 / DH5 $\alpha$ & Galinier et al., 1997 \\
\hline
\end{tabular}

Table 3.2. Proteins used for the protein marker. 


\section{Storage buffer for unstained protein marker ,Page King ‘}

\section{Tris- $\mathrm{HCl}(\mathrm{pH} 7.7)$}

DTT

SDS
$62.5 \mathrm{mM}$

$10 \mathrm{mM}$

Glycerol $33 \%$

Fig. 1: Protein marker Page King covering 11 to $77 \mathrm{kDa}$. The protein concentration is $0.2 \mu \mathrm{g} / \mu \mathrm{l}$. Prior to use, $5 \mu \mathrm{l}$ of marker were boiled for $5 \mathrm{~min}$ at $95^{\circ} \mathrm{C}$ and then loaded on the gel.

\section{Coomassie staining of polyacrylamide gels}

Protein gels were stained with Coomassie Brilliant Blue. For this purpose, the gels were incubated in fixing solution for 10 minutes. Staining occurred with coomassie staining solution for about 5-15 minutes and the gels were destained until an optimal contrast between protein bands and background was reached.

Solutions for coomassie staining

Fixing solution
\[ \begin{array}{l}50 \% \text { Methanol } \\ 10 \% \text { Acetic acid } \\ 40 \% \mathrm{H}_{2} \mathrm{O}_{\text {deion }} \\ \\ \text { Staining solution } \\ 2.5 \mathrm{~g} \text { Coomassie Brillant Blue R250 } \\ 10 \% \text { Acetic acid } \\ 50 \% \text { Methanol } \\ 40 \% \mathrm{H}_{2} \mathrm{O}_{\text {deion }}\end{array} \]




\section{Destaining solution $\quad 10 \%$ Acetic acid \\ $90 \% \mathrm{H}_{2} \mathrm{O}_{\text {deion }}$}

\section{Silver staining of polyacrylamide gels}

Silver staining is one of the most sensitive staining methods for polyacrylamide gels. It was used to verify the purity of protein purifications and for the analysis of proteinprotein interactions. The advantage of this method is the high sensitivity (detection limit of approximately $5 \mathrm{ng}$ protein). The disadvantage is that it is not exactly reproducible and quantifiable, due to the physics of the accumulation of the silver particles (Butcher and Tomkins, 1985). The silver staining of the protein band was performed as described by Nesterenko (1994). For staining, the polyacrylamide gels were incubated with the following solutions with shaking.

\begin{tabular}{lll} 
Step & Reagent & Duration \\
\hline Fixing & Fixer & 1 to $24 \mathrm{~h}$ \\
Washing & Ethanol $50 \%$ & $3 \times 20 \mathrm{~min}$ \\
Reduction & Thiosulfate solution & $90 \mathrm{~s}$ \\
Washing & $\mathrm{H}_{2} \mathrm{O}_{\text {deion }}$ & $3 \times 20 \mathrm{~s}$ \\
Staining & Impregnating & $25 \mathrm{~min}$ \\
Washing & $\mathrm{H}_{2} \mathrm{O}_{\text {deion }}$ & $2 \times 20 \mathrm{~s}$ \\
Developing & Developer & until sufficiently stained \\
Washing & $\mathrm{H}_{2} \mathrm{O}_{\text {deion }}$ & $20 \mathrm{~s}$ \\
Stoping & Stop solution & $5 \mathrm{~min}$ \\
\hline
\end{tabular}




\section{Solutions for silver staining}

\section{Fixing solution $(100 \mathrm{ml})$}

Methanol (100\%)

Acetic acid (100\%)

Formaldehyde (37\%)

$$
\mathrm{H}_{2} \mathrm{O}_{\text {deion }}
$$

$$
\mathrm{Na}_{2} \mathrm{~S}_{2} \mathrm{O}_{3} \times 5 \mathrm{H}_{2} \mathrm{O}
$$$$
\mathrm{H}_{2} \mathrm{O}_{\text {deion }}
$$

Thiosulfate solution $(100 \mathrm{ml})$

Impregnater $(100 \mathrm{ml})$

$\mathrm{AgNO}_{3}$

Formaldehyde (37\%)

$\mathrm{H}_{2} \mathrm{O}_{\text {deion }}$

$\mathrm{NaCO}_{3}$

Thiosulfate solution

Formaldehyde (37\%)

$\mathrm{H}_{2} \mathrm{O}_{\text {deion }}$

\begin{tabular}{llr} 
Developer $(100 \mathrm{ml})$ & $\mathrm{NaCO}_{3}$ & $6 \mathrm{~g}$ \\
& Thiosulfate solution & $2 \mathrm{ml}$ \\
& Formaldehyde $(37 \%)$ & $50 \mu \mathrm{l}$ \\
& $\mathrm{H}_{2} \mathrm{O}_{\text {deion }}$ & $\mathrm{ad} 100 \mathrm{ml}$ \\
& & 1.86 \\
Stop solution $(100 \mathrm{ml})$ & EDTA & ad $100 \mathrm{ml}$ \\
\hline
\end{tabular}

$50 \mathrm{ml}$

$12 \mathrm{ml}$

$100 \mu 1$

ad $100 \mathrm{ml}$

$20 \mathrm{mg}$

ad $100 \mathrm{ml}$

$0.2 \mathrm{~g}$

$37 \mu 1$

ad $100 \mathrm{ml}$

$6 \mathrm{~g}$

$\mathrm{ml}$

\section{Two-dimensional SDS polyacrylamide gel electrophoresis (SDS-PAGE)}

For the separation of complex protein mixtures, two-dimensional gel electrophoresis was used. Briefly, the proteins were separated in two dimensions according to the characteristics of proteins, their charge and their size. In the first dimension, the separation is based on the isoelectric point of the proteins. In the second dimension, the separation is carried out according to the relative molecular masses.

For the separation in the first dimension, IPG strips with a linear $\mathrm{pH}$ range of 4-7, 4.55.5 or 6-11 were used (Immobiline ${ }^{\mathrm{TM}}$ DryStrip, Amersham Biosciences). The proteins were mixed with rehydration solutions $\mathrm{A}$ and $\mathrm{B}$. The mixture was applied to the IPG 
strips which were placed into a chamber with the gel coated side upside down. The dry gel on the strips swelled and the proteins were soaked into the gel. The swelling chamber was sealed with parafilm to protect the strips from evaporation. The strips were further incubated for $16 \mathrm{~h}$ at RT. The IEF was performed using the following program at RT and constant currency of $50 \mu \mathrm{A}$ per gel.

\section{Program for isoelectric focussing}

\begin{tabular}{lll}
\hline Step & Voltage & Time \\
1 & $250 \mathrm{~V}$ & $1 \mathrm{~h}$ \\
2 & $500 \mathrm{~V}$ & $1 \mathrm{~h}$ \\
3 & $1000 \mathrm{~V}$ & $1 \mathrm{~h}$ \\
4 & $5000 \mathrm{~V}$ & $4 \mathrm{~h}$ \\
5 & $500 \mathrm{~V}$ & $1 \mathrm{~h}$ \\
6 & Break &
\end{tabular}

After the IEF, the $\mathrm{pH}$-gradient strips were incubated for $15 \mathrm{~min}$ in equilibration buffer containing $15 \mathrm{mM}$ DTT. Subsequently, an incubation of $15 \mathrm{~min}$ was carried out in equilibration buffer containing $150 \mathrm{mM}$ of iodacetamide. All steps occurred at RT. The $\mathrm{pH}$-gradient strips were placed on the top of the SDS-PAGE gel and fixed.

After electrophoresis, the gels were consecutively stained with Pro-Q Diamond (Invitrogen) and Flamingo ${ }^{\mathrm{TM}}$ fluorescent dye (BioRad) to visualize the phosphoproteins and the whole proteome, respectively. The determination of phosphorylated proteins was based on the Pro-Q/ Flamingo ${ }^{\mathrm{TM}} \log$ ratio. Phosphoprotein spots were cut from the gel and identified by mass spectrometry.

Solutions for two-dimensional SDS polyacrylamid gel electrophoresis

$\begin{array}{clr}\text { Rehydration solution A } & \text { Urea } & 7 \mathrm{M} \\ & \text { Thio urea } & 2 \mathrm{M} \\ & \text { CHAPS } & 4 \%(\mathrm{w} / \mathrm{v}) \\ & \text { DTT } & 50 \mathrm{mM} \\ & \mathrm{H}_{2} \mathrm{O}_{\text {deion }} & \end{array}$




\begin{tabular}{llr} 
Rehydration solution B & Rehydration solution A & $2.625 \mathrm{ml}$ \\
& Ampholyte solution (for pH 3-10) & $125 \mu \mathrm{l}$ \\
& Bromphenol blue & $335 \mu \mathrm{l}$ \\
& & $50 \mathrm{mM}$ \\
SDS equilibration buffer & Tris-HCl (pH 8.8) & $6 \mathrm{M}$ \\
& Urea & $2 \%(\mathrm{w} / \mathrm{v})$ \\
& SDS & $35 \%(\mathrm{w} / \mathrm{v})$ \\
\hline
\end{tabular}

\section{Protein identification by mass spectrometry}

Gel pieces were washed twice with $200 \mu \mathrm{l} 20 \mathrm{mM} \mathrm{NH}_{4} \mathrm{HCO}_{3}$; acetonitrile (ACN) $(30 \%(\mathrm{v} / \mathrm{v}))$ for $30 \mathrm{~min}$, at $37^{\circ} \mathrm{C}$ and dried in a vacuum (Concentrator 5301 (Eppendorf, Hamurg, Germany)). Trypsin solution (10 $\mathrm{ng} / \mu \mathrm{l}$ trypsin in $20 \mathrm{mM}$ ammonium bicarbonate) was added until gel pieces stopped swelling and digestion was allowed to proceed for 16 to 18 hours at $37^{\circ} \mathrm{C}$. Peptides were extracted from gel pieces by incubation in an ultrasonic bath for 15 min in $20 \mu 1$ HPLC grade water and transferred into micro vials for mass spectrometric analysis. Peptides were separated by liquid chromatography and measured online by ESI-mass spectrometry using a nanoACQUITY UPLC ${ }^{\mathrm{TM}}$ system (Waters, Milford, USA) coupled to an LTQ Orbitrap ${ }^{\mathrm{TM}}$ mass spectrometer (Thermo Fisher Scientific, Waltham, USA). Peptides were desalted onto a trap column (Symmetry ${ }^{\circledR} \mathrm{C} 18$, Waters). Elution was performed onto an analytical column (BEH130 C18, Waters) by a binary gradient of buffer A $(0.1 \%(\mathrm{v} / \mathrm{v})$ acetic acid) and $\mathrm{B}(100 \%(\mathrm{v} / \mathrm{v})$ acetonitrile, $0.1 \%(\mathrm{v} / \mathrm{v})$ acetic acid) over a period of $80 \mathrm{~min}$ with a flow rate of $400 \mathrm{nl} / \mathrm{min}$. The LTQ Orbitrap ${ }^{\mathrm{TM}}$ was operated in data-dependent MS/MS mode for phospho-relevant masses. Proteins were identified by searching all MS/MS spectra in .dta format against all B. subtilis proteins (extracted from the NCBI database) using SEQUEST (Bioworks 3.3.1/Sequest v. 2.7 rev. 11, Thermo Electron). Initial mass tolerance for peptide identification on MS and MS/MS peaks were $10 \mathrm{ppm}$ and $1 \mathrm{Da}$ respectively. Up to two missed tryptic cleavages were allowed. Methionine oxidation 
$(+15.99492 \mathrm{Da})$ as well as carbamidomethylation $(+57,021465 \mathrm{Da})$ and phosphorylation $(+79,966331 \mathrm{Da})$ of serine, threonine, and tyrosine were set as variable modifications. Proteins were identified by at least two peptides applying a stringent SEQUEST filter (Xcorr vs. charge state: 1.90 for singly, 2.2 for doubly and 3.3 for triply charged ions). Phosphorylated peptides which passed this filter were examined manually and accepted only, when b- or y- ions confirmed the phosphorylation site.

\section{Assays for protein phosphorylation}

Protein phosphorylation assays were carried out with purified proteins $(10 \mu \mathrm{g})$ and crude extracts $(20 \mu \mathrm{g})$ in assay buffer with $\left[\gamma^{3}{ }^{32} \mathrm{P}\right] \mathrm{ATP}(480 \mathrm{Ci} / \mathrm{mmol})$. Different cations and metabolites were tested. The assays were carried out at $37^{\circ} \mathrm{C}$ for $30 \mathrm{~min}$ followed by thermal inactivation of the proteins $\left(95^{\circ} \mathrm{C} ; 10 \mathrm{~min}\right)$. The assay mixtures were analyzed on $16 \%$ SDS-polyacrylamide gels. Proteins were visualized by Coomassie staining. Gels were dried (Gel Dryer585, Biorad, Munich, Gemany) and radioactive protein spots were detected using a Phosphoimager (STORM 860, Molecular Dynamics, USA).

Assay buffer for protein phosphorylation experiments (25 $\mu \mathrm{l})$

\begin{tabular}{lccc}
\hline & Stock solution & Working concentration & Volume $(\mu \mathrm{l})$ \\
Tris-HCl $(\mathrm{pH} \mathrm{7.4})$ & $250 \mathrm{mM}$ & $25 \mathrm{mM}$ & 2.5 \\
$\mathrm{MgCl}_{2}$ & $200 \mathrm{mM}$ & $5 \mathrm{mM}$ & 0.625 \\
DTT & $40 \mathrm{mM}$ & $1 \mathrm{mM}$ & 0.625 \\
\hline
\end{tabular}

Strep-protein interaction experiment (SPINE) for the analysis of protein- protein interactions

The Strep-protein interaction experiment (SPINE) was performed according to Herzberg et al. 2007. This experiment was used to identify potential interaction partners of B. subtilis proteins in vivo. For this purpose, the gene of interest was cloned into 
expression vectors for $B$. subtilis. The gene was fused to a $\mathrm{N}$-terminal or C-terminal Strep-tag (pGP380, pGP382). The transcription of the fusion proteins was under the control of the constitutive $\operatorname{deg} Q$ promoter, which assured a high expression of the proteins. For the experiment a preculture of B. subtilis, carrying the appropriate plasmid was grown for 10 hours at $37^{\circ} \mathrm{C}$ in LB medium containing erythromycin. This culture was used to inoculate $100 \mathrm{ml} \mathrm{CSE} \mathrm{medium}(0.5 \%$ glucose $)$ and was grown overnight at $37^{\circ} \mathrm{C}$. One liter of the same medium was then inoculated with the second preculture to an $\mathrm{OD}_{600}$ of 0.1 . When this culture had reached an $\mathrm{OD}_{600}$ of $1.0,500 \mathrm{ml}$ were supplemented with formaldehyde (4\% in PBS) to a final concentration of $0.6 \%$. This culture was and incubated for additional 20 minutes. After cross-linking, the cells of the formaldehyde treated and the untreated culture were harvested by centrifugation (10 min; 5,000 rpm; $4^{\circ} \mathrm{C}$ ) (Sorvall RC 5B, SLA-3000 rotor). The cells were washed in buffer $\mathrm{W}$ and harvested again. The pellets were stored at $-20^{\circ} \mathrm{C}$. For the preparation of the crude extract, the cell pellet was thawed and resuspended in $5 \mathrm{ml}$ buffer W. Cell disruption was carried out using a French press or OneShot.

\subsubsection{Determination of enzyme activities}

\section{Determination of pyruvate kinase activity}

The pyruvate kinase catalyzes the transfer of one phosphate group from phosphoenolpyruvate (PEP) to ADP. Pyruvate and ATP are the products of this reaction. Enzymatic activity was achieved by the lactate dehydrogenase (LDH) reaction. LDH reduces pyruvate to lactate under oxidation of $\mathrm{NADPH}_{2}$. The decrease of $\mathrm{NADPH}_{2}$ by oxidation was measured at wavelength of $340 \mathrm{~nm}$. Furthermore, the pyruvate kinase require $\mathrm{Mg}^{2+}$ for its activity. It is important to note that the pyruvate kinase of $B$. subtilis is allosteric activated by ribose-5-phosphate. The assay conditions were examinated by using commercial pyruvate kinase (lactate dehydrogenase) purchased from Roche.

Pyruvate kinase: $\quad$ PEP + ADP $\leftrightarrow$ pyruvate + ATP 
Lactate dehydrogenase: $\quad$ pyruvate $+\mathrm{NADPH}_{2} \leftrightarrow$ lactate $+\mathrm{NADP}^{+}$

Solutions for pyruvate kinase assay

\begin{tabular}{lcr}
\hline & Stock solution & Assay approach \\
Potassium phosphate buffer & $100 \mathrm{mM}$ & $200 \mu \mathrm{l}$ \\
$\mathrm{MgSO}_{4}$ & $100 \mathrm{mM}$ & $100 \mu \mathrm{l}$ \\
$\mathrm{ADP}$ & $10 \mathrm{mM}$ & $50 \mu \mathrm{l}$ \\
$\mathrm{NADH}_{2}$ & $1.5 \mathrm{mM}$ & $50 \mu \mathrm{l}$ \\
Ribose-5-phosphate & $100 \mathrm{mM}$ & $10 \mu \mathrm{l}$ \\
Lactate dehydrogenase $(5 \mathrm{mg} / \mathrm{ml}))$ & $970 \mu \mathrm{l}+30 \mu \mathrm{lDH}$ & $20 \mu \mathrm{l}$ \\
Pyruvate kinase $(10 \mathrm{mg} / \mathrm{ml})$ & $970 \mu \mathrm{l}+30 \mu \mathrm{l}(\mathrm{Pyk})$ & $20 \mu \mathrm{l}$ \\
$\mathrm{H}_{2} \mathrm{O}_{\text {deion }}$ & & $\mathrm{ad} 1 \mathrm{ml}$ \\
\hline
\end{tabular}

The absorption was monitored at $\mathrm{OD}_{340}$ for $3-5 \mathrm{~min}$. The specific activity was calculated with the following formula.

Units $/ \mathrm{mg}=\frac{\Delta \mathrm{A}_{340} / \mathrm{min}}{6.22 \times \mathrm{mg} \text { enzyme } / \mathrm{ml} \mathrm{reaction} \mathrm{mixture}}$

\section{Measurement of methylglyoxal concentrations}

Methylglyoxal is a reactive dicarbonyl compound formed as a by-product of glycolysis. Due to the fact that methylglyoxal is toxic, the levels must be kept low in the cell. For this reason, living cells exhibit several glyoxalases for the detoxification of methylglyoxal. Measurement of methylglyoxal was performed by addition of 2,4 dinitrophenylhydrazin and results in a violet coloration. The methylglyoxal concentration was quantified colorimetrically at $550 \mathrm{~nm}$. Factor for the calculation of the total amount of methylglyoxal: $\mathrm{OD}_{550}=16.4$ corresponds to $1 \mu \mathrm{mol}$ of methylglyoxal. Cells were grown in liquid medium. At defined time points, samples of 
$2 \mathrm{ml}$ were taken and centrifuged ( $8 \mathrm{~min} ; 8,000 \mathrm{rpm}$; RT). The supernatants were stored on ice. For the measurement $320 \mu \mathrm{l}, 160 \mu \mathrm{l}$ and $80 \mu \mathrm{l}$ were mixed with 2,4-dinitrophenylhydrazin $(10 \mathrm{mg} / \mathrm{ml}$ in $2 \mathrm{M} \mathrm{HCl})$ and incubated at $30^{\circ} \mathrm{C}$ for $15 \mathrm{~min}$. Afterwards, the samples were mixed with $560 \mu \mathrm{l}$ of $10 \% \mathrm{NaOH}$ and incubated for 10 min at RT. The samples were centrifuged again (10 min; 13,000 rpm; RT) and the supernatants were measured at $\mathrm{OD}_{550}$ against a blank without supernatant.

\section{Disk diffusion assay (Cao et al., 2002)}

The analysis of phenotypes of kinase mutants was carried out with a disk diffusion assay. LB cultures of the respective mutant and wild type strains were grown to $\mathrm{OD}_{600}$ 1.0. Twenty microliters of the culture was mixed with $3 \mathrm{ml}$ of LB soft agar $(0.7 \%$ agar) and poured onto the bottom agar. After cooling and drying of the plates $(20 \mathrm{~min}$ at $37^{\circ} \mathrm{C}$ ), filter paper disks (6-mm diameter) carrying $5 \mu 1$ of stock solution (antibiotics at a concentration of $100 \mathrm{mg} / \mathrm{ml}$ each; lysozyme at $10 \mathrm{mg} / \mathrm{ml}$; and uncouplers at $5 \mathrm{mg} / \mathrm{ml}$ ) were placed on top of the agar. After incubation for 12 to $24 \mathrm{~h}$ at $37^{\circ} \mathrm{C}$, the plates were scored for growth inhibition produced by the diffusion of the antibiotics from the filter disks .After incubation for 12 to $24 \mathrm{~h}$, the plates were scored for growth inhibition produced by the diffusion of the antibiotics from the filter disks. 


\section{Results}

\subsection{Construction and analysis of multiple Ser/ Thr kinase mutants}

\subsubsection{Phosphoproteome analysis of kinase mutants}

Analysis of the annotated genome sequence revealed the presence of three additional potential kinases, PrkD, YabT and YxaL. For PrkC autokinase activity was already shown (Madec et al., 2002). Sequence comparison revealed that PrkD is similar to the kinase domain of PrkC and is also autophosphorylated in the presence of ATP (Pietack et al., 2010). However, the functions and the contributions of these potential kinases to the phosphoproteome of $B$. subtilis were unknown. To investigate, whether these uncharacterised kinases are responsible for protein phosphorylation events in B. subtilis, deletion mutants of prkC, prkD and yabT were constructed. YxaL was excluded from this study, since it contains a signal peptide and is mainly part of the secretome (Voigt et al., 2009).

To avoid redundant kinase activity, the mutations were combined, resulting in the triple kinase mutant strain GP581 ( $\triangle p r k C:: s p e c \triangle p r k D:: k a n$ AyabT::erm). This strain was used for further phosphoproteomic investigations. Therefore, GP581 was grown in LB medium to an optical density of 0.8 , according to other phosphoproteomic studies (Eymann et al., 2007). Protein extracts were separated by 2D-SDS-PAGE and specifically stained as described in Material and Methods. No differences in the phosphoproteome were detected between the B. subtilis 168 wild type strain and the triple kinase mutant (data not shown). In further experiments, both strains were grown in CSE medium with glucose; however, no differences in the protein- and phosphorylation pattern were detected, too.

In conclusion it has to be stated that the annotated Ser/Thr kinases are not responsible for the phosphorylation events in B. subtilis under standard conditions. Perhaps, these kinases have specific targets or require a specific stimulus for their activation. 


\subsubsection{The phenotype of the triple kinase mutant}

The triple kinase mutant GP581 showed no differences in the phosphorylation pattern compared to the B. subtilis wild type strain 168 under the tested conditions. Thus, it was of interest under which conditions the kinases are active. To address this question, the phenotype of GP581 was investigated. Growth tests were performed in rich medium (LB), sporulation medium (SP) and minimal medium (CSE-glucose). However, the mutant strain demonstrated no differences in growth compared to the wild type strain (data not shown).

The kinase mutant strain showed no significant phenotype under standard growth conditions. Additionally, the amount of the respective kinases in the cell was unclear. Thus, the single kinases were overexpressed in B. subtilis, to force potential effects on the phenotype. Growth tests were performed in different media, like described above. However, the overexpression of kinases had no effect on growth. A further approach, to identify potential interaction partners or substrates of the respective kinases by in vivo cross linking (SPINE) was not successful.

The deletion and overexpression of PrkC, PrkD and YabT had no effect on the phenotype. Thus it must be concluded that either the kinases do need a specific stimulus or the specific substrate(s) is only present under certain conditions. Furthermore, it is possible that these kinase are only active under specific conditions.

Consequently, conditions must be found were the kinase function is necessary. A starting point for this approach was the PASTA domain of PrkC (Fig. 3.1.). PASTA domains are described as binding domains for beta-lactam antibiotics and analogues of peptidoglycan (Yeats et al., 2002). For that reason, disk diffusion assays were performed with detergents and an extensive set of antibiotics that target cell wall synthesis (Jordan et al., 2008). Furthermore, the B. subtilis wild type and GP581 strains were treated with lysozyme during growth, but neither the disk diffusion assays nor the lysozyme treatments showed a significant difference between both strains (data not shown). 


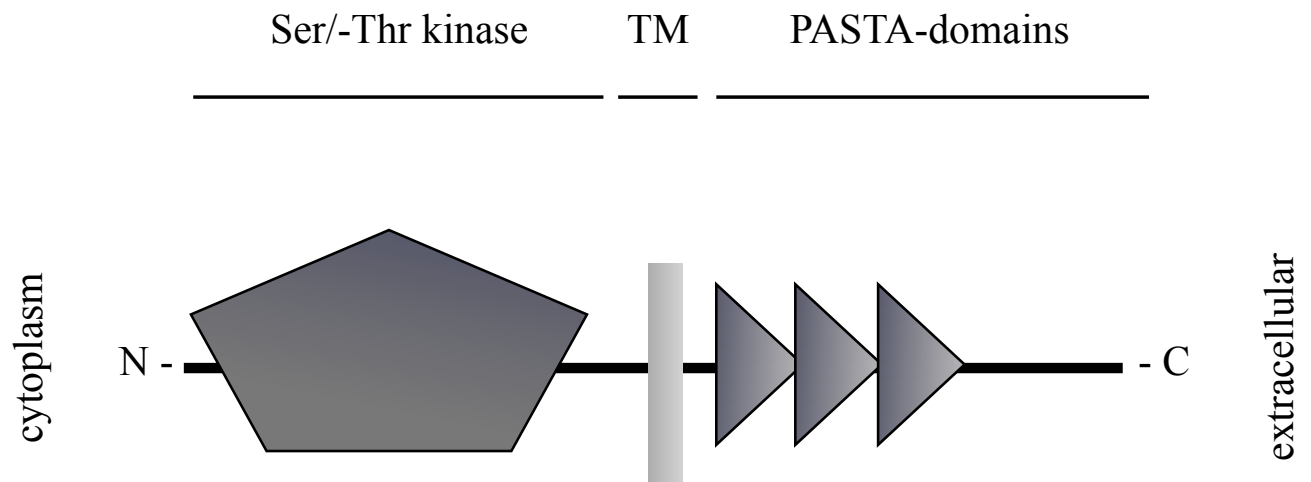

Figure 3.1.: Domain structure of PrkC (prediction by EMBL)

PrkC consists of N-terminal, extracellular PASTA domains (beta-lactam-binding domains) followed by a transmembrane domain (TM). The Ser/-Thr kinase domain is localized in the cytoplasm, at the C-terminal end.

\subsection{Investigation of conserved GTPases}

The investigation of the multiple kinase mutant revealed, that the annotated Ser/Thr kinases were not responsible for the bulk of phosphorylation events in B. subtilis under standard conditions. Therefore, it is tempting to speculate that an unknown Ser/Thr kinase is responsible for these phosphorylation events.

Phosphoproteome analysis in B. subtilis, E. coli and Campylobacter jejuni revealed a common set of proteins that are phosphorylated in these bacteria (Macek et al., 2007; Voisin et al., 2007 Macek et al., 2008). Hence, it seemed likely that the orthologous proteins were phosphorylated by a kinase that is conserved in all three organisms. The B. subtilis genome with a size of $4.2 \mathrm{Mb}$ comprises 4,106 protein coding genes, similar to that of E. coli with $4.6 \mathrm{Mb}$, coding for 4,288 proteins (Barbe et al., 2009; Kunst et al., 1997; Blattner et al., 1997). In contrast to B. subtilis and E. coli, the genome of Campylobacter jejuni with a size of $1.6 \mathrm{Mb}$ encodes just 1,654 proteins (Parkhill et al., 2000).

An in silico comparison of annotated proteins of B. subtilis, E. coli and Campylobacter jejuni revealed a common set of around 500 conserved proteins. Subsequently, all proteins with walker A and walker B motifs were summarized (Ramakrishnan et al., 
2002; Walker et al., 1982). Furthermore, proteins were selected where the coding genes were described as essential in B. subtilis(Kobayashi et al., 2003). These criteria resulted in a selection of six GTP-binding proteins (Era, Obg, YdiB, YphC, YyaF and YsxC). These proteins are present in all domains of life and were predicted to be essential (Mittenhuber, 2001). The selected genes were cloned into expression vectors for B. subtilis, and fused to an N-terminal Strep-tag. The expressed proteins were investigated in protein-protein interaction experiments, without success.

Furthermore, genes of the GTP-binding proteins were cloned into overexpression vectors for $E$. coli $\mathrm{DH} 5 \alpha$ and purified via N-terminal His6-tag. The purified proteins were investigated in in vitro phosphorylation experiments. Proteins were tested for autophosphorylation activity using $\left[\gamma_{-}{ }^{32} \mathrm{P}\right]$ ATP and $\left[\gamma_{-}{ }^{32} \mathrm{P}\right]$ GTP. As negative control $\left[\alpha^{32} \mathrm{P}\right]$ GTP was used to exclude non-specific binding of nucleotides. Moreover, all proteins were tested for their ability to phosphorylate purified proteins of different metabolic pathways of $B$. subtilis. However, none of the potential target proteins were phosphorylated by the selected proteins.

Interestingly, GTP-dependent autophosphorylation was observed for Obg, and ATPdependent phosphorylation for YdiB (Fig. 3.2.). The GTP-dependent autophosphorylation of Obg is in good agreement with previous studies (Welsh et al., 1994). Obg is a ribosome-associated protein and the association is stabilised by GTP (Zhang \& Haldenwang, 2004). Recently, it was shown that deletion of the 'essential' $y d i B$ gene yielded in reduced growth of a mutant, but the cells were still viable. The growth defect was dependent on the ATPase activity of YdiB (Karst et al., 2009; Hunt et al., 2006). 


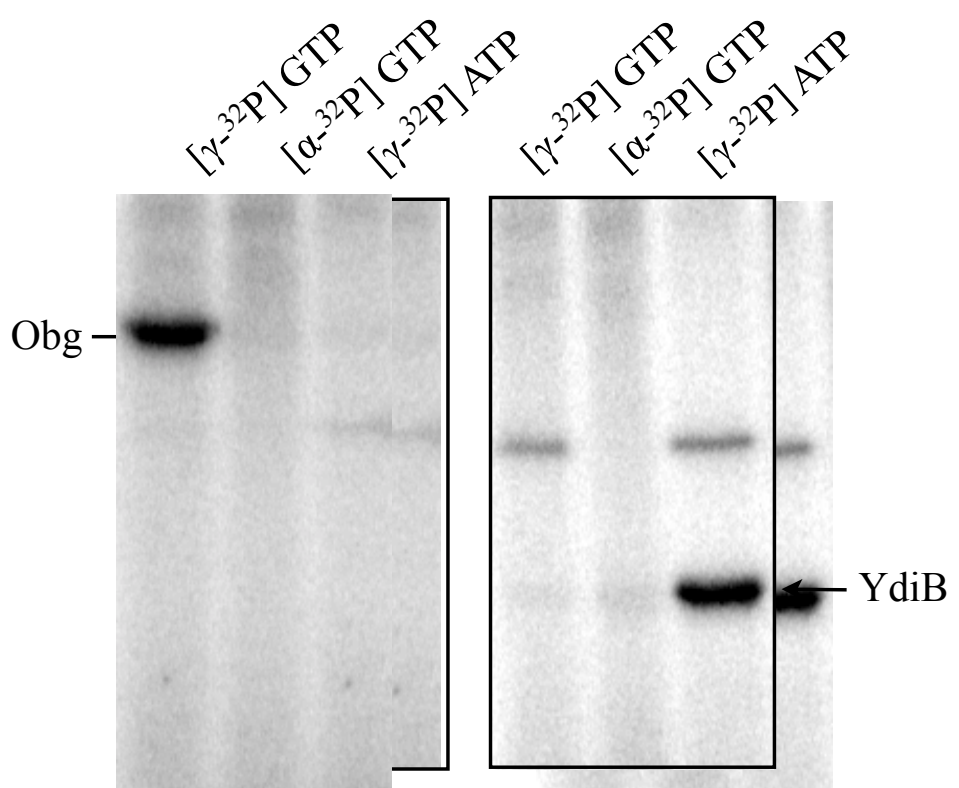

Figure 3.2.: Autophosphorylation of conserved GTP binding proteins

The B. subtilis proteins $\mathrm{Obg}$ and $\mathrm{YdiB}$ were overexpressed in E. coli and purified by making use of the His6-tag. Ten microgram of dialysed proteins were incubated in phosphorylation buffer at $37^{\circ} \mathrm{C}$ for 15 min. Radiolabeled nucleotides were used to determine the substrate specificity for either ATP or GTP. To exclude non-specific binding of nucleotides, [ $\left.\alpha-{ }^{32} \mathrm{P}\right]$ GTP was used as control. Obg (approx. $47 \mathrm{kDa}$ ) showed GTP dependent autophosporylation, whereas YdiB (approx. $17 \mathrm{kDa}$ ) showed ATP dependent autophosphorylation.

\subsection{Analysis of the phosphorylation of HPr}

HPr (histidine containing protein) is a prime example for protein phosphorylation. It is phosphorylated on His-15 by enzyme I in the phosphotransferase system (PTS) and on Ser-46 by the HPrK/P (Reizer et al., 1998). A recent analysis of the B. subtilis phosphoproteome revealed a novel phosphorylation of the HPr protein on Ser-12 (Macek et al., 2007). However, the source of this phosphorylation was unknown. Phosphorylation experiments with purified kinases and $\mathrm{HPr}$ revealed, that PrkC phosphorylates HPr in the presence of $\left[\gamma_{-}{ }^{32} \mathrm{P}\right] \mathrm{ATP}$ (Pietack et al., 2010). A HPr (Ser-46-Ala) mutant was used to exclude a phosphorylation on Ser-46. As expected, the mutant protein was not longer phosphorylated by the HPr kinase, thus 
confirming that Ser-46 is the only phosphorylation site for HPr kinase. PrkC was still able to phosphorylate HPr (Ser-46-Ala), on Ser-12.

The biological relevance of the phosphorylation of HPr on Ser-12 was unknown. To investigate the function of the Ser-12 of HPr in vivo a HPr (Ser-12-Ala) mutant was constructed and expressed from plasmid in GP105. In GP105 the His-15 of HPr is replaced by an alanine, therefore HPr is not active in its function in the PTS. It was not possible to use a deletion mutant of HPr, because of the negative polar effect on the expression of the downstream gene ptsI (EI). GP105 carrying the empty vector (pBQ200) and derivates for expression of HPr (WT), HPr (His-15-Ala) and HPr (Ser-12-Ala) were analysed in growth tests in minimal medium with fructose as single carbon source (Fig. 3.3.). In contrast to glucose, fructose uptake only occurs over the PTS, thus active HPr is required.

Growth tests showed that the His-15 of HPr is absolutely required for the sugar uptake, whereas the Ser-12 phosphorylation is not necessary for HPr activity. Interestingly, recent studies with purified HPr and EI revealed that HPr is phosphorylated on Ser-12 after extended incubation in the presence of PEP(Sebastian Himmel, unpublished data). These results indicate that Ser-/Thr- phosphorylations are not strictly dependent on kinases. However, the function of this phosphorylation event is still unclear.

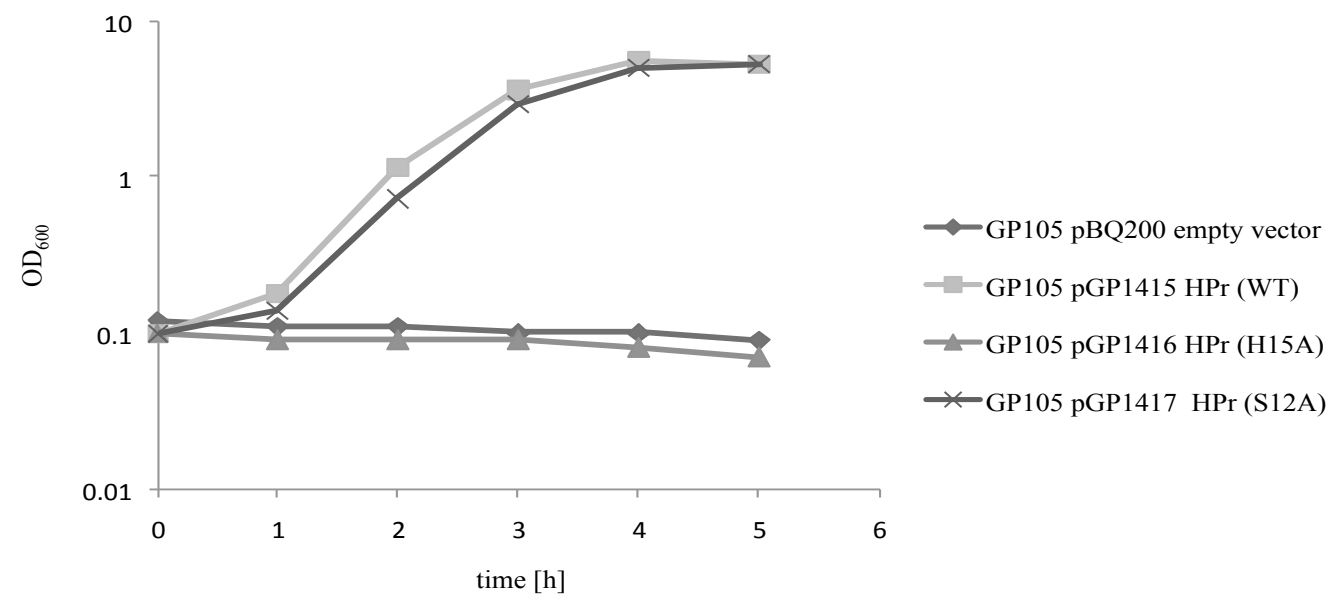

Figure 3.3.: Analysis of the implication of S12 of HPr in sugar uptake

Growth with different HPr variants was analysed. The strain GP105 (HPr; His-15-Ala) carrying the vectors pGP1415, pGP1416, pGP1417 and pBQ200 was grown in C-minimal medium with fructose as sole carbon source. 


\subsection{Investigation of essential glycolytic genes in $B$. subtilis}

\subsubsection{Conditions for the construction of mutants of glycolytic genes}

The B. subtilis genome codes for around 4,106 proteins (Barbe et al., 2009). A study in B. subtilis revealed that 271 genes are indispensable for growth (Kobayshi et al., 2003; Thomaides et al., 2007). Among these essential genes are almost all genes that code for glycolytic enzymes. However, it was unknown why these genes should be essential, while other metabolic pathways might have the capability to compensate the loss of several glycolytic enzymes in rich media. Furthermore, rich medium contains substrates and products of the glycolysis that should allow growth in the absence of single enzymatic reactions.

During investigation of protein phosphorylation events, mutants of glycolytic enzymes were constructed. Before deletion, the mutants were complemented with expression vectors carrying the respective genes. Surprisingly, deletion strains were also viable when complementation occurred with enzymatic inactive enzymes. Therefore, growth in absence of the respective gene must be examined.For that reason, deletion mutants of glycolytic genes were constructed. The respective genes were replaced by antibiotic resistance cassettes, using LFH-PCR fragments (described in material and methods). It is important to note, that after the transformation the clones were selected on SP medium supplemented with glucose and malate.

Surprisingly, it was possible to construct deletion mutants of all glycolytic genes of B. subtilis. Up to that, only a pyruvate kinase mutant was described in detail (Frey et al., 2000) However, the pyk-gene was not reported to be essential (Kobayashi et al., 2003). Interestingly, deletion mutants of pgm- and the eno were described previously (LeyvaVazquez \& Setlow, 1994). In addition, it was possible to construct mutant strains with multiple deletions (Fig. 3.4.). This was mainly du to the fact, that glycolytic genes are coded in operons. The gapA-operon codes the genes gapA, pgk, tpiA, pgm and eno which products are enzymes of the lower part of the glycolysis. It was possible to delete a maximum of four genes in one step, with exception of gapA (Fig. 3.4.C.). 
A

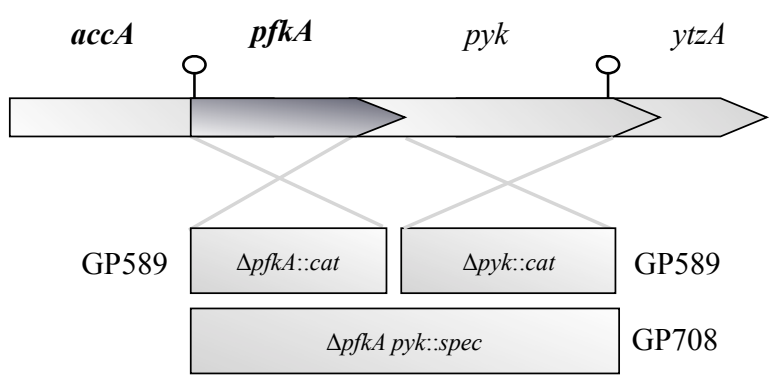

B

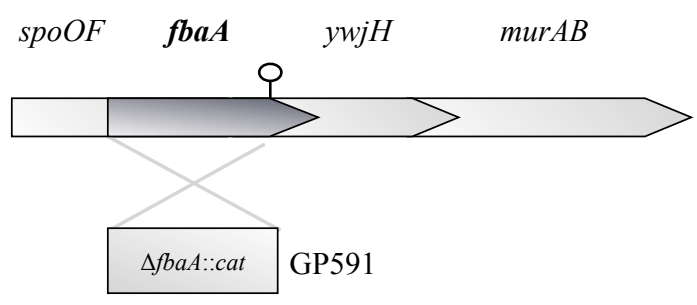

C

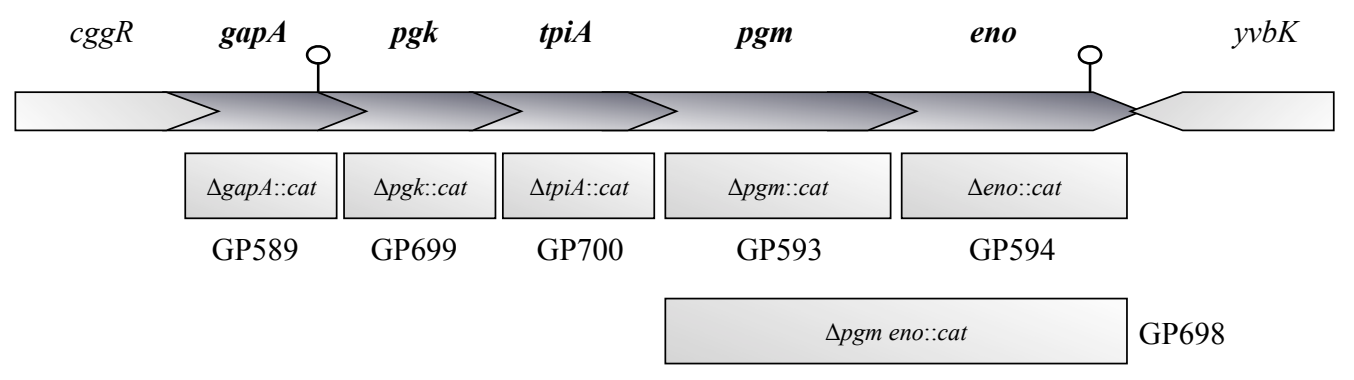

$\Delta$ tpiA pgm::cat GP709 GP710

Figure 3.4.: Schematic overview about constructed multiple glycolytic mutants.

(A) Illustration of the genetic organisation of the phosphofructokinase $(p f k A)$ and the pyruvate kinase $(p y k)$. (B)The gene for fructose-1,6-bisphosphate aldolase $(f b a A)$ is localised upstream of the transaldolase $(y w j H)$. (C) Organisation of the gapA operon coding the genes for glyceraldehyde-3-phosphate dehydrogenase ( $g a p A)$, phosphoglycerate kinase (pgk), triosephosphate isomerase (tpiA), phosphoglycerate mutase (pgm) and enolase (eno). 
After the examination of the single mutant strains by PCR and sequencing, the isolated genomic DNA was used for the transformation of B. subtilis 168. Transformation approaches were used to decide the optimal supplementation of the growth medium (Tab. 3.1.). With the exception of $\Delta p f k A$ and $\Delta p y k$, all mutants require malate for growth. This is plausible, while malate can be metabolised in the Krebs cycle and passed through glyconeogenesis by malic enzymes and PEP-caboxykinase ( $p c k A)$. This need of malate is a disadvantage for storing of glycolysis mutants, as malate like glucose repress sporulation in B. subtilis (Ohné et al., 1976; Freese et al., 1970; Schaeffer et al., 1965; ). Therefore, the strains were stored in DMSO cryo cultures.

\begin{tabular}{cccccccc}
\hline Strain & & LB & SP & $\begin{array}{c}\text { SP- } \\
\text { glucose }\end{array}$ & $\begin{array}{c}\text { SP- } \\
\text { malate }\end{array}$ & $\begin{array}{c}\text { SP- } \\
\text { glucose, } \\
\text { malate }\end{array}$ & $\begin{array}{c}\text { SP- } \\
\text { glycerol, } \\
\text { succinate }\end{array}$ \\
\hline GP590 & $\Delta p f k A$ & ++ & + & ++ & ++ & ++ & ++ \\
GP591 & $\Delta$ fbaA & + & n.g. & - & + & + & - \\
GP700 & $\Delta t p i A$ & + & - & + & + & + & - \\
GP592 & $\Delta$ gapA & n.g. & n.g. & n.g. & ++ & + & n.g. \\
GP699 & $\Delta p g k$ & + & - & - & + & + & - \\
GP593 & $\Delta p g m$ & n.g. & n.g. & n.g. & + & + & n.g. \\
GP594 & $\Delta e n o$ & n.g. & n.g. & n.g. & + & + & - \\
GP589 & $\Delta p y k$ & +++ & + & + & + & +++ & + \\
\hline
\end{tabular}

Tab. 3.1.: Determination of the optimal growth medium and supplementation.

B. subtilis wild type was transformed with genomic DNA of the respective mutant and stroke out on LB and SP plates, supplemented with glucose, malate, glycerol and succinate. The plates were incubated at $42^{\circ} \mathrm{C}$ for $24 \mathrm{~h}$ at. Evaluation occurred as followed: (n.g. no growth); (- very small colonies); (+ growth); (++ normal growth); (good growth).

Furthermore, optimal $\mathrm{pH}$ value was investigated by streaking out transformed cells on SP plates with glucose and malate. The $\mathrm{pH}$ value of the medium was adjusted at $\mathrm{pH}$ of 6 and 8 , respectively. 


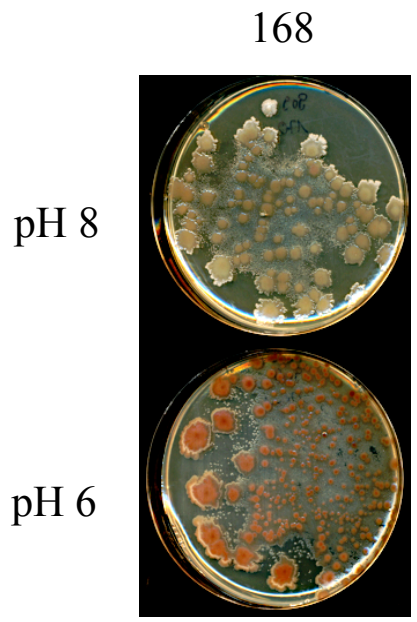

$$
\text { GP590 }(\triangle p f k A) \quad \text { GP591 }(\Delta f b a A)
$$
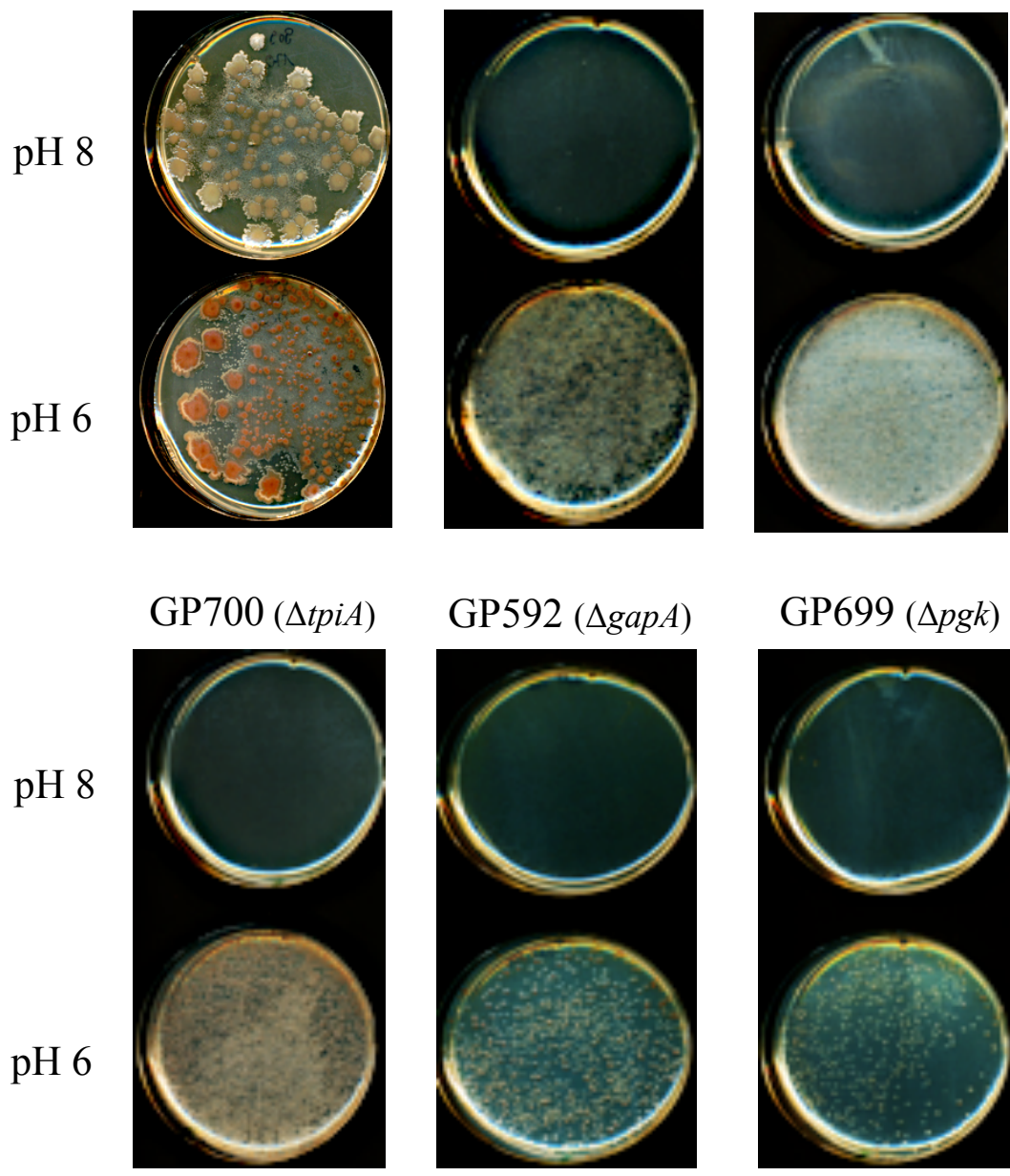

\section{GP699 ( $\Delta p g k)$}
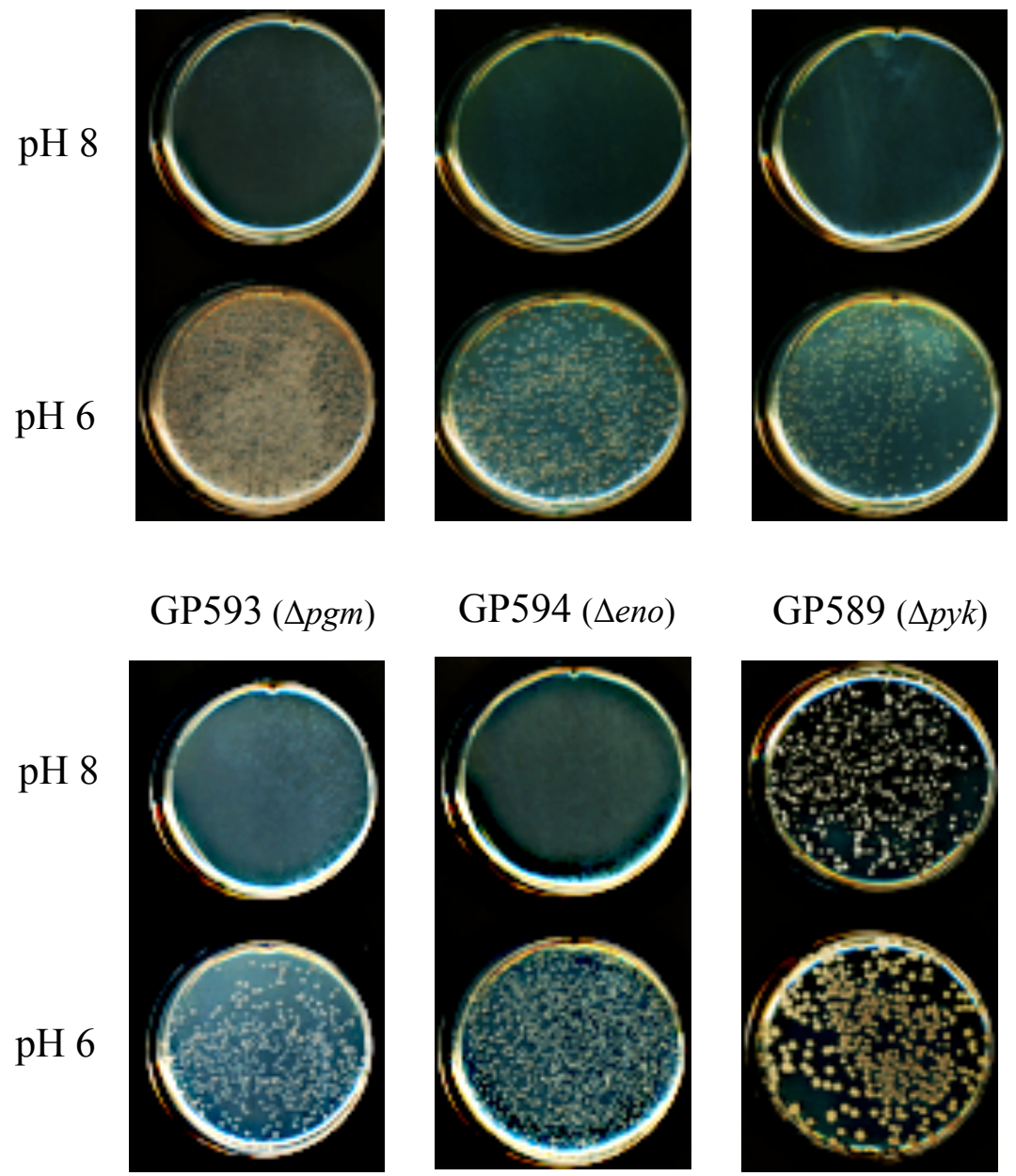

\section{GP594 (Аeno)}

GP589 ( $\Delta p y k)$
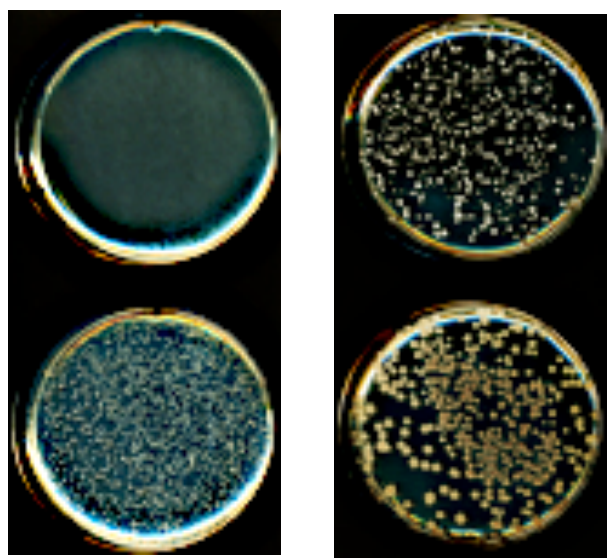

Figure 3.5.: Analysis of optimal pH value for construction of glycolytic mutants

B. subtilis was transformed with chromosomal DNA of the respective mutant strain. Selection occurred on SP medium with glucose and malate. The $\mathrm{pH}$ of the media was adjusted to 6 and 8 with MES and Tris- $\mathrm{HCl}$. Plates were incubated at $42^{\circ} \mathrm{C}$ for $24 \mathrm{~h}$. 
The plates with a $\mathrm{pH}$ of 6.0 were adjusted with $0.5 \mathrm{M}$ MES buffer $(50 \mathrm{mM}$ final concentration). For plates with a $\mathrm{pH}$ of $8.0,0.5 \mathrm{M}$ Tris- $\mathrm{HCl}$ was used (50 mM final concentration). The plates were incubated at $42^{\circ} \mathrm{C}$ for $24 \mathrm{~h}$ and documented (see fig. 3.5.). Transformants for all glycolysis mutants were obtained. The colonies showed a striking red coloration that could be due to expression of cytochromes at acidic conditions (Wilks et al., 2009). However, at $\mathrm{pH} 8$ glycolytic mutants were unable to grow, with exception of the wild type and the pyruvate kinase mutant (see discussion).

\subsubsection{Morphological phenotype of glycolytic mutants}

B. subtilis is a rod shaped peritrichous flagellate with a cell length of 3-5 $\mu \mathrm{m}$. The glycolysis mutants showed diminished growth on plates, therefore the morphological phenotype of the mutant strains was investigated. The mutants were grown in LB medium supplemented with glucose and malate to an optical density of 0.8 . The mutants were investigated by light microscopy (Fig. 3.6.). The mutants displayed a normal cell length of around 3-5 $\mu \mathrm{m}$, that is similar to the wild type. With the exception of the $\Delta p y k$ mutant, all mutants displayed abnormal cell morphology. Cells were mostly organized in chains and fixed. Only the $\Delta p y k$ mutant formed single motile cells.

The most severy effect of knock-out of glycolytic genes on morphology was observed for GP591 ( $\triangle f b a A:: c a t)$ and GP700 ( $\Delta t p i A:: c a t)$. The $\triangle f b a A$ mutant displayed long cells and irregular morphology. In contrast, the $\Delta$ tpiAmutant showed abnormal long cell chains. When cultures of the $\triangle t p i A$ mutant were harvested, no typical pellet was received. The pellet was fluffy, sponge-like impossible to compress. 

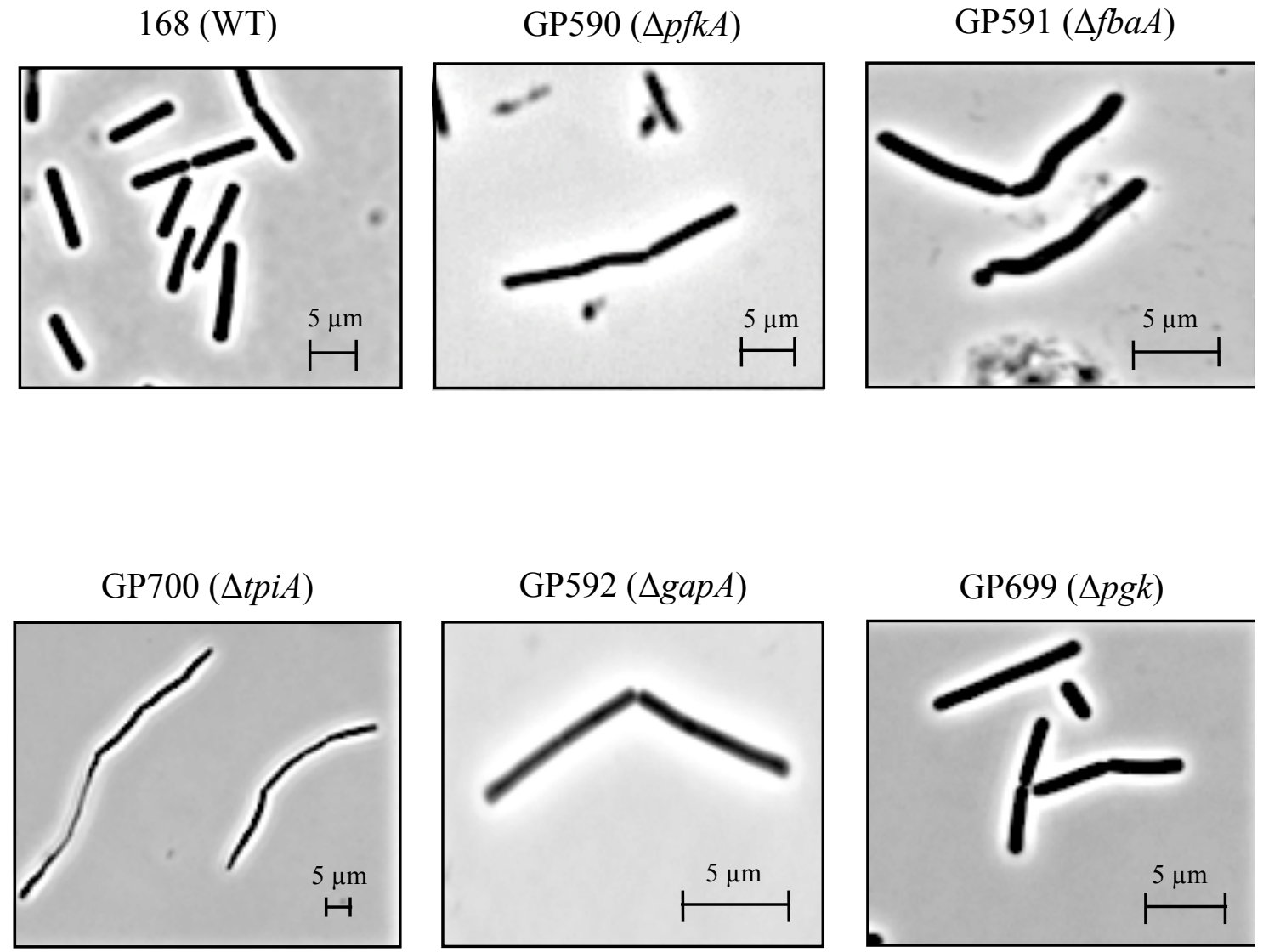

GP593 ( $\Delta p g m)$

GP594 (Aeno)

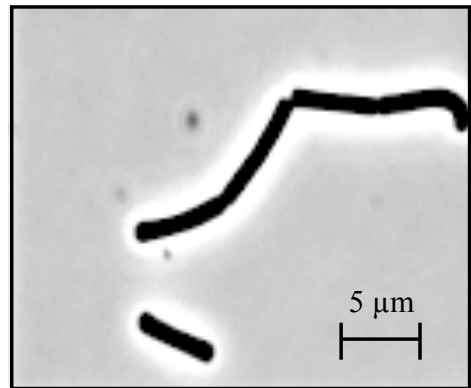

GP589 ( $\Delta p y k)$

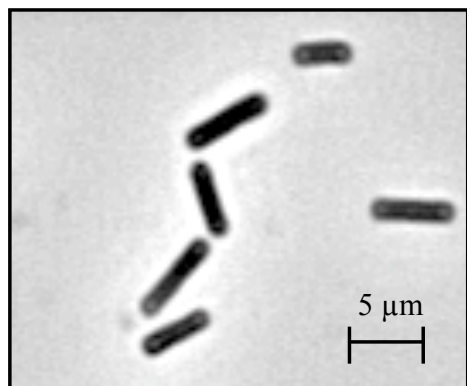

Figure 3.6.: Phase-contrast microscopy of glycolytic mutants.

Glycolysis mutants were grown in LB medium with glucose and malate to $\mathrm{OD}_{600}$ of around 0.8 . Morphology of cells was examined by light microscopy at enlargement 100x (Zeiss). 


\subsubsection{Growth of glycolytic mutants on different carbon sources}

Glycolysis can be summarized as a sequence of reactions that produce oxidizable, energy yielding substrates and essential biosynthetic precursors such as hexose monophosphates, dihydroxyacetone phosphate, glycerate-3-phosphate, phosphoenolpyruvate and pyruvate. A block in any of these enzymes should divide this pathway into two branches with opposite directions starting with glucose from the glycolytic direction and pyruvate from the gluconegenetic direction.

Extensive studies were made with mutants deficient in glycolytic enzymes in $S$. cerevisiae and E. coli (Irani \& Maitra, 1977; Clifton et al., 1978). In B. subtilis, the glycolytic genes were described to be essential, thus little is known about the properties of mutants lacking enzymes of glycolysis.

As described before, mutants lacking single enzymes and multiple deletions of glycolytic genes were now available. On this basis the growth of each mutant on glycolytic and gluconeogenetic substrates was analyzed. For this purpose, the strains were precultured in LB medium with glucose and malate. The growth test was performed on C-minimal medium with glucose, with malate and both carbon sources (Fig. 3.7.). The plates were incubated for 3 days at $42^{\circ} \mathrm{C}$. All strains were selected on chloramphenicol. GP909 carrying a cat-resistance gene in the $a m y E$ gene was used as positive control (WT). The results of the growth test are summarized in table 3.2..

\section{Growth of glycolytic mutants on glucose}

As expected, the wild type strain and strain GP589 ( $\Delta p y k:: c a t)$ were able to grow with glucose. In addition, GP 590 ( $\triangle p f k A:: c a t)$ and GP592 ( $\Delta$ gapA::cat) grew with glucose as single carbon source. In $S$. cerevisiae, a phosphofructokinase mutant was described, that showed growth on glucose similar to the wild type under aerobic condition (Lobo et al.,

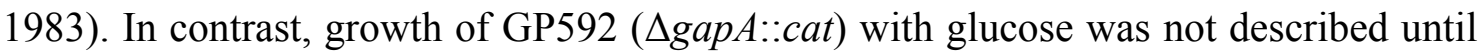
now. 


\section{Growth of glycolytic mutants on malate}

When malate was used as the single carbon source, growth of the 'wild type' strain

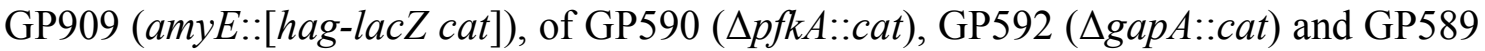
( $\Delta p y k: c a t)$ was observed. Malate can be metabolized in gluconegenesis.

In glycolysis the enzymatic reactions of phosphofructokinase and pyruvate kinase are irreversible. In gluconeogenesis the reverse reaction of phosphofructokinase is accomplished by fructose-1,6-bisphosphatase (Fbp) (Fujita et al., 1979; 1981; 1998). To circumvent the pyruvate kinase reaction different reactions are possible. Malate can be converted to oxaloacetate by malate dehydrogenase and by PEP carboxykinase (PckA) to phosphoenolpyruvate. Besides, pyruvate can also be converted to oxaloacetate by pyruvate carboxylase and further to PEP. Growth was also observed for GP592 ( $\triangle$ gapA::cat) with malate. B. subtilis possesses two glyceraldehyde-3-phosphate dehydrogenases with different roles in metabolism, gapA and gapB (Fillinger et al., 2000). Under glycolytic conditions GapA is expressed, whereas GapB is only expressed under gluconeogenetic conditions (Servant et al., 2005). Under glycolytic conditions the expression of $p c k A$ and $g a p B$ is repressed by transcription regulator CcpN (Tännler et al., 2008). Therefore, growth of GP592 ( $\triangle$ gapA::cat) on glucose was surprising.

\section{Growth of glycolytic mutants on glucose and malate}

With glucose and malate, all strains were able to grow. Growth tests on C-glucose and

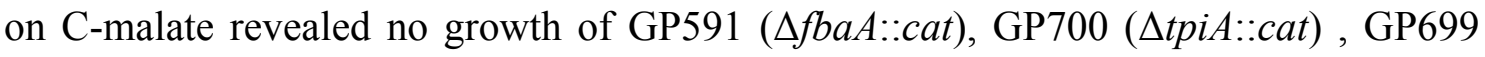

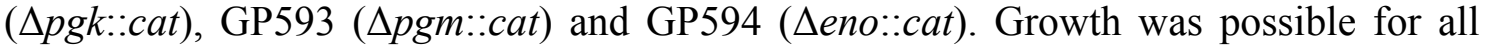
mutants when a glycolytic and a gluconeogenetic carbon source were provided. Gluconeogenesis can supply metabolites that cannot be formed because of the missing glycolytic enzyme. 


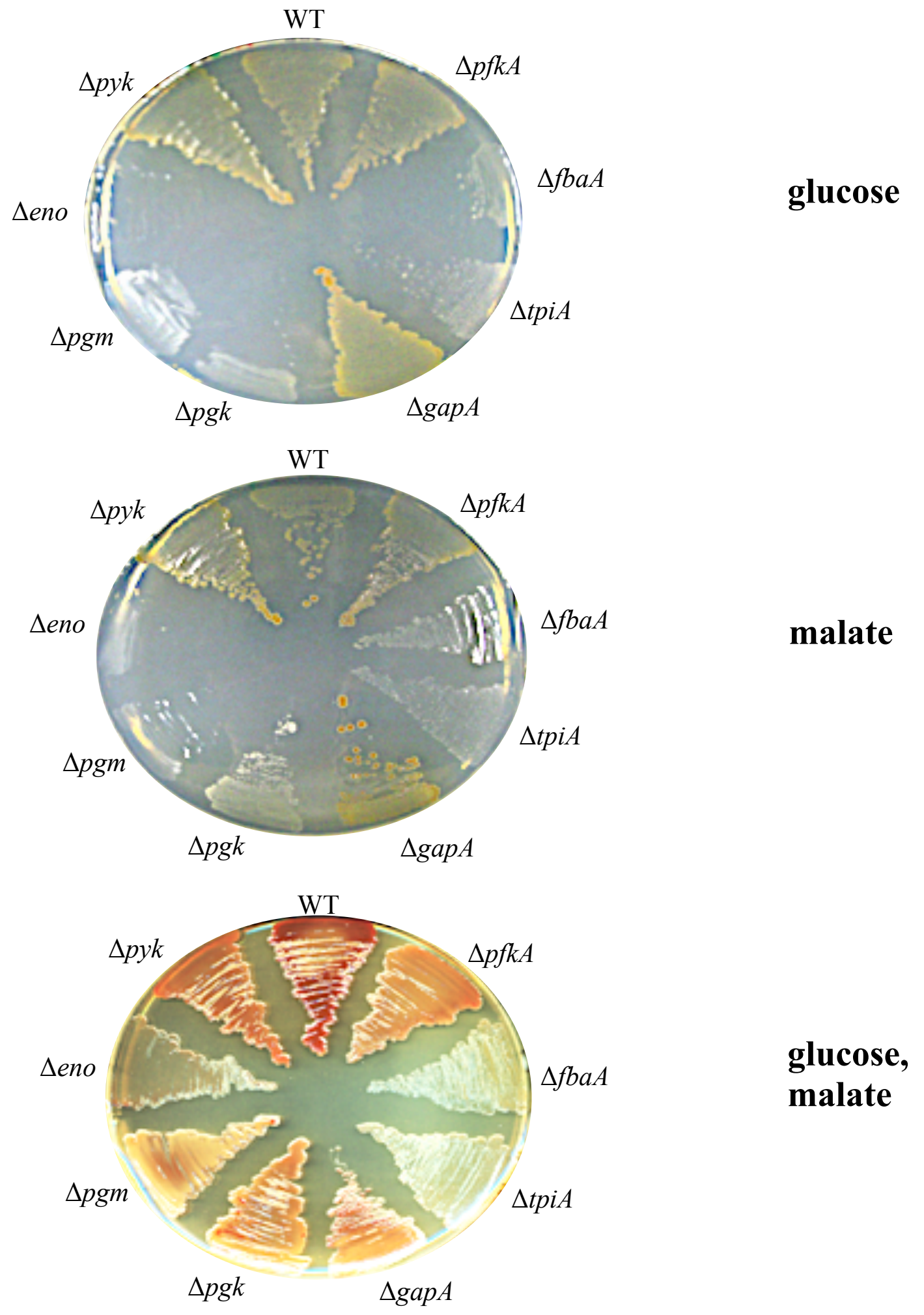

Figure 3.7.: Growth test of glycolysis mutants on minimal medium with glucose and malate. Strains were grown in C-medium with glucose, malate. Growing cultures were streaked out on C-glucose, $\mathrm{C}$-malate and C-glucose, malate agar plates and incubated at $42^{\circ} \mathrm{C}$ for 3 days. Growth of mutants is summarized in table 3.2 .. 


\begin{tabular}{llccc}
\hline Strain & & C-glucose & C-malate & C-glucose, malate \\
\hline GP909 & WT & $\checkmark$ & $\checkmark$ & $\checkmark$ \\
GP590 & $\Delta p f k A$ & $\checkmark$ & $\checkmark$ & $\checkmark$ \\
GP591 & $\Delta f b a A$ & - & - & $\checkmark$ \\
GP700 & $\Delta t p i A$ & - & $\checkmark$ & $\checkmark$ \\
GP592 & $\Delta g a p A$ & $\checkmark$ & - & $\checkmark$ \\
GP699 & $\Delta p g k$ & - & $\checkmark$ \\
GP593 & $\Delta p g m$ & - & - & $\checkmark$ \\
GP594 & $\Delta e n o$ & - & $\checkmark$ & $\checkmark$ \\
GP589 & $\Delta p y k$ & $\checkmark$ & - & $\checkmark$ \\
\hline
\end{tabular}

Table 3.2.: Growth glycolysis mutants on glucose and malate as carbon and energy source. All mutants strains were able to grew on C-minimal medium with glucose and malate agar plates. Growth on glucose and malate alone was only observed for GP909, GP590, GP592 and GP589. For the further description the deleted gene will be used instead of the strain number.

\subsubsection{Elucidation of growth of a gap $A$ mutant on glucose}

Growth experiments with glycolysis mutants revealed, that the GP590 ( $\Delta p f k A:: c a t$ ),

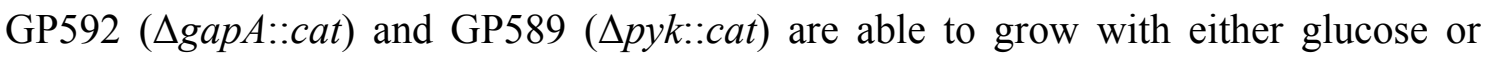
malate as sole carbon source. The growth of the pyruvate kinase mutant is dependent on the intracellular PEP level, whose concentration is connected to the phosphoenolpyruvate: sugar phosphotransferase system (PTS). The PTS is the only method to modulate the intracellular PEP level (Pan et al., 2006). Furthermore it was observed, that GP592 ( $\operatorname{gapA}:$ :cat) was able to grow on glucose as sole carbon source. gapA codes for the $\mathrm{NAD}^{+}$-dependent glyceraldehyde-3-phosphate dehydrogenase (GapDH), that converts glyceraldehyde-3-phosphate to D-glycerate-1,3-bisphosphate. The reverse reaction is catalyzed by GapB. The two GapDHs of B. subtilis have opposite roles in metabolism and are differentially expressed. gapA expression is induced under glycolytic conditions whereas gapB is repressed under glycolytic conditions and induced under gluconeogenetic conditions (Fillinger et al., 2000). 
Since GapB is active in the opposite direction and not expressed with glucose, the question arised how the glycolytic flux is modified to allow growth of a $\triangle g a p A$ mutant on glucose. The lower part of the glycolytic pathway can be bypassed by the methylglyoxal pathway (Fig. 3.8.). This pathway starts with dihydroxyacetone phosphate (DHAP) that is converted to methylglyoxal by the methylglyoxal synthase (MgsA). Methylgloxal is further metabolized to lactate and pyruvate that can be fed into overflow metabolism and the TCA cycle. This pathway produces a toxic intermediate, methylglyoxal.

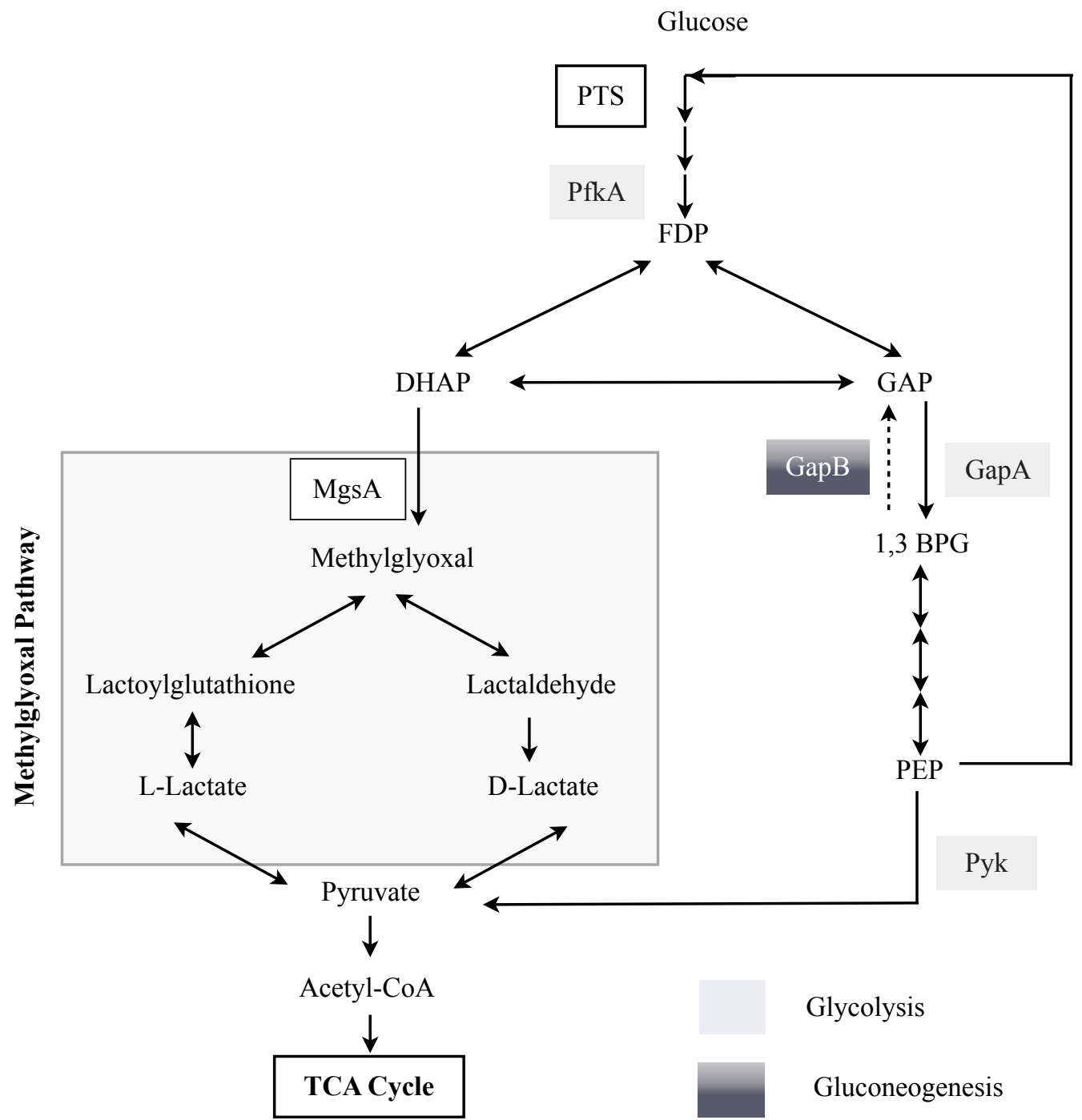

Figure 3.8: The methylglyoxal pathway integrated in glycolysis.

The network is shown in a simplified manner. Reversible reactions are indicated with double headed arrows. Glycolytic enzymes catalyzing irreversible reactions are labeled in grey boxes. Enzymes involved in gluconeogenesis are indicated in dark boxes. 
To study whether the methylglyoxal pathway is responsible for growth of the $\Delta$ gapA mutant on glucose, a $\triangle m g s A \Delta g a p A$ double mutant (GP705) was constructed and tested for growth on glucose. The double mutant was still able to grow with glucose. Furthermore, measurement of methylglyoxal concentration of B. subtilis 168 compared with GP592 ( $\triangle$ gapA::cat) grown with glucose revealed no elevated methylglyoxal level in the mutant (data not shown). Consequently, the methylglyoxal pathway is not responsible for the growth of the $\triangle g a p A$ mutant on glucose.

Therefore, a $\triangle g a p A \triangle g a p B$ double mutant (GP703) was constructed to determine whether GapB is able to replace the enzymatic activity of GapA under conditions when gapB expression is repressed by $\mathrm{CcpN}$. Growth tests on $\mathrm{C}$-glucose and C-glucose, malate were carried out with $B$. subtilis 168, GP592 ( $\operatorname{copap}::$ cat), GP701

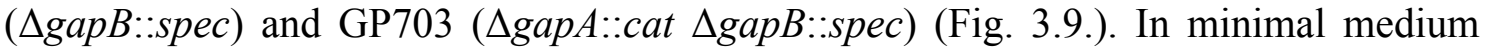
with glucose and malate, the single mutants showed growth comparable to the B. subtilis 168. Only the double mutant displayed a significant growth defect (Fig. 3.9.A). In minimal medium with glucose, growth of GP701 ( $\operatorname{gapB}:: s p e c)$ was similar to B. subtilis 168. GP592 ( $\Delta$ gapA::cat) displayed growth after a lag-phase of around 5 hours, whereas GP703 ( $\operatorname{gapA}::$ cat $\Delta$ gapB::spec) was unable to grow with glucose alone (Fig. 3.9. B). This result confirmed that GapB can complement the enzymatic activity of GapA in glycolysis under the tested conditions. Tests on solid medium verified that GP703 ( $\triangle$ gapA::cat $\triangle g a p B:: s p e c)$ does not grow with glucose or malate as sole carbon source.

The expression of gapB is repressed by $\mathrm{CcpN}$ in the presence of glucose, it can therefore be suggested that there is might be a mutation affecting $\mathrm{CcpN}$ that allows gap $B$ expression in the gapA mutant. To test this, the $\operatorname{cp} N$ gene was analysed by sequencing. Furthermore, the negative effector of CcpN activity, YqfL was examined by sequencing. However, no mutations were found in $c c p N$ and $y q f L$. It was suspected, that $\mathrm{CcpN}$ is responsible for the delayed growth of the $\Delta g a p A$ mutant on glucose. To test this hypothesis, the strain GP706 ( $\triangle$ gapA::erm $\Delta c c p N:: c a t)$ was constructed and growth on glucose was tested. The strain GP706 was unable to grow on glucose as sole carbon source (data not shown). A possible explanation could be given by the expression of 
$p c k A$. Derepression of $p c k A$ under glycolytic conditions leads to a growth defect in a $c c p N$ mutant (Tännler et al., 2008). Expression of PckA under glycolytic condition could result in block at the intersection between glycolysis and gluconeogenesis.

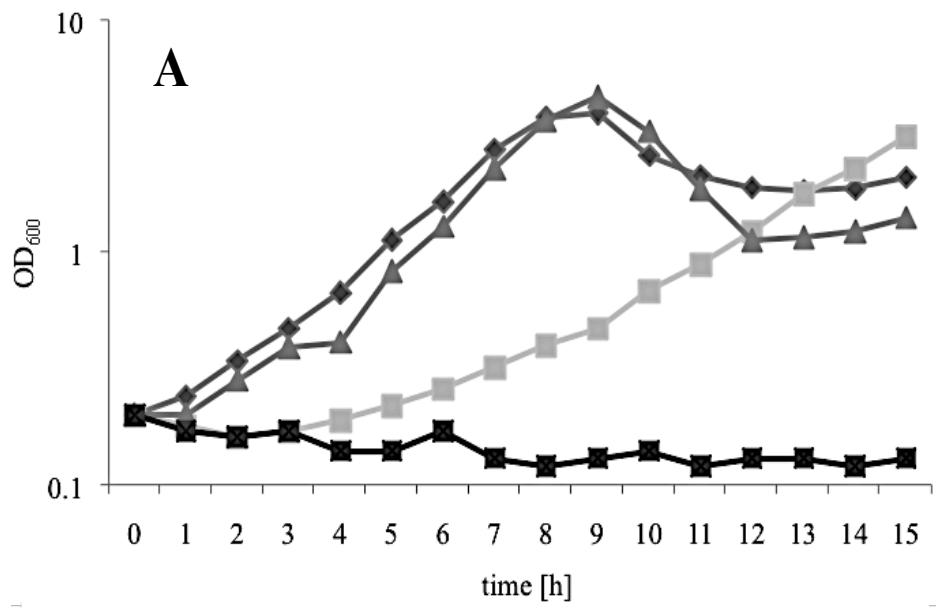

$\rightarrow 168$

-1-GP592 (4gapA)

$-\operatorname{GP701}(\operatorname{\triangle gapB})$

$\rightarrow \mathrm{GP703}(\triangle \mathrm{gapA} \triangle \mathrm{gapB})$

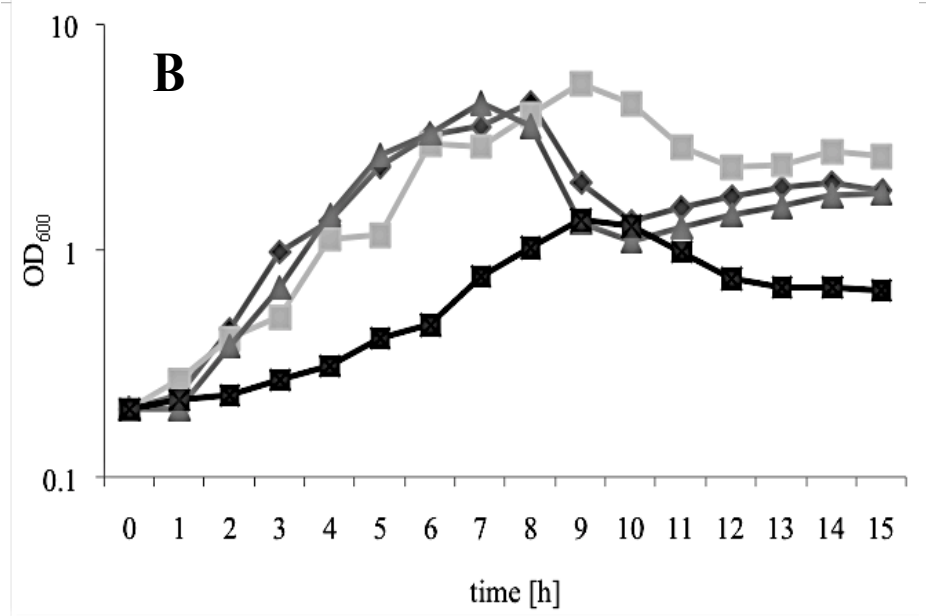

$\rightarrow 168$

$-\operatorname{GP5} 52(\operatorname{LgapA})$

$\multimap \operatorname{GP701}(\triangle \mathrm{gapB})$

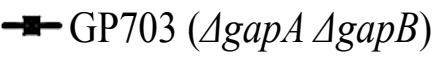

Figure 3.9.: Growth tests of glyceraldehyde-3-phosphate dehydrogenase mutants with glucose and

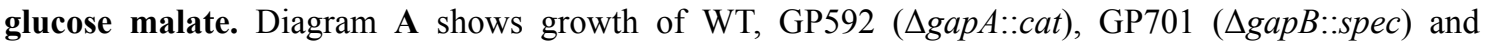
GP703 ( $\triangle$ gapA::cat $\triangle$ gapB::spec) in C-medium with glucose. Diagram B illustrates growth of these strains in C-medium with glucose and malate. 


\subsection{Phosphorylation of glycolytic enzymes}

In B. subtilis almost all glycolytic enzymes were found to be phosphorylated on Ser/Thr and tyrosine residues (Levine et al., 2006; Macek et al., 2007; Eymann et al., 2007). The origin and relevance of their phosphorylation is unknown. Investigation of the phosphorylated residues showed that the glycolytic enzymes are mainly phosphorylated on residues in close proximity to their active centres or close to their substrate or cofactor binding sites.

\subsubsection{ATP dependent phosphorylation events in crude extracts}

The glycolytic enzymes are among the most abundant cytoplasmatic proteins in living cells (Tobisch et al., 1999). Recent phosphoproteome analysis revealed that phosphorylation of glycolytic enzymes is widespread in bacteria, archaea and eukaryotes (Soufi et al., 2008; Aivaliotes et al., 2009; Gnad et al., 2009).

In general, protein kinases use ATP as phosphate donor for the phosphorylation of their substrates. Therefore it was tested, if proteins in B. subtilis crude extracts were phosphorylated after addition of radioactively labeled $\left[\gamma-{ }^{32} \mathrm{P}\right]$ ATP or GTP. Four distinct phosphorylation signals were detected after incubation with either nucleotide at approximately 70, 65, 45 and $30 \mathrm{kDa}$ (Fig. 3.10.). Unfortunately, the identity of the phosphorylated proteins is unknown.

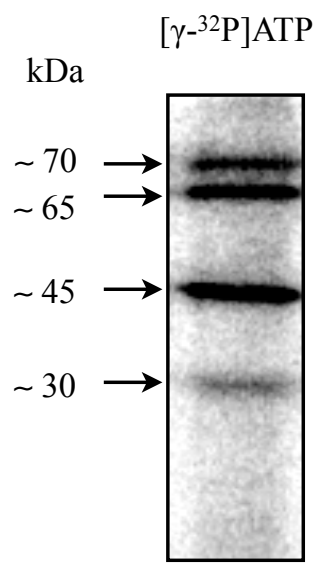

Figure 3.10.: Nucleotide dependent phosphorylation in $B$. subtilis crude extracts. B. subtilis was grown in LB medium to an optical density of 0.8 . The cells were disrupted by sonification and remaining cell debits were removed by centrifugation. For the phosphorylation approach $20 \mu \mathrm{g}$ of cytoplasmic proteins were incubated with $\left[\gamma_{-}{ }^{32} \mathrm{P}\right] \operatorname{ATP}(480 \mathrm{Ci} / \mathrm{mmol})$ for $30 \mathrm{~min}$ at $37^{\circ} \mathrm{C}$. 


\subsubsection{Autophosphorylation of the phosphoglycerate mutase}

Nucleotide dependent protein phosphorylation in B. subtilis crude extracts was discovered. The main interest was to investigate the phosphorylation of glycolytic enzymes. Genes, encode glycolytic enzymes were cloned into the expression vector pWH844. Proteins were overexpressed in E. coli, and purified via the fused N-terminal His6-tag.. The purified proteins were incubated with and without crude extracts of B. subtilis and analyzed on phosphorylation.

A

without crude extract

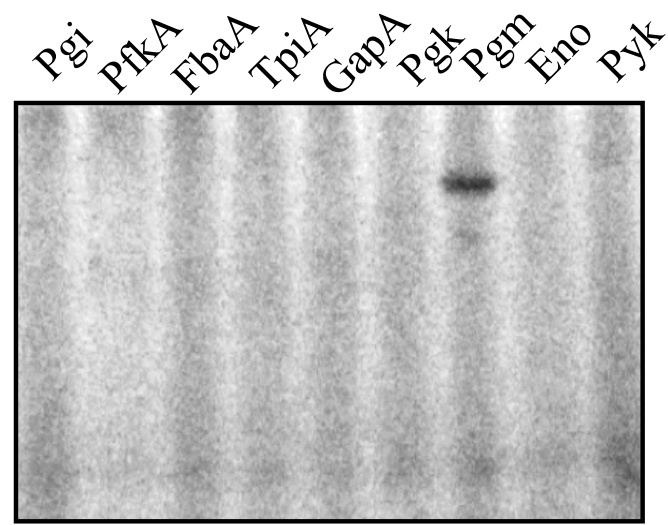

B

$20 \mu \mathrm{g}$ crude extract

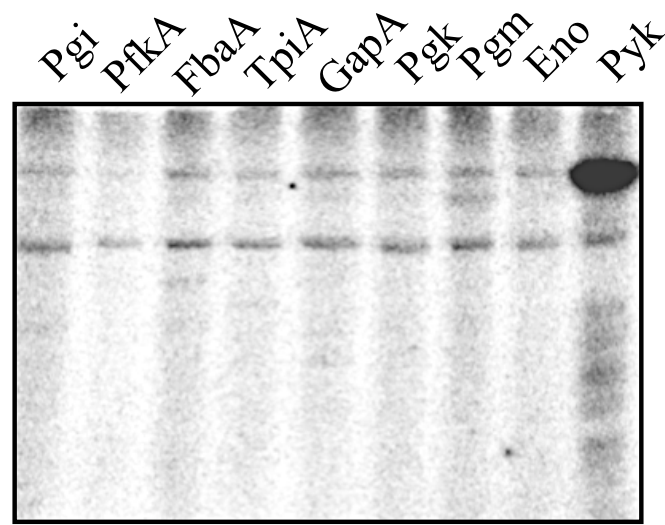

Figure 3.11.: Phosphorylation of glycolytic enzymes.

Autoradiogram A shows a phosphorylation experiment with $10 \mu \mathrm{g}$ of purified proteins that were incubated with phosphorylation buffer including $10 \mathrm{mM} \mathrm{MgCl}_{2}$ and $0.4 \mathrm{mM}\left[\gamma_{-}{ }^{32} \mathrm{P}\right] \mathrm{ATP}(480 \mathrm{Ci} / \mathrm{mmol})$ ). The assays were carried out at $37^{\circ} \mathrm{C}$ for $30 \mathrm{~min}$ followed by thermal inactivation of proteins $(10 \mathrm{~min}$ at $\left.95^{\circ} \mathrm{C}\right)$.

Glycolytic enzymes were tested for autophosphorylation. For this purpose, the proteins were incubated without addition of crude extract. The phosphoglycerate mutase (Pgm) was identified as autophosphorylated; however, no phosphorylation of further proteins was detected (Fig.3.11.A). After incubation of the glycolytic enzymes with crude extracts a strong phosphorylation signal for the pyruvate kinase was detected and was further investigated, see chapter 3.5.5. (Fig.3.11.B). Phosphoproteome analysis revealed the Pgm as phosphorylated on the Ser-62 residue (Eymann et al., 2007; Macek et al., 
2007). In previous works the Ser-62 residue of Pgm was identified as the catalytic active residue that forms a phosphoserine intermediate during the phosphotransferase part of the catalytic reaction (Chander et al., 1999; Jedrzejas et al., 2000). The autophosphorylation of $B$. subtilis Pgm has not been previously reported. However, autophosphorylation of phosphoglycerate mutase was also found in the archaeon Sulfolobus solfataricus (Potter et al., 2003).

\subsubsection{Significance of phosphorylation of phosphoglycerate mutase}

The phosphoglycerate mutase was identified as autophosphorylated. However, ATP is no known in vivo substrate of Pgm. Do determine the phosphorylation site an amino acid exchange of the catalytic Ser-62 residue to alanine was performed by CCR. The mutated gene was cloned into an overexpression vector. Both purified proteins (wild type and mutated) were analysed in phosphorylation experiments. Pgm (Ser-62-Ala) was unable to autophosphorylate (Fig. 3.12.). Pgm that catalyzes the interconversion 3-phosphoglyceric acid to 2-phosphoglyceric acid requires manganese ions for its enzymatic activity (Oh \& Freese, 1976). When phosphorylation assays with Pgm were supplemented with manganese, increased phosphorylation signals for Pgm were obtained in contrast to incubation magnesium (data not shown).

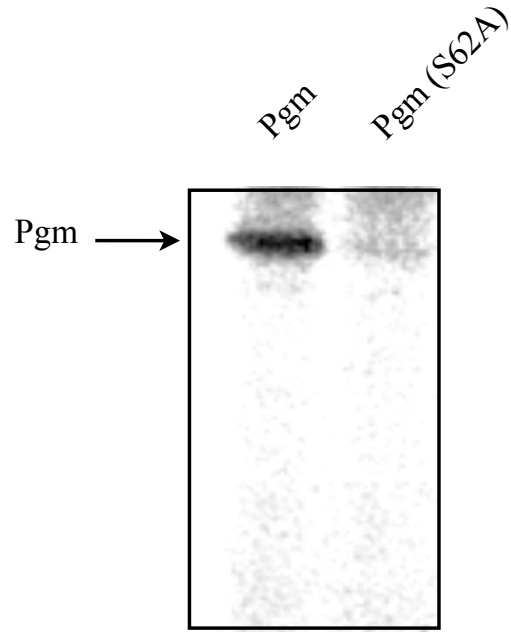

Figure 3.12.: Identification of the phosphorylated amino acid residue of phosphoglycerate mutase (Pgm).

The autoradiogram shows phosphorylation assays with $10 \mu \mathrm{g}$ of purified Pgm and Pgm (S62A). Proteins were incubated with phosphorylation buffer including $10 \mathrm{mM}$ $\mathrm{MnCl}_{2}$ and $\left.0.4 \mathrm{mM}\left[\gamma^{32} \mathrm{P}\right] \mathrm{ATP}(480 \mathrm{Ci} / \mathrm{mmol})\right)$. The assays were carried out at $37^{\circ} \mathrm{C}$ for $15 \mathrm{~min}$ followed by thermal inactivation of the proteins $\left(10 \mathrm{~min}\right.$ at $\left.95^{\circ} \mathrm{C}\right)$. 


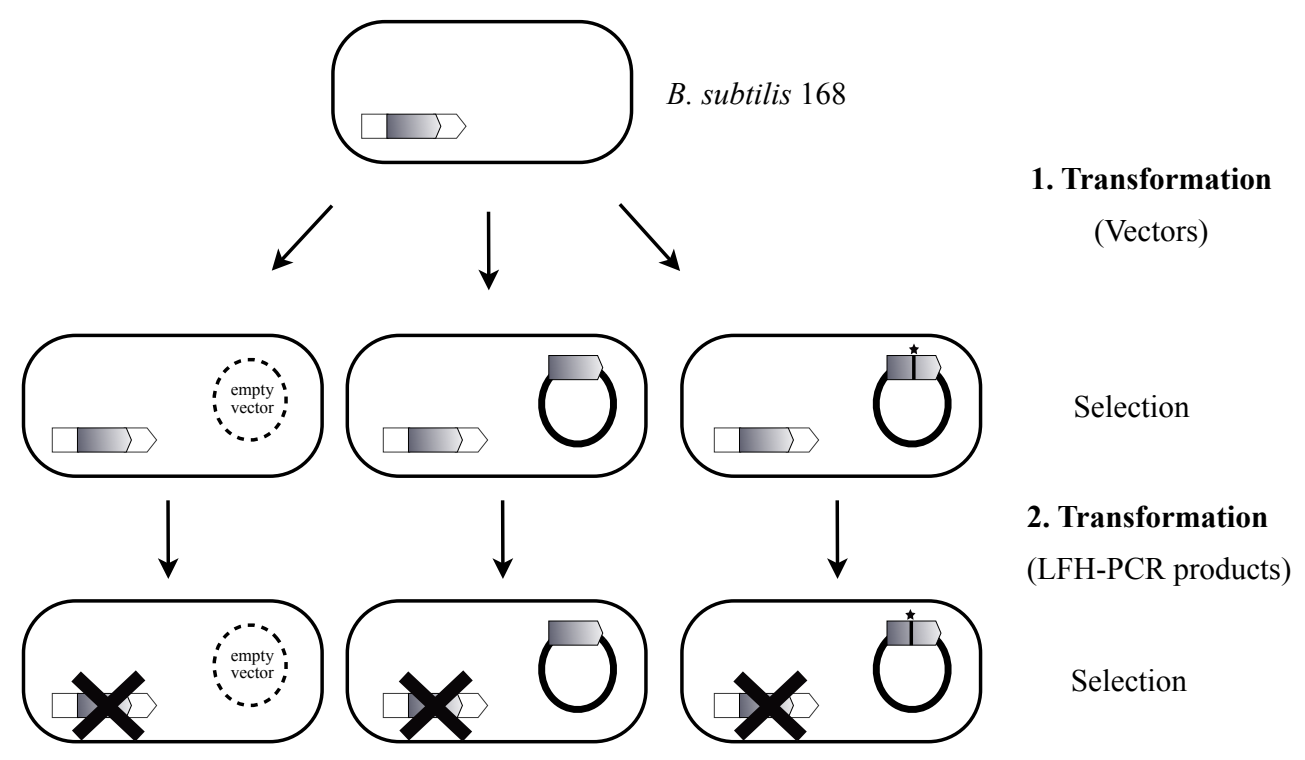

Figure 3.13.: General test procedure for determination of essential amino acid residues. $B$. subtilis 168 was transformed plasmids for complementation. Transformants were selected for erythromycinresistance conferred by the plasmid. In the second step, the transformants were transformed with LFHPCR products for the deletion of the chromosomal gene. Selection occurred on spectinomycin or chloramphenicol, for the genomic integration of the resistance cassette, and on erythromycin for the vector. Transformants were checked for the integrity of the resistance cassette and the vector-encoded gene by PCR and sequencing. The asterisk indicates the point mutation.

\subsubsection{Relevance of the phosphorylation of triosephosphate isomerase}

The triosephosphate isomerase (TpiA) catalyses the reversible interconversion of dihydroxyacetone phosphate and D-glyceraldehyde-3-phosphate in glycolysis. TpiA was identified as phosphorylated on Ser-213 residue (Macek et al., 2007). For Pgm it was shown that the phosphorylated Ser-62 residue is essential for its enzymatic activity. To test whether the Ser-213 residue is similarly essential for the enzymatic activity of TpiA, complementation tests were performed (Fig. 3.13.). As described previously, a $\Delta t p i A$ mutant is unable to grow on glucose or malate alone. If Ser-213 of TpiA is essential for the enzymatic activity, a TpiA-S213A mutant should be unable to grow on glucose alone. Therefore, the Ser-213 residue of TpiA was replaced by the nonphosphorylatable alanine. Overexpression vectors, carrying the native gene, the mutant variant as well as the empty vector were transformed into B. subtilis 168. GP700 $(\triangle t p i A:: c a t)$ showed diminished growth, thus the genomic tpiA gene was deleted after 
transformation with the respective vectors. The strains were grown in C-minimal medium with glucose and malate (Fig. 3.14.A.). Here, all strains were able to grow. The $\Delta t p i A$ mutant carrying the empty vector displayed strongest growth defect followed by the mutant without vector. Best growth was observed for B. subtilis 168 . The mutants complemented with wild type gene and the gene coding for the S213A mutation showed growth similar to $B$. subtilis 168 . In C-medium with glucose, were the active form of TpiA is required, the $\triangle t p i A$ mutant displayed no growth (Fig. 3.14.B.). However, the growth of the complemented mutants was equal to the wild type. Thus, Ser-213 of TpiA and its phosphorylation are not essential for the enzymatic activity of TpiA. It is unknown, if the phosphorylated form would be affected. In contrast, it seems likely that the phosphorylation of TpiA is comparable to the phosphorylation of HPr on Ser-12.
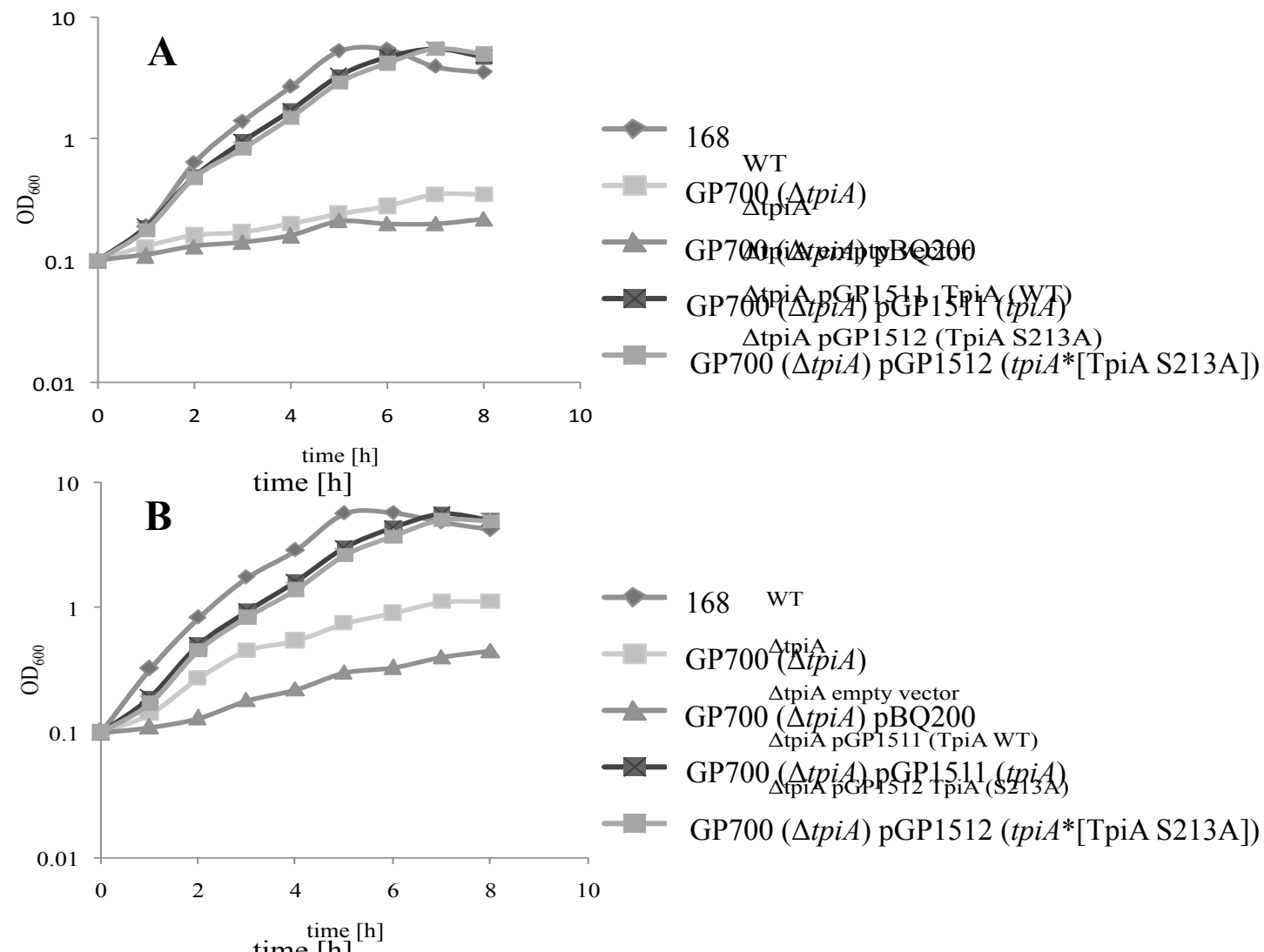

Figure 3.14.: Complementation tests of the $\Delta t p i A$ mutant.

Growth tests were carried out with GP700 ( $\Delta t p i A)$ complemented with plasmids expressing TpiA (WT), mutated TpiA (S213A) and the empty vector pBQ200. (A) Growth tests was performed in C- minimal medium with glucose. (B) Growth tests in C- minimal medium with glucose and malate. *Complementations with mutated tpiA gene, expressing TpiA (Ser213Ala). 


\subsubsection{Identification of phosphorylation sites of the pyruvate kinase}

The pyruvate kinase of $B$. subtilis catalyzes the last and irreversible step in glycolysis. Thus, it plays an important role in the transition from glycolysis to citric acid cycle during carbon utilization. The enzyme converts PEP to pyruvate, yielding one molecule of ATP. The gene pyk that codes for the pyruvate kinase is not essential. However, the generation of pyruvate by the pyruvate kinase is sufficient for growth on non PTS carbon sources (Frey et al., 2000).

Pyruvate kinase was identified as phosphoprotein in several bacteria including B. subtilis, E. coli, C. jejuni, and Lactococcus lactis (Schmidl et al., 2010; Voisin et al., 2008; Soufi et al., 2008; Macek et al., 2008, Macek et al., 2007; Eymann et al., 2007). One conserved phosphorylation site is known, serine-36 that is also phosphorylated in E. coli (Macek et al., 2008). In addition, the pyruvate kinase of B. subtilis is phosphorylated on a further serine residue, which has not exactly been identified (S536 or S538) (Eymann et al., 2007). As shown before, pyruvate kinase became phosphorylated when incubated with crude extracts (Fig. 3.11.B \& 3.15.). The question appeared whether pyruvate kinase was phosphorylated in a kinase dependent manner or by autophosphorylation. Furthermore, protein kinase activity that is dependent on specific metabolites or ions was suspected. No phosphorylation of Pyk occurred when the proteins of crude extract were denaturated by boiling. This could indicate that phosphorylation of Pyk is dependent on other proteins in the crude extract.

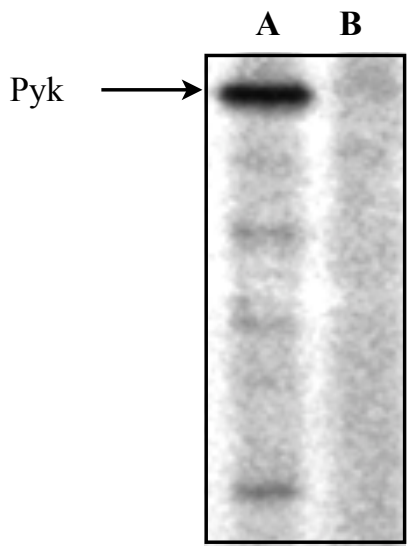

Figure 3.15.: Autoradigram: Phosphorylation of pyruvate kinase (Pyk) with crude extracts.

(A) Ten microgram of purified His 6 -Pyk was incubated with $20 \mu \mathrm{g}$ of $B$. subtilis crude extract. (B) Proteins in crude extracts were denatured by boiling for $10 \mathrm{~min}$ at $95^{\circ} \mathrm{C}$ and supernatant was then incubated with His6-Pyk. 
Phosphorylation experiments with crude extracts displayed a phosphorylation signal at the size of Pyk after incubation with labeled ATP (Fig. 3.15.). To check, whether Pyk is phosphorylated in crude extracts, strain GP589 ( $\Delta p y k:: c a t)$ was analysed. When crude extracts of the wild type strain 168 were incubated with His6-Pyk, a strong signal was detected. At the same height, a signal was found in the crude extract of wild type strain (Fig. 3.16). However, this signal was missing in GP589 ( $\Delta p y k:: c a t)$, confirming Pyk as the suspected phosphoprotein. Furthermore, additional phosphorylation signals were detected when purified Pyk was phosphorylated with crude extracts. However, these phosphorylation signals could be the result of degradation of the supplemented, phosphorylated Pyk. Additional phosphorylation signals were also found in the crude extract of B. subtilis 168, in the lower part of the autoradigraph (Fig. 3.16.). These phosphosignals are missing in GP589 ( $\Delta$ pyk::cat), suggesting that the pyruvate kinase is involved in further phosphorylation events in B. subtilis.

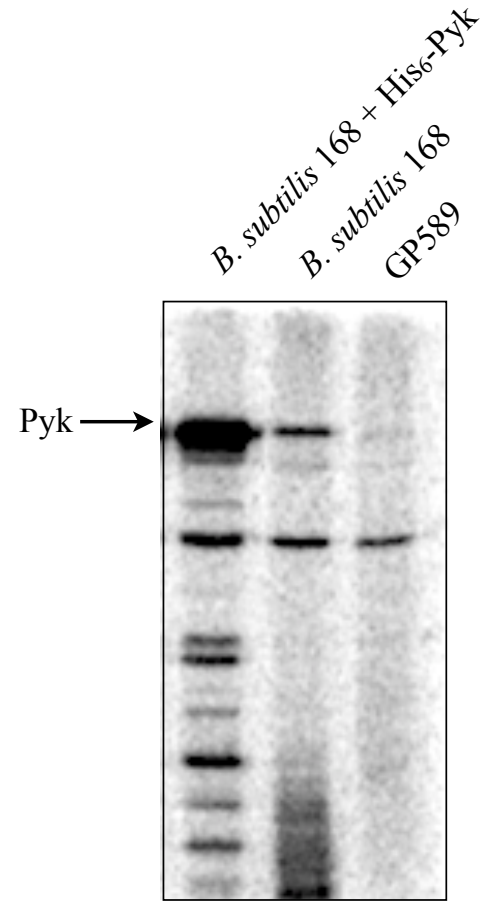

Figure 3.16: Autoradigraph: Identification of phosphoprotein in B. subtilis crude extracts. Crude extracts of $B$. subtilis WT $(20 \mu \mathrm{g})$ was incubated alone and with His 6 -Pyk $(10 \mu \mathrm{g})$. Additionally, crude extract of the $\Delta p y k$ mutant (GP589) was applied.

Phosphorylation assays revealed that single amino acid replacement of the conserved Ser-36 residue did not prevent phosphorylation of Pyk (Fig. 3.17.). A second phosphorylation site was suspected in the PEP-binding domain of Pyk, around His-539. For the determination of the second phosphorylation site of pyruvate kinase, the 
potential phosphorylated serine residues (S36; S538) and the catalytically active His-539; were mutated against alanine. The mutated His6-tagged Pyk variants were purified and tested on phosphorylation with B. subtilis crude extracts (Fig. 3.17.). Only the exchange of both, the Ser-36 and Ser-538 residue against alanine prevented phosphorylation of Pyk in crude extracts (Fig.3.17.).

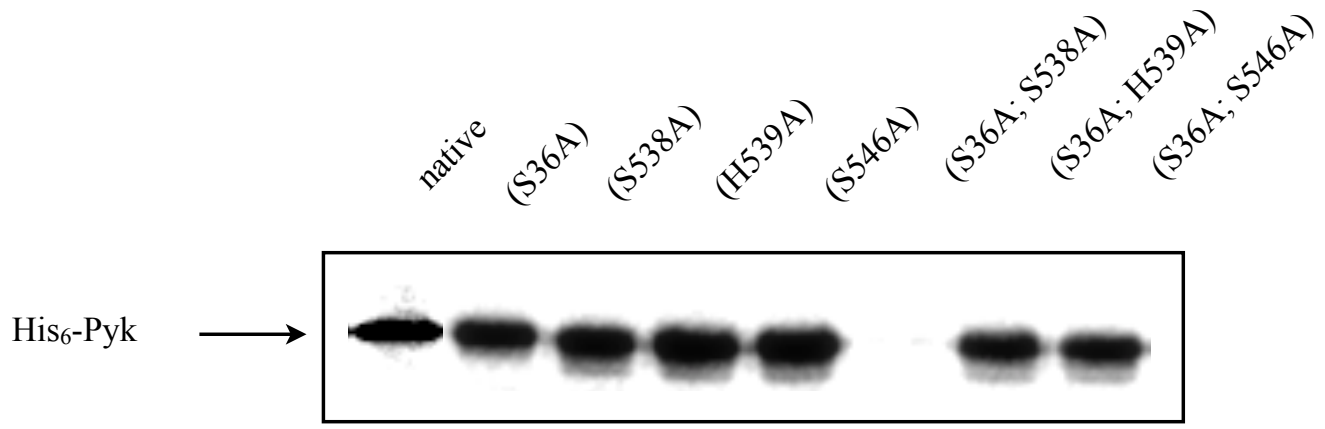

Figure 3.17.: Determination of phosphorylated residues of the pyruvate kinase.

Crude extracts of $B$. subtilis $168(20 \mu \mathrm{g})$ were incubated with His6-Pyk variants $(10 \mu \mathrm{g})$ and analyzed by autoradiography.

\subsection{Conservation of autophosphorylation of phosphosugar mutases}

In B. subtilis five mutases (AroA, Drm, Pgm, GlmM and PgcM) were found to be phosphorylated at Ser-/Thr- and Tyr residues (Eymann et al., 2007; Macek et al., 2007). These mutases are involved in central carbon metabolism, amino acid synthesis and cell wall biosynthesis. In this work it was already shown that the phosphoglycerate mutase is autophosphorylated in the presence of ATP. In addition, several other proteins in B. subtilis crude extracts were phosphorylated after incubation with ATP. However, only Pyk was identified so far. For the identification of the remaining phosphoproteins 2D-gels were used. 


\subsubsection{Autophosphorylation of GImM from B. subtilis and ManB from M. pneumoniae}

In B. subtilis crude extract different proteins were phosphorylated. This observation gave a clue to investigate the origin of certain phosphorylation events. Furthermore, it was shown that phosphorylation of proteins could be stimulated by specific metal ions or intermediates of carbon metabolism.

Therefore, B. subtilis crude extracts were supplemented with different intermediates of glycolysis and changes in the phosphorylation pattern were observed (Fig. 3.18.). When crude extracts were dialyzed, the intensity of the phosphorylation signals was enhanced. The addition of pyruvate had a negative effect on the phosphorylation pattern, and addition of phosphoenolpyruvate (PEP) had no effect on phosphorylation. Supplementation with FBP leads to two significant signals. The phosphorylation signal in the lower part of the autoradiograph is HPr. HPr phosphorylation on Ser-46 by HPrK is known to be stimulated by FBP. The identity of the phosphorylated protein in the upper part of the autoradiograph, at around $45 \mathrm{kDa}$, was unknown.

To identify the corresponding proteins, the treated crude extracts were analyzed in 2D-PAGE (Fig.3.19.). Two dimensional gel analysis revealed YbbT, now renamed GlmM, as a significant phosphoprotein, when incubated with ATP and FBP. GlmM is a phosphoglucosamine mutase that catalyzes the conversion of $\alpha$-D-glucosamine-1phosphate to D-glucosamine-6-phosphate. Autophosphorylation was also shown for GlmM of E. coli (Jolly et al., 2000).

In $B$. subtilis the enzymatic activity of GlmM is essential for peptidoglycan synthesis. Protein alignments of phosphosugar mutases showed, that the active centers of these mutases are conserved across the domains of life (Jolly et al., 1999). It seems unambiguous that the enzymatic reaction mechanism by which the mutases are phosphorylate in vivo is conserved as well. It seems likely that autophosphorylation as result of the enzymatic activity is common. 


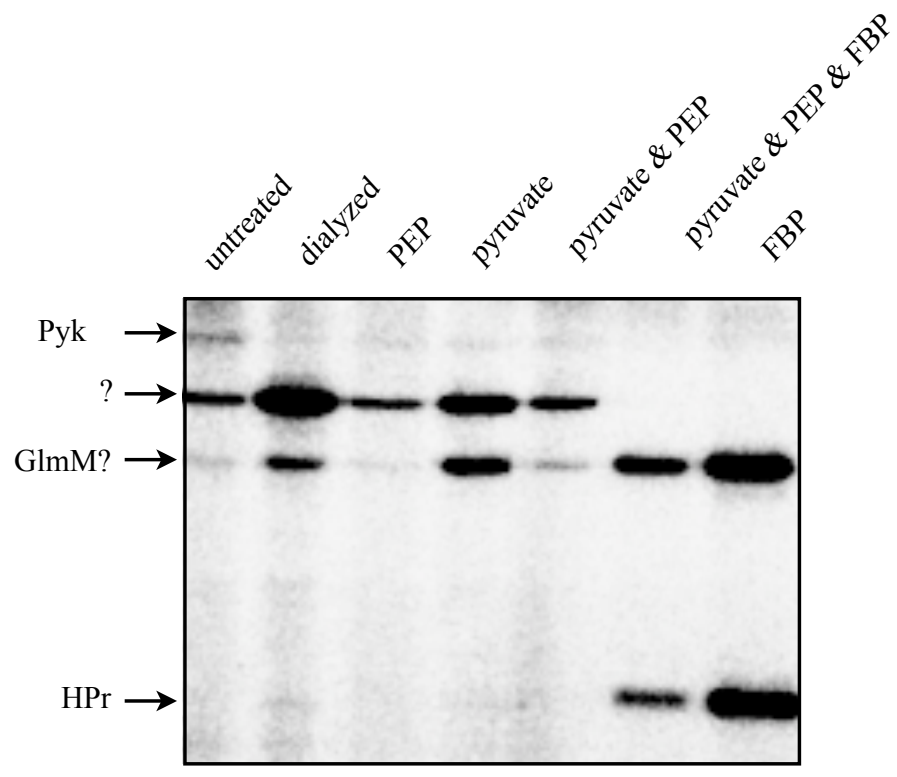

Figure 3.18.: Influence of glycolytic intermediates on phosphorylation events. Crude extracts of $B$. subtilis were dialyzed and following incubated in phosphorylation buffer with manganese and $\left[\gamma-{ }^{32} \mathrm{P}\right]$ ATP. Additionally, the approaches were supplemented with $20 \mathrm{mM}$ of PEP, pyruvate and FBP.

A

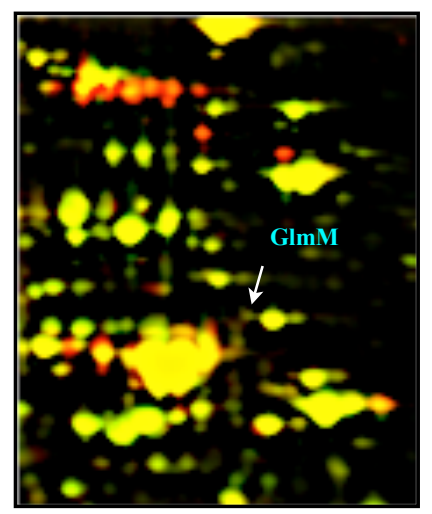

Flamingo (D Pro-Q Diamond
B

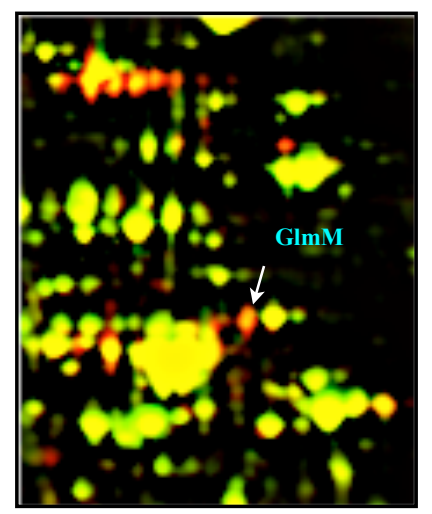

Figure 3.19.: Sector of 2D-PAGE analysis: (A) Dialyzed crude extract was incubated with phosphorylation buffer alone. (B) Dialyzed crude extract was incubated with phosphorylation buffer, ATP and FBP. Phosphorylation signal for GlmM is indicated by arrows. 
GlmM was analyzed for autophosphorylation (Fig. 3.20.). The previously identified phosphorylation site, Ser-100 was replaced by alanine (Macek et al., 2007; Eymann et al., 2007). Phosphorylation assays revealed that GlmM is autophosphorylated in the presence of manganese and ATP (Fig. 3.20.). Furthermore, autophosphorylation on Ser-100 was confirmed by amino acid exchange against alanine.

Phosphoproteome analysis of Ser- and Thr phosphorylated proteins in Mycoplasma pneumoniae revealed a phosphorylated paralog of GlmM. ManB is a potential phosphosugar mutase in M. pneumoniae with high similarity to GlmM. Phosphorylation was found at the conserved Ser-149 residue. Phosphorylation assays revealed manganese dependent autophosphorylation of ManB on Ser-149. The phosphorylation site was confirmed by alanine replacement (Fig.3.20.). GlmM of B. subtilis and ManB of $M$. pneumoniae showed enhanced autophosphorylation signals when incubated with manganese (Fig.3.21.).

Consequently, autophosphorylation of phosphosugarmutases, like Pgm and GlmM is not exclusively conserved in B. subtilis. Investigation of ManB of M. pneumoniae revealed that autophosphorylation also occurs on conserved residues of paralogous proteins in other species like M. pneumoniae (Schmidl et al., 2010).

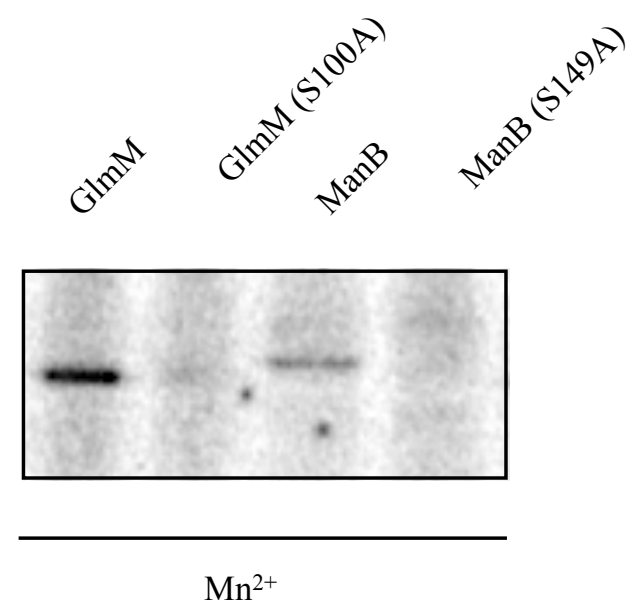

Figure 3.20.: Autophosphorylation of GImM (B. subtilis) and ManB (M. pneumoniae).

Proteins were analyzed for autophosphorylation. Autoradiograph of His 6 -tagged GlmM and ManB and the respective point mutants. 


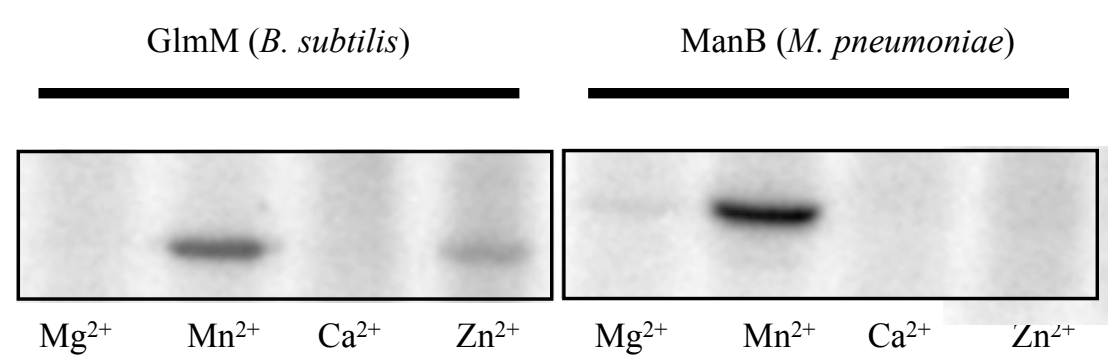

Figure 3.21: Specificity of metal ions for autophosphorylation of GImM and ManB. Ten microgram of GlmM and ManB were incubated with $10 \mathrm{mM}$ of magnesium $\left(\mathrm{Mg}^{2+}\right)$, manganese $\left(\mathrm{Mn}^{2+}\right)$, calcium $\left(\mathrm{Ca}^{2+}\right)$ and zinc $\left(\mathrm{Zn}^{2+}\right)$.

\subsubsection{Importance of the conserved Ser-100 of GImM for the viability of B. subtilis}

In previous experiments it was shown that GlmM is able to perform autophosphorylation. This raised the question, whether Ser-100 is essential for the enzymatic activity, as for Pgm. The test procedure for the analysis of essential residues is shown in Fig. 3.13. Overexpression plasmids for B. subtilis were constructed. The $\operatorname{glm} M$ wild type gene and the mutated $\operatorname{glm} M$ gene (Ser-100-Ala) were cloned into vectors (pBQ200) for expression in B. subtilis. B. subtilis 168 was transformed with the respective plasmids (pBQ200; pGP400; pGP1403) and the gained transformants were transformed again with LFH-PCR products for the deletion of the genomic copy of glmM. Transformation of the wild type strain carrying the empty vector (pBQ200) gave no clones. Previous studies already showed that $y b b T(\mathrm{~g} \operatorname{lm} M)$ is essential under standard conditions (Kobayashi et al., 2003). B. subtilis was able to complement the loss of glmM when expression of the wild type gene occurred from plasmid (pGP400). Expression of the mutated GlmM (S100A) variant from pGP1403 was not able to complement the loss of the chromosomal $\operatorname{glm} M$ gene. Therefore, it can be concluded that the S100 of GlmM is essential for the enzymatic activity. Furthermore, GlmM was found as phosphorylated on its conserved serine residue in all tested organisms so far. 


\section{Discussion}

\subsection{Mutants of essential glycolytic genes}

The natural habitat of $B$. subtilis is the soil. In this habitat it is exposed to various kinds of environmental stress conditions. Furthermore, it needs to maintain against other competitors for nutritions. Therefore, a rapid uptake and utilization of carbon and nitrogen sources is essential for survival. The preferred carbon sources of $B$. subtilis are glucose and malate. Glucose is mainly metabolised in glycolysis, followed by incomplete oxidation in overflow metabolism. The main products of overflow metabolism, acetic acid is secreted. When glucose is exhausted, acetic acid can be again taken up and further oxidized in tricarboxylic acid cycle. The incomplete but rapid oxidation of hexoses gives $B$. subtilis an advantage towards other soil bacteria.

This shows that glycolysis is indispensable for rapid carbon sugar utilization. Studies with the aim to identify essential genes in B. subtilis revealed that nearly all genes coding for enzymes of glycolysis are indispensable for survival (Kobayashi et al., 2003; Thomaides et al., 2007). It was not obvious why these genes should be essential, when cells were grown in rich medium. Because, precursors that are required for amino acid and cell wall biosynthesis are available in rich medium. Moreover, in other organisms like E. coli and Saccharomyces cerevisiae mutants in glycolysis were already described (Irani \& Maitra, 1974; Lam \& Marmur, 1976).

In this work it was shown that single and multiple mutants of glycolytic genes can be generated and that these mutants are still viable. From this, the question appeared how Kobayashi and colleagues analyzed B. subtilis genes for essentiality. In this work, the mutants were generated by replacement of the specific gene by a terminator-less antibiotic resistance cassette, that was introduced via double homologous recombination of a LFH-PCR product into the specific gene locus. In contrast to that, Kobayashi and co-workers used the pMUTIN vector for their deletion experiments. Negative effects of

the integrated vector on the expression of the downstream genes is avoided by IPTG- dependent expression (Vagner et al., 1998). It could be possible that an enhanced expression of downstream genes has a negative effect on the viability of the glycolytic 
mutants. Moreover, it must be noted that not every essential gene can be deleted with LFH-PCR products, as shown for $g \operatorname{lm} M$ in this work. Similarly, other genes that were previously described as essential were later found to be not essential, as in the case of ydiB, yloQ, yqeL and ywlC (Kobayashi et al., 2003; Hunt et al., 2006; Karts et al., 2009).

In general, the construction of glycolytic mutants was limited by two factors, the $\mathrm{pH}$ value and for certain mutants the presence of a gluconeogenetic carbon source. Mutants were only obtained when the $\mathrm{pH}$ value of the medium was below 7.5 and addition of malate supported growth of the mutants. In contrast to malate, supplementation with succinate was not sufficient. This could be explained by the preference of B. subtilis for malate as carbon source (Kleijn et al., 2009). Furthermore, mutants of the eno and pgm genes were already described sixteen years ago and that growth of these mutants is enhanced by supplementation with malate (Leyva-Vazquez and Setlow, 1994). The malate uptake and utilization could give an clue for the viability defect at $\mathrm{pH}$ 8. In B. subtilis malate uptake is driven by the transporters, MaeN, CimH, MleN and YflS (Wei et al., 2000; Krom et al., 2001). However, only MaeN is indispensible for growth on malate (Tanaka et al., 2003). Transcriptome analysis revealed that alkaline stress results in downregulation of maeN (Kitko et al., 2009; Wilks et al., 2009). Moreover, the enzymatic activity of the malate dehydrogenase, catalyzing the conversion of malate to oxaloacetate in the citric acid cycle, is inhibited at $\mathrm{pH}$ above 7.5 (Yoshida, 1965).

It was shown that growth of the mutants ( $\triangle g a p A, \Delta p g k, \Delta p g m$ and $\Delta e n o)$, that miss the enzymes of the lower part of glycolysis is supported by malate. Growth of the $\triangle f b a A$ and $\triangle t p i A$ mutant was not affected by malate. Furthermore, the $\Delta p f k A, \Delta g a p A$ and $\Delta p y k$ mutants were able to grow with glucose as sole carbon source. Studies with a transaldolase mutant of $E$. coli revealed that the transaldolase reaction, that is located in the pentose phosphate pathway can be taken over by the activity of the phosphofructokinase and aldolase (Nakahigashi et al., 2009). When B. subtilis is grown on glucose as the main carbon source, about $40 \%$ of the carbon is utilized via the pentose phosphate pathway (Kleijn et al., 2010). Thus, it can be suggested that the 
pentose phosphate pathway alone allows growth of a phosphofructokinase mutant on glucose. To test this hypothesis, the pentosephosphate pathway should be interrupted in the $\triangle p f k A$ mutant. The B. subtilis genome encodes a fructose-1-phosphate kinase (fruK) that might complement the missing phosphofructokinase combined with activity of a hexosephosphate mutase (Reizer et al., 1999).

The glyceraldehyde-3-phosphate dehydrogenase mutant was also able to grow with glucose as sole carbon source, but displaying a growth delay of around five hours in liquid medium. It was assumed that the methylglyoxal pathway is able to bypass the block in glycolysis. However, it displayed no capacity for complementation of the lack of gapA. Certain bacteria possess a NAD independent glyceraldehyde-3-phosphate dehydrogenases $(\mathrm{GapN})$ that does not phosphorylate its substrate. Interestingly, this enzyme can substitute the reactions of two glycolytic enzymes, the glyceraldehyde-3-phosphate dehydrogenase and phosphoglycerate kinase. GapN was proven, in addition to the GapDH, in Neisseria meningitidis, Streptococcus mutans and Sulfolobus solfataricus (Pailot et al., 2006; Ettema et al., 2006; Fourrat et al., 2007. However, the B. subtilis genome does not code for GapN. Therefore GapB came into the focus of this study. In the literature, the gapA gapB gene pair was proposed as essential, because of the essentiality of gapA (Thomaides et al., 2007). However, in this work a double mutant of the gapA and $\operatorname{gap} B$ gene was constructed. This shows, that disruption of both genes is possible. Growth tests revealed that the double mutant can not grow on glucose as sole carbon source. Therefore, it is suggested that GapB is able to complement the function of GapA. However, gapA and gapB are differently expressed dependent on the carbon source. The expression of the glycolytic GapDH (gapA) is repressed under gluconeogenetic conditions by $\mathrm{CggR}$ and the expression of the gluconeogenetic GapDH $(\operatorname{gapB})$ is repressed under glycolytic conditions by CcpN (Doan \& Aymerich, 2003; Servant et al., 2005). Therefore, it can be assumed that the growth delay of a gapA mutant on glucose is a result of $\mathrm{CcpN}$ dependent repression. However, sequencing of genes for $\mathrm{CcpN}$, and its negative regulator regulator YqfL, revealed no mutations. Additionally, the formation of suppressor mutants can be excluded, because, the growth delay also occurred when growing cells were used to 
inoculate fresh medium. These results lead to the suggestion that $\mathrm{CcpN}$ dependent repression is further modulated. It seems reasonable, that glycolytic intermediates influence the DNA binding activity of CcpN. However, Licht and co-workers showed, that glycolytic metabolites and nucleotides have no negative effect on $\mathrm{CcpN}$ activity in vitro (Licht et al., 2008). In addition, in this work it was tested, whether the absence of CcpN supports growth of the gapA mutant on glucose. Unlike the assumption, the double mutant was unable to grow with either glucose or glucose and malate as sole carbon source. It is known that the disruption of $c c p N$ results in a drastically reduced growth rate and in alteration of the metabolic flux, that is mainly due to the pyruvate carboxykinase (Pck) activity (Tännler et al., 2008). Perhaps, derepression of Pck prevents growth of the $\triangle c c p N \triangle g a p A$ double mutant. However, in this case the $\triangle g a p A$ mutants should be unable to grow, if the growth delay would be dependent on CcpN repression. Therefore, other mechanism of regulation must be suspected.

The remaining mutants $(\triangle f b a A, \Delta t p i A, \Delta p g k, \Delta p g m$ and $\Delta e n o)$ required both a glycolytic and gluconeogenetic carbon source for growth on minimal medium. This addiction is due to the deletion of these genes that divide the amphibolic sequence into two branches, starting from glucose and pyruvate or PEP, respectively. Both branches are functioning in opposite directions and provide biosynthetic precursors for the cell. However, accumulation of phosphorylated intermediates can be assumed and should be investigated by metabolome analysis.

Fructose-1,6-bisphosphate aldolase is required for the cleavage and synthesis of fructose-1,6-bisphosphate in glycolysis and gluconeogenesis. Mutants lacking the $f b a A$ gene showed diminished growth and impaired cell morphology. When $\triangle f b a A$ mutants were grown with hexose supplementation, FBP accumulates. FBP displays the metabolic status of the cell and regulates the activity of transcription factors like CcpA and CggR. It was tried to eliminate the effect of FBP on carbon catabolite repression via CcpA by constructing a $\triangle f b a A \triangle c c p A$ double mutant. However, it was not possible to construct such a mutant, suggesting that the lack of CcpA dependent regulation prevents efficient carbon utilisation. 
For the triosephosphate isomerase mutant, growth was only observed in the presence of both glycolytic and glyconeogenetic carbon sources. In E. coli a metabolic bypass of this enzymatic reaction was found. Growth of mutants, lacking the tpiA gene on gluconeogenetic carbon sources is enabled by an enzyme (YghZ), that reduces L-glyceraldehyde-3-phosphate to dihydroxyacetone phosphate in a NADPH dependent manner (Desai \& Miller, 2008). This enzyme is unable to catalyze the reverse direction to allow growth on glycolytic substrates. However, Blast analysis revealed that B. subtilis does not possess this enzyme.

Around forty years ago a mutant of $B$. subtilis was described, that lacks phosphglycerate kinase activity. In this mutant initiation of spore germination by alanine was extremely diminished (Prasad et al., 1972). The relevance of glycolytic enzymes for cell differentiation processes was also shown for further enzymes. About the phophoglycerate mutase it is known that activity is inhibited when the intracellular $\mathrm{pH}$ becomes more acidic during sporulation (Magill et al., 1996; Chander et al., 1998). Moreover, mutants lacking phosphoglycerate mutase or enolase are unable to sporulate (Leyva-Vazquez \& Setlow, 1994). In general, phosphoglycerate mutases are subdivided into two classes, depending on their catalytical mechanism. For one class of Pgm, the reaction is dependent on 2,3-bisphosphoglycerate (dPgm), whereas the enzymes of the other class are independent from this metabolite (iPgm) (Pearson et al., 2000). In $B$. subtilis only the iPgm is the common mutase, whereas in E. coli the dPgm is the common (Fraser et al., 1999).

Growth of a $\Delta p y k$ mutant on glucose as sole carbon source was not unexpected, thus PEP is converted to pyruvate during glucose uptake by the PTS (Fry et al., 2000).

Glycolytic enzymes from different organisms were identified to have secondary roles in the cell. For enolase various secondary functions were found in different organisms. It was shown that this enzyme is involved in the regulation of transcription, the transport of proteins, the regulation of DNA and RNA synthesis and several other cellular processes (Feo et al., 2000; Decker \& Wickner, 2006; Tovy et al., 2010). Studies in B. subtilis revealed that glycolytic enzymes interact with each other and with other essential proteins. Therefore, they were assumed to be involved multienzyme 
complexes, like glycosome and RNA-degradosome (Commichau et al., 2009). It was suggested that glycolytic enzymes are essential because of their interaction with other essential enzymes. However, on the basis of this work this hypothesis must be reconsidered.

\subsection{Protein phosphorylation in B. subtilis: Of conservation and coincidence}

Protein phosphorylation is one of the most important forms of modification, but the origin and function of phosphorylation events are unknown to great extent. In this work the phosphorylation of proteins on Ser/Thr and Tyr residues in B. subtilis was investigated. For this purpose multiple protein kinase mutants were analyzed. The well-known kinases were not required for the majority of phosphorylation events in B. subtilis. Moreover, the annotated protein kinases seem to have specific target proteins and consequently specific functions in the cell, for example as shown for PrkC in spore germination (Shah et al., 2008; Shah et al., 2010). In conclusion, it was suspected that other unknown kinases or mechanism are responsible for these phosphorylations events. The comparison of the phosphorylation sites in B. subtilis displayed no generally conserved motif. However, individual phosphorylation sites are conserved among species like E. coli and B. subtilis (Macek et al., 2007; Macek et al., 2008).

In general, kinases do phosphorylate specific targets on defined residues. For example the HPr kinase specifically phosphorylates HPr and its ortholog Crh on Ser-46 (Galinier et al., 1997). Moreover, the number and diversity of phosphorylation peptides in B. subtilis would lead to the assumption that B. subtilis possesses a great number of uncharacterized kinases or that some of these kinases phosphorylate promiscuous substrates. In previous studies, the knowledge about phosphorylation sites in eukaryotes was used to predict phosphorylation sites in bacteria, with the aim to identify substrate kinase couples. However, only around $14 \%$ of the experimentally verified phosphorylation sites were confirmed in these bioinformatic approaches (Soufi et al., 2007). Therefore, phosphorylation events in bacteria seem to be more different then in eukaryotes. 
In this work it was shown that the GTPase Obg and YdiB are autophosphorylated as well as the phosphosugar mutases Pgm and GlmM. Besides, the HPr protein and glycolytic enzymes were investigated. Previous studies identified a new phosphorylation of $\mathrm{HPr}$ at the Ser-12 residue (Macek et al., 2007). The known phosphorylation sites of HPr, His-15 and Ser-46 are sufficient for sugar uptake via PTS and carbon catabolite repression. An attempt for the identification of targets of protein kinases in B. subtilis revealed, that PrkC is able to phosphorylate HPr on Ser-12 in vitro (Pietack et al., 2010). However, the relevance of this phosphorylation is unclear. It was assumed that phosphorylation on Ser-12 influences the conformation of the neighbouring amino acids including His-15 and, hence the sugar uptake is influenced. However, growth tests revealed that the Ser-12 residue is not sufficient for the function of HPr in the PTS. Moreover, experiments with purified HPr and enzyme I revealed that HPr is phosphorylated on Ser-12, during phosphate transfer through His-15. This leads to the assumption that Ser-12 phosphorylation of HPr is just an coincidence. In contrast to His-15 and Ser-46, the Ser-12 residue is not conserved among Firmicutes and other bacteria (Deutscher et al., 2006). Interestingly, in E. coli HPr was also found to be phosphorylated on an additional residue, the Thr-12 (Macek et al., 2008). However, it is not clear, if phosphorylation of HPr on Ser-12 or Thr-12 is of biological relevance for the common functions of HPr. It could be speculated, that the Ser-12 phosphorylation is associated with a unknown function. In the literature, several interaction partners of HPr were described. Recently, interaction of HPr (His-P) with the transcriptional regulator YesS was found and was described as a novel form of carbon catabolite repression (Poncet et al., 2009). Perhaps, HPr (Ser-12-P) mimics histidine phosphorylated HPr and is therefore associated in YesS interaction. A further interaction of HPr was described for GapA. It was shown that only HPr (Ser-46-P) is able to interact with GapA, and that the interaction inhibits the activity of GapA (Pompeo et al., 2007). To determine the function of the Ser-12 phosphorylation, the amount of HPr (Ser-12-P) in the cell must be elucidated. And in addition the influence of permanent phosphorylation of Ser-12 on the HPr activity must be clarified. 
A further phosphorylation event that was analysed in this work was the phosphorylation of TpiA on Ser-213 (Macek et al., 2007). The relevance of the Ser-213 for the enzymatic activity was tested in complementation assays with the result that Ser-213 of TpiA is not required for the enzymatic activity in vivo. However, in contrast to Ser-12 of HPr, the Ser-213 residue of TpiA is conserved among other species (Fig.:6.1).

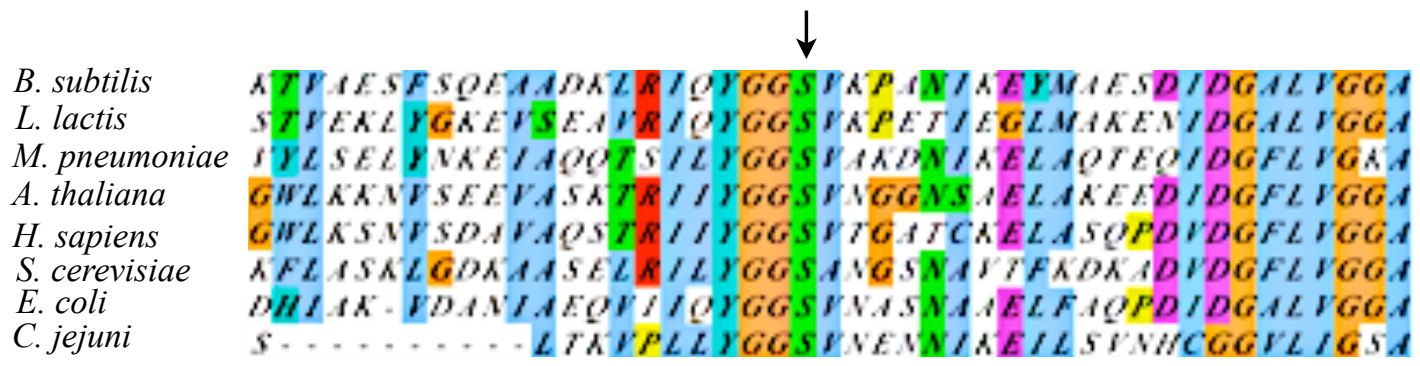

Figure 6.1.: Multiple sequence alignment of triosephosphate isomerase of different organism. The protein sequences of triosephosphate isomerases of B. subtilis, Lactococcus lactis, Mycoplasma pneumoniae, Arabidopsis thaliana, Homo sapiens, Saccharomyces cerevisiae, Escherichia coli and Campylobacter jejuni were aligned with ClustalW2. The alignment displays conservation of the Ser-213 (indicated by arrow) residue that is phosphorylated in B. subtilis.

Moreover, TpiA was not found as phosphorylated in all species that were investigated so far. In M. pneumoniae and C. jejunii, TpiA was identified as phosphoprotein, but the phosphorylated residues are unknown (Voisin et al., 2007; Schmidl et al., 2010). Studies on the reaction mechanism of TpiA in Trypanosoma revealed that the conserved Ser-213 residue is part of peptide flip, a structural element of the enzyme. The peptide bond of the flip provides a hydrogen bounding partner for the phosphate of the substrate (Casteleijn et al., 2006). The direct binding of the phosphate on Ser-213 suggests, that phosphorylation of TpiA on Ser-213 is just a result of enzymatic activity. For the Pgm it was already described that phosphorylation on the conserved Ser-62 occurs during the enzymatic reaction. However, in the case of Pgm the enzymatic activity gets lost when the catalytic serine was replaced against a nonphosphorylateable amino acid (Rigden et al., 2003 ). Perhaps phosphorylation of TpiA on Ser-213 influences its activity, but it is questionable if the amount of phosphorylated TpiA in the cells has an effect on growth. 
The first regulatory phosphorylation of an enzyme in prokaryotes was identified for the isocitrate dehydrogenase of E. coli (Garnak \& Reeves, 1979). This phosphorylation is catalyzed by a specific kinase and leads to a change of the carbon flow from the citric acid cycle to the glyoxylate pathway. In $B$. subtilis the isocitrate dehydrogenase is also phosphorylated on a different residue; however, B. subtilis possesses no glyoxylate pathway and no counterpart of the E. coli kinase. This leads to the assumption that phosphorylation of enzymes is not strictly associated with the regulation of enzymatic activity. The phosphorylation of proteins can be required to regulate the formation of multimers and protein-protein interaction in general. Moreover, phosphorylation can regulate the localization of proteins in the cell. For example, tyrosine phosphorylation of B. subtilis enolase by PtkA leads to migration to the cell poles (Mijakovic, unpublished). In $S$. cerevisiae it was described that the phosphorylation of the hexokinase depends on extracellular glucose concentration. The phosphorylation results in the dissociation of the dimeric to the monomeric form, that has a higher affinity for the substrate (Vojtek \& Fraenkel, 1990).

Another subject of this study was the pyruvate kinase. Phosphorylation of pyruvate kinase was described on the conserved Ser-36 residue and in the PEP-binding domain (Macek et al., 2007; Eymann et al., 2007). Phosphorylation of this enzyme was also found in C. jejuni, L. lactis and in E. coli on Ser-36 (Macek et al., 2008; Voisin et al., 2008; Soufi et al., 2008). The identified phosphorylation site (Ser-36 ) is located at the interface between the edge of the catalytic domain A and the domain B, so it seems obvious that it could be an important feature in regulating the enzymatic activity of Pyk. This kind of regulation can be found for example in the mammalian pyruvate kinase isoform L, where the enzymatic activity is inhibited upon phosphorylation (Pilkis \& Claus, 1991). The second phosphorylation site, was identified at Ser-538 and is located in the PEP-binding domain of the enzyme, next to the catalytically active His-539 residue. Pyk was phosphorylated when incubated with crude extracts of B. subtilis. In addition, further phosphorylation signals were detected in crude extracts together with Pyk phosphorylation. Only replacement of both phosphorylation sites prevents phosphorylation of Pyk and of the additional proteins. 
For the human pyruvate kinase 2 it was shown that it binds phosphotyrosine peptides. Binding of these peptides result in the release of the activator fructose-1,6-bisphosphate and consequently in loss of enzymatic activity (Christofk et al., 2008). However, the Pyk in Bacilli is not activated by FBP as was shown for the Pyk of B. stearothermophilus (Sakai et al., 1986). Phosphorylation of Pyk in B. subtilis could have a regulatory influence on enzymatic activity and moreover could be a part of suspected protein kinase activity. This is not unlikely, because protein kinase activity was previous reported for the glyceraldehyde-3-phosphate dehydrogenase from rabbit (Duclos-Vallee et al., 1998). In this example, the enzyme forms a high-energy acetyl complex that behaves as a protein kinase. Protein kinase activity of conserved glycolytic enzymes could explain the absence of other protein kinases in B. subtilis.

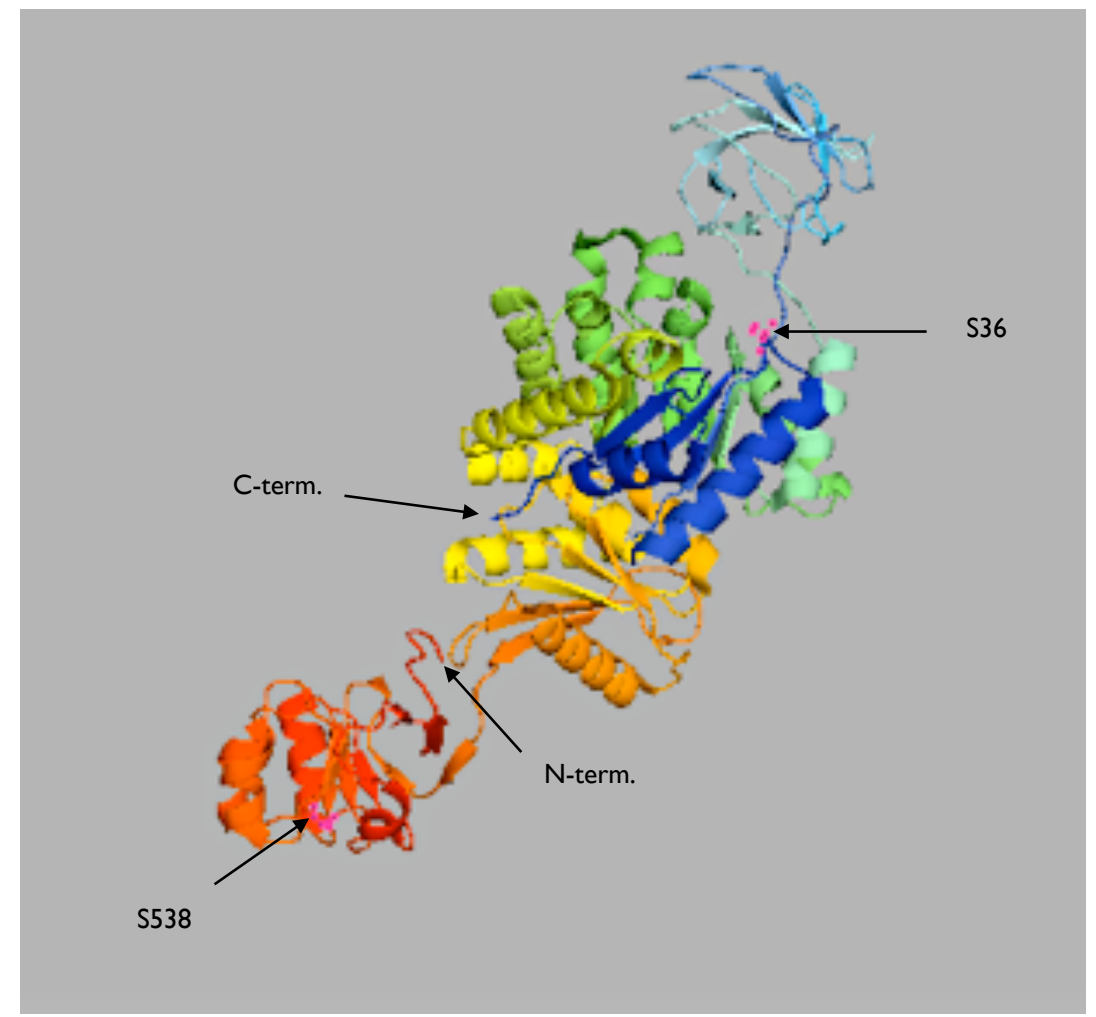

Figure 6.2.: Model of the pyruvate kinase from $B$. subtilis based on the Pyk structure from Geobacillus. stearothermophilus.

The overall structure of the enzyme. Following the nomenclature used by Suzuki et al. (2008) the following colors represent: cyan - domain A (catalytic domain), magenta - domain C (capped domain), green - domain $\mathrm{C}$ (containing the allosteric effector binding site) and red - domain C' (PEP-binding domain). The locations of the N-terminus, the C-terminus, Ser- 36 and S538 are indicated by arrows. 


\subsection{Autophosphorylation: The answer for kinase independent protein phosphorylation?}

The identification of around 80 proteins that are phosphorylated on Ser/Thr/Tyr-residues in $B$. subtilis leads to the question of the biological origin of these modifications. Since the known kinases were not responsible for these phosphorylation events, other origins came into focus. Moreover, the question about the biological relevance of these phosphorylation is important. For several proteins, phosphorylation must be interpreted as snapshot of their catalytic activity. The results of this work revealed that several proteins in B. subtilis are autophosphorylated. Furthermore, autophosphorylation of proteins would explain, why certain phosphorylation events are conserved among the domains of life.

In this work mainly two groups of proteins were identified to perform autophosphorylation, GTP-binding proteins and phosphosugar mutases. Genome comparisons revealed that GTP-binding proteins are conserved in prokaryotes and eukaryotes. These proteins are involved in essential cellular processes working as molecular switches (Koonin, 1998). They bind and hydrolyse GTP resulting in a conformational change of the protein (Bourne et al., 1991). It was shown that Obg and YdiB are autophosphorylated in the presence of their substrates GTP and ATP respectively. Autophosphorylation was also identified for the GTP-binding protein Era in E. coli (Sood et al., 1994). However, the biological sense of these autophosphorylations is questionable and just seems to be a snapshot of the switched-on or switched-off configuration (Welsh et al., 1994). This underlines the hypothesis that phosphoproteomes partially display the short-term state of autophosphorylation during catalytic activity of proteins. The brief phosphorylation of proteins stands in contrast to autophosphorylations that are required for enzymatic activity. For example most protein kinases must be autophosphorylated to be active as protein kinase.

The phosphosugar mutases Pgm and GlmM were also identified as autophosphorylated. GlmM is an enzyme that is required for the interconversion of glucosamine-6-phosphate and glucosamine-1-phosphate, an essential reaction for peptidoglycan and 
lipopolysaccharide biosynthesis. For the ortholog of GlmM in E. coli it was shown that the protein is only active in the phosphorylated form (Jolly et al., 1999; Jolly et al., 2000). However, it is not clear if ATP or another molecule is required for the initial autophosphorylation in vivo. Within this work it was also shown that the conserved Ser-100 residue of GlmM is required for the viability of B. subtilis. In Streptococcus gordonii and Pseudomonas aeruginosa mutants lacking GlmM were constructed. However, these mutants displayed impaired growth, elongated cells, reduced biofilm formation and sensitivity to lysozyme (Shimazu et al., 2008; Tavares et al., 2000). Furthermore, autophosphorylation of Pgm was shown in this work. It is already known that Pgm forms a phosphoserine intermediate during the enzymatic reaction (Rigden et al., 2003). In addition it is known that the conserved Ser-62 is required for the enzymatic activity in vitro. The phosphorylation of this glycolytic enzyme is therefore, a further example for reaction dependent phosphorylation. Mutases are also conserved in other organisms to great extent. In consequence, the reaction mechanisms are conserved, too. Therefore, it was not unexpected that autophosphorylation of mutases was also found in other organisms, like in the archaeon Sulfolobus solfataricus and in mouse (Potter et al., 2003; Gururaj et al., 2004). Different studies indicated that also other glycolytic enzymes do perform autophosphorylation, like the mammalian glyceraldehyde-3-phosphate dehydrogenase (Kawamoto \& Caswell, 1986).

However, autophosphorylation is also known for other classes of enzymes, like phosphatases and chaperones. Phosphatases also form phosphoserine intermediates as consequence of their activity (Jedrzejas \& Setlow, 2001; Rigden et al., 2003 ). Heat shock proteins are required for folding of misfolded proteins. For the chaperones DnaK and GroEL of E. coli, it was described that autophosphorylation is a result of ATPase activity. The autophosphorylation of these chaperones is increased after temperature shift, as consequence of enhanced ATPase activity. Replacement of phosphorylated Thr residues results in the loss of activity, too (Żylicz et al., 1983; McCarty and Walker, 1991). The same was shown for the heat shock protein Hsp70 of Mycobacterium tuberculosis (Preneta et al., 2004). Orthologs of these proteins are also phosphorylated 
in B. subtilis and phosphorylation was found to be increased after heat shock exposure (Lévine et al., 2006; Eymann et al., 2007).

\subsection{Outlook}

The results of this study show, that the glycolytic genes are not essential in B. subtilis. The glycolytic mutants build a perfect basis for the further investigation of the central metabolism in this model organism. In addition, the possibility to delete glycolytic genes allows the modulation of the carbon flow in B. subtilis, and is in consequence interesting for biotechnological applications. Metabolome analysis will provide further insights into the metabolic characteristics of these mutants. Besides, these mutants can be used to investigate the function of multienzyme complexes and additional functions in the cell. 


\section{References}

Absalon, C., Obuchowski, M., Madec, E., Delattre, D., Holland, I. B., and S. J. Séror. 2009. CpgA, EF-Tu and the stressosome protein YezB are substrates of the Ser/Thr kinase/phosphatase couple, PrkC/PrpC, in Bacillus subtilis. Microbiology. 155:932-943.

Abu-Qarn, M., Eichler, J. and N. Sharon. 2008. Not just for Eukarya anymore: protein glycosylation in Bacteria and Archaea. Curr. Opin. Struct. Biol. 18:544-550.

Aivaliotis, M., Macek, B., Gnad, F., Reichelt, P., Mann, M. and D. Oesterhelt. 2009. Ser/Thr/Tyr protein phosphorylation in the archaeon Halobacterium salinarum-a representative of the third domain of life. PLoS ONE. 4:e4777.

Alper, S., Dufour, A., Garsin, D. A., Duncan, L. and R. Losick. 1996. Role of adenosine nucleotides in the regulation of a stress-response transcription factor in Bacillus subtilis. J Mol Biol. 260:165-177.

Amaro, A. and C. Jerez. 1984. Methylation of ribosomal proteins in bacteria: Evidence of conserved modification of the eubacterial 50S subunit. J. Bacteriol. 158:84-93.

Arigoni, F., Talabot, F., Peitsch, M., Edgerton, M. D., Meldrum, E., Allet, E., Fish, R., Jamotte, T., Curchod, M.-L. and H. Loferer. 1998. A genome based approach for the identification of essential bacetrial genes. Nature Biotechnology. 16:851-856.

Arnold, M. 2009. In vivo-Relevanz der Phosphorylierung von glykolytischen Enzymen in Bacillus subtilis. Diplomarbeit. Georg-August-Universität Göttingen.

Bachem, S., Faires, N., and J. Stülke. 1997. Characterization of the presumptive phosphorylation sites of the Bacillus subtilis glucose permease by site-directed mutagenesis: implication in glucose transport and catabolite repression. FEMS Microbiol. Lett. 156:233-238.

Barbe, V., Cruveiller, S., Kunst, F., Lenoble, P., Meurice, G., Sekowska, A., Vallenet, D., Wang, T., Moszer, I., Médigue, C. and A. Danchin. 2009. 
From a consortium sequence to a unified sequence: Bacillus subtilis 168 reference genome a decade later. Microbiology. 155:1758-1775.

Bisicchia, P., Lioliou, E., Noone, D., Salzberg, L. I., Botella, E., Hübner, S. and K. M. Devine. 2010. Peptidoglycan metabolism is controlled by the WalRK (YycFG) and PhoPR two-component systems in phosphate limited Bacillus subtilis cells. Mol. Microbiol. ahead of print.

Blattner, F. R., Plunkett, III G., Bloch, C. A., Perna, NT., Burland, V., Riley, M., Collado-Vides, J., Glasner, J. D., Rode, C. K., Mayhew, G. F., Gregor, J., Davis, N. W., Kirkpatrick, H. A., Goeden, M. A., Rose, D. J., Mau, B. and Y. Shao. 1997. The Complete Genome Sequence of Escherichia coli K-12. Science. 277:1453-1462.

Blencke, H. M., Homuth, G., Ludwig, H., Mäder, U., Hecker, M. and J. Stülke. 2003. Transcriptional profiling of gene expression in response to glucose in Bacillus subtilis: regulation of the central metabolic pathways. Metab. Eng. 5:133-149.

Bourne, H. R., Sanders, D. A. and F. McCormick. 1991. The GTPase superfamily: conserved structure and molecular mechanism. Nature. 349:117-127.

Bradford, M. M. 1976. A rapid and sensitive method for quantitation of microgram quantities of protein utilizing the prinziple of protein-dye binding. Anal. Biochem. 72:248-254.

Brückner, R. and F. Titgemeyer. 2002. Carbon catabolite repression in bacteria: choice of the carbon source and autoregulatory limitation of sugar utilization. FEMS Microbiol. Lett. 209:141-148.

Butcher, L. A. and J. K. Tomkins. 1985. A comparison of silver staining methods for detecting proteins in ultrathin polyacrylamide gels on support film after isoelectric focusing. Anal. Biochem. 148:384-388. 
Chae, Y. K. and J. L. Markley. 2000. Functional recombinant rabbit muscle phosphoglucomutase from Escherichia coli. Protein Expr. Purif. 20:124-127.

Cao, V., Ratsima, E., Van Tri, D., Bercion, R., Fonkoua, M. C., Richard, V. and A. Talarmin. 2008. Antimicrobial susceptibility of Neisseria gonorrhoeae strains isolated in 2004-2006 in Bangui, Central African Republic; Yaoundé, Cameroon; Antananarivo, Madagascar; and Ho Chi Minh Ville and Nha Trang, Vietnam. Sex. Transmission Dis. 35:941-945.

Casteleijn, M. G., Alahuta, M., Groebel, K., El-Sayed, I., Augustyns, K., Lambeir, A. M., Neubauer, P. and R. K. Wierenga. 2006. Functional role of the conserved active site proline of triosephosphate isomerase. Biochemistry. 45:15483-94.

Chander, M., Setlow, B. and P. Setlow. 1998. The enzymatic activity of phosphoglycerate mutase from gram-positive endospore-forming bactria requires $\mathrm{Mn}^{2+}$ and is $\mathrm{pH}$ sensitive. Can. J. Microbiol. 44: 759-767.

Chander, M., Setlow, P., Lamani,E. and M. J. Jedrzejas. 1999. Structural studies on a 2,3-diphosphoglycerate independent phospho- glycerate mutase from Bacillus stearothermophilus. J. Struct. Biol. 126:156-165.

Christofk, H. R., Vander Heider, M. G., Wu, N., Asara, J. M. and L. C. Cantley. 2008. Pyruvate kinase M2 is a phosphotyrosine-binding protein. Nature 452: 181-186.

Clifton, D., Weinstock, S.B. and D.G. Fraenkel. 1978. Glycolysis mutants in Saccharomyces cerevisiae. Genetics. 88:1-11.

Commichau, F. M., Rothe, F. M., Herzberg, C., Wagner, E., Hellwig, D., LehnikHabrink, M., Hammer, E., Völker, U. and J. Stülke. 2009. Novel activities of glycolytic enzymes in Bacillus subtilis: interactions with essential proteins involved in mRNA processing. Mol. Cell. Proteomics. 8:1350-60. 
Cozzone, A. J. 1998. Regulation of acetate metabolism by protein phosphorylation in enteric bacteria. Annu. Rev. Microbiol. 52:127-164.

Decker, B. L. and W. T. Wickner. 2006. Enolase activates homotypic vacuole fusion and protein transport to the vacuole in yeast. J. Biol. Chem. 281:14523-14528.

Desai, K. K. and B. G. Miller. 2008. A metabolic bypass of triosephosphate isomerase reaction. Biochemistry. 47:7983-7985.

Deutscher, J. and M. H. Saier Jr. 1983. ATP-dependent protein kinase-catalyzed phosphorylation of a seryl residue in HPr, a phosphate carrier protein of the phosphotransferase system in Streptococcus pyogenes, Proc. Natl. Acad. Sci. US A. 80:6790-6794.

Deutscher, J. and M. H. Saier Jr. 2005. Ser/Thr/Tyr protein phosphorylation in bacteria-for long time neglected, now well established. J. Mol. Microbiol. Biotechnol. 9:125-131.

Doan. T. and S. Aymerich. 2003. Regulation of the central glycolytic genes in Bacillus subtilis: binding of the repressor CggR to its single DNA target sequence is modulated by fructose-1,6-bisphosphate. Mol. Microbiol. 47:1709-1721.

Eichenberger, P., Jensen, ST., Colon, EM., van Ooij, C., Silvaggi, J., GonzálesPastor, JE., Fujita, M., Ben-Yehuda, S., Straiger, P., Liu, JS., and R. Losick. 2003. The sigmaE regulon and the identification of additional sporulation genes in Bacillus subtilis. J. Mol. Biol. 327:945-972.

Errington, J. 2003. Regulation of endospore formation in Bacillus subtilis. Nat. Re. Microbiol. 1:117-127.

Ettema, T. J., Ahmed, H., Geerling, A. C., van der Oost, J., and B. Siebers. The non-phosphorylating glyceraldehyde-3-phosphate dehydrogenase (GAPN) of Sulfolobus solfataricus: a key enzyme of the semi-phosphorylative branch of the Entner-Doudoroff pathway. Extremophiles. 12:75-88. 
Eymann, C., Becher, D., Bernhardt, J., Gronau, K., Klutzny, A., and M. Hecker. 2007. Dynamics of protein phosphorylation on Ser/Thr/Tyr in Bacillus subtilis. Proteomics. 7:3509-3526.

Fabret, C., Feher, V.A., and J. A. Hoch. 1999. Two-Component Signal Transduction in Bacillus subtilis: How One Organism Sees Its World. J Bacteriol. 181:1975-1983.

Feo, S., Arcuri, D., Piddini, E., Passantino R. and A. Giallongo. 2000. ENO1 gene product binds to the c-myc promoter and acts as a transcriptional repressor: relationship with Myc promoter-binding protein 1 (MBP-1). FEBS Lett. 473:47-52.

Fillinger, S., Boschi-Muller, S., Azza, S., Dervyn, E., Branlant, G. and S. Aymerich. 2000. Two glyceraldehyde-3-phosphate dehydrogenases with opposite physiological roles in a nonphotosynthetic bacterium. J Biol Chem. 275:14031-1437.

Fischer, C., Geourion, C., Bourson, C. and J. Deutscher. 1996. Cloning and characterization of the Bacillus subtilis prkA gene encoding a novel serine protein kinase. Gene 168:55-60.

Fourrat, L., Iddar, A., Valverde, F., Serrano, A. and Soukri. 2007. Cloning, gene expression and characterization of a novel bacterial NAD-dependent nonphosphorylating glyceraldehyde-3-phosphate dehydrogenase from Neisseria meningitidis strain Z2491. Mol. Cell. Biochem. 305:209-219.

Fraenkel, D. G. 1986. Mutants in glucose metabolism. Annu. Rev. Biochem. 55:317-337.

Fraser, C. M., Gocayne, J. D., White, O., Adams, M. D., Clayton, R. A., Fleichmann, R. D., Bult, C. J., Kerlavage, A. R., Sutton, G., Kelley J. M., Fritchmann, R. D., Weidmann, J. F., Small, K. V., Sandusky, M., Fuhrmann, J., Nguyen, D., Utterback, T. R., Saudek, D. M., Phillips, C. A., Merrick, J. M., Tomb, J. F., Dougherty, B. A., Bott, K. F., Hu, P. C., Lucier, T. S., Peterson, S. N., Smith, H. O., Hutchison, C. A. 3rd. and J. C. 
Venter. 1995. The minimal genome of Mycoplasma genitalium. Science. 270:397-403.

Fraser, H. I., Kvaratskhelia, M. and M. F. White. 1999. The analogous phosphoglycerate mutases of Escherichia coli. FEBS Lett. 455: 344-348.

Freese, E., Klofat, W. and E. Galliers. 1970. Commitment to sporulation and induction of glucose-phosphoenolpyruvate-transferase. Biochim. Biophys. Acta 222:265-289.

Fry, B., Zhu, T., Domach, M.M., Koepsel, R.R., Phalakornkule, C. and M. M. Ataai. 2000. Characterization of growth and acid formation in a Bacillus subtilis pyruvate kinase mutant. Appl .Environ. Microbiol. 66:4045-4049.

Fuhrer, T., Fischer, E. and U. Sauer. 2005. Experimental identification and quantification of glucose metabolism in seven bacterial species. J. Bacteriol. 187:1581-1590.

Fuhrmann, J., Schmidt, A., Spiess, S., Lehner, A., Turgay, K., Mechtler, K., Charpentier, E. and T. Clausen. 2009. McsB is a protein arginine kinase that phosphorylates and inhibits the heat-shock regulator CtsR. Science. 324:1323-11327.

Fujita, Y. and E. Freese. 1979. Purification and properties of fructose-1,6bisphosphatase of Bacillus subtilis. J. Biol. Chem. 254:5340-5349.

Fujita, Y. and E. Freese. 1981. Isolation and properties of a Bacillus subtilis mutant unable to produce fructose-bisphosphatase. J. Bacteriol. 145:760-767.

Fujita, Y., Yoshida, K., Miwa, Y.,Yanai, N., Nagakawa, E. and Y. Kasahara. 1998. Identification and expression of the Bacillus subtilis fructose-1,6bisphosphatase gene (fbp). J. Bacteriol. 180:4309-4313.

Fujita, Y. 2009. Carbon catabolite control of the metabolic network in Bacillus subtilis. Biosci. Biotechnol. Biochem. 73:245-259. 
Gaidenko, T. A., Kim, T. J., and C. W. Price. 2002. The PrpC serine-threonine phosphatase and PrkC kinase have opposing physiological roles in stationary- $\quad$ phase Bacillus subtilis cells. J. Bacteriol. 184:6109-6114.

Galinier, A., Haiech, J., Kilhoffer, M. C., Jaquinod, M., Stülke, J., Deutscher, J. and I. Martin-Verstaete. 1997. The Bacillus subtilis crh gene encodes a HPr- like protein involved in carbon catabolite repression. Proc. Natl. Sci. US A. 94:8439-8444.

Galinier, A., Kravanja, M., Engelmann, R., Hengstenberg, W., Kilhoffer, M.-C. Deutscher J. and J. Haiech. 1998. New protein kinase and protein phosphatase families mediate signal transduction in bacterial catabolite repression. Proc. Natl. Acad. Sci. USA 95:1823-1828.

Garnak, M. and H. C. Reeves. 1979. Phosphorylation of Isocitrate dehydrogenase of Escherichia coli. Science. 203:1111-1112.

Gnad, F., de Godoy, L. M., Cox, J., Neuhauser, N., Ren, S., Olsen, J. V. and M. Mann. High-accuracy identification and bioinformatic analysis of in vivo protein phosphorylation sites in yeast. Proteomics. 9:4642-4652.

Guérout-Fleury, A. M., Shazand, K., Frandsen, N. and P. Stragier. 1995. Antibiotic-resistance cassettes for Bacillus subtilis. Gene. 167:335-336.

Gururaj, A., Barnes, C. J., Vadlamudi, R. K. and R. Kumar. 2004. Regulation of phosphoglucomutase 1 phosphorylation and activity by a signaling kinase. Oncogene. 23:8118-81127.

Görke, B. and J. Stülke. 2008. Carbon catabolite repression in bacteria: many ways to make the most out of nutrients. Nature Re. Microbiol. 6:613-624.

Halbedel, S. and J. Stülke. 2006. Probing in vivo promoter activities in Mycoplasma pneumoniae: a system for generation of single-copy reporter constructs. Appl Environ Microbiol. 72:1696-1699. 
Hannay, K., Marcotte, E. M. and C. Vogel. 2008. Buffering by gene duplicates: an analysis of molecular correlates and evolutionary conservation. BMC Genomics. 9:609doi

Hecker, M., Pané-Farré, J. and U. Völker. 2007. SigB-dependent general stress response in Bacillus subtilis and related gram-positive bacteria. Annu. Rev. Microbiol. 61:215-236.

Herzberg, C., Weidinger, L. A., Dörrbecker, B., Hübner, S., Stülke, J. and F. M. Commichau. 2007. SPINE: a method for the rapid detection and analysis of protein-protein interactions in vivo. Proteomics. 7:4032-405.

Hunt, A., Rawlins, J. P., Thomaides, H. B. and J. Errington. 2006. Functional analysis of 11 putative essential genes in Bacillus subtilis. Microbiology. 152:2895-2907.

Irani, M. H., and P.K. Maitra. 1977. Properties of Escherichia coli mutants deficient in enzymes of glycolysis. J. Bacteriol. 132:398-410.

Jedrzejas, M. L., Chander, Setlow, P. and G. Krishnasamy. 2000. Mechanism of catalysis of the cofactor-independent phosphoglycerate mutase from Bacillus stearothermophilus. Crystal structure of the complex with 2-phosphoglycerate. J. Biol. Chem. 275:23146-23153.

Jolly, L., Pompeo, F., van Heijenoort, J., Fassy, F. and D. Mengin- Lecreulx. 2000. Autophosphorylation of phosphoglucosamine mutase from Escherichia coli. J. Bacteriol. 182:1280-1285.

Jordan, S., Hutchings, M.I. and T. Mascher. 2008. Cell envelope stress response in Gram-positive bacteria. FEMS Microbiol Rev. 32:107-146.

Jules, M., Le Chat, L., Aymerich, S. and D. Le Coq. 2009. The Bacillus subtilis ywjI (glpX) gene encodes a class II fructose-1,6-bisphosphatase, functionally equivalent to the class III Fbp enzyme. J Bacteriol. 191:3168-71.

Karst, J.C., Foucher, A. E., Campbell, T. L., Guilmi, A. M., Stroebel, D., Mangat, C. S., Brown, E. D.and J. M. Jault. 2009. The ATPase activity of an 'essential' 
Bacillus subtilis enzyme, $\mathrm{YdiB}$, is required for its cellular function and is modulated by oligomerization. Microbiology. 155:944-956.

Kawamoto, R. M. and A. H. Caswell. 1986. Autophosphorylation of glyceraldehydephosphate dehydrogenase and phosphorylation of protein from skeletal muscle microsomes. Biochemistry. 25:657.661.

Kearns, D. B., Chu, F., Branda, S. S., Kolter, R. and R. Losick. 2005. A master regulator for biofilm formation by Bacillus subtilis. Mol. Microbiol. 55:739-749.

Kitko, R. D., Cleeton, R. L., Armentrout, E. I., Lee, G. E., Noguchi, K., Berkmen, M. B., Jones, B. D., and J. L. Slonczewski. 2009. Cytoplasmic acidification and the benzoate transcriptome in Bacillus subtilis. PLoS One. 4:e8255.

Kleijn, R. J., Buescher, J. M., Le Chat, L., Jules, M., Aymerich, S. and U. Sauer. 2009. Metabolic fluxes during strong carbon catabolite repression by malate in Bacillus subtilis. J. Biol. Chem. 285:1587-1596.

Kobayashi, K., Ehrlich, S. D., Albertini, A., Amati, G., Andersen, K. K., Arnaud, M., Asai, K., Ashikaga, S., Aymerich, S., Bessieres, P., Boland, F., Brignell, S. C., Bron, S., Bunai, K., Chapuis, J., Christiansen, L. C., Danchin, A., Debarbouille, M., Dervyn, E., Deuerling, E., Devine, K., Devine, S. K., Dreesen, O., Errington, J., Fillinger, S., Foster, S. J., Fujita, Y., Galizzi, A., Gardan, R., Eschevins, C., Fukushima, T., Haga, K., Harwood, C. R., Hecker, M., Hosoya, D., Hullo, M. F., Kakeshita, H., Karamata, D., Kasahara, Y., Kawamura, F., Koga, K., Koski, P., Kuwana, R., Imamura, D., Ishimaru, M., Ishikawa, S., Ishio, I., Le Coq, D., Masson, A., Mauel, C., Meima, R., Mellado, R. P., Moir, A., Moriya, S., Nagakawa, E., Nanamiya, H., Nakai, S., Nygaard, P., Ogura, M., Ohanan, T., O'Reilly, M., O'Rourke, M., Pragai, Z., Pooley, H. M., Rapoport, G., Rawlins, J. P., Rivas, L. A., Rivolta, C., Sadaie, A., Sadaie, Y., Sarvas, M., Sato, T., Saxild, H. H., Scanlan, E., Schumann, W., Seegers, J. F., Sekiguchi, J., Sekowska, A., Seror, S. J., Simon, M., Stragier, P., Studer, R., Takamatsu, H., Tanaka, T., Takeuchi, M., Thomaides, H. B., 
Vagner, V., van Dijl, J. M., Watabe, K., Wipat, A., Yamamoto, H., Yamamoto, M., Yamamoto, Y., Yamane, K., Yata, K., Yoshida, K., Yoshikawa, H., Zuber, U. and N. Ogasawara, 2003. Essential Bacillus subtilis genes. Proc Natl Acad Sci U S A 100:4678-4683.

Koonin, E. V. 1998. Genomic microbiology: right on target? Nat. Biotechnol. 16:821:822.

Koonin, E. V., and Y. I. Wolf. 2008. Genomics of bacteria and archaea: the emergingdynamic view of the prokaryotic world. Nucleic Acids Res. 36:6688-6719.

Krom, B. P., Aardema, R. and J. S. Lolkema. 2001. Bacillus subtilis YxkJ is a secondary transporter of the 2-hydroxycarboxylate trans- porter family that transports L-malate and citrate. J. Bacteriol. 183:5862-5869.

Kunst, F., Ogasawara, N., Moszer, I., Albertini, A. M., Alloni, G., Azevedo, V., Bertero, M. G., Bessières, P., Bolotin, A., Borchert, S., Borriss, R., Boursier, L., Brans, A., Braun, M., Brignell, S. C., Bron, S., Brouillet, S., Bruschi, C. V., Caldwell, B., Capuano, V., Carter, N. M., Choi, S. K., Codani, J. J., Connerton, I. F., Danchin, A., et al. 1997. The complete genome sequence of the gram-positive bacterium Bacillus subtilis. Nature. 390:249-256

Lam, K. B. and J. Marmur. 1977. Isolation and characterization of Saccharomyces cerevisiae glycolytic pathway mutants. J. Bacteriol. 130:746-749.

Laemmli, U. K. 1970. Cleavage of structural proteins during the assembly of the head of bacteriophage T4. Nature. 277:680-685.

Lerondel, G., Doan, T., Zamboni, N., Sauer, U. and S. Aymerich. 2006. YtsJ has the major physiological role of the four paralogous malic enzyme isoforms in Bacillus subtilis. J. Bacteriol. 188:4727-4736.

Lévine, A., Vannier, F., Absalon, C., Kuhn, L., Jackson, P., Scrivener, E., Labas, V., Vinh, J., Courtney, P., Garin, J. and SJ. Séror. 2006. Analysis of the dynamic Bacillus subtilis Ser/Thr/Tyr phosphoproteome implicated in a wide variety of cellular processes. Proteomics. 6:2157-2173. 
Leyva-Vazquez, M. A. and P. Setlow. 1994. Cloning and nucleotide sequences of the genes encoding triose phosphate isomerase, phosphoglycerate mutase, and enolase from Bacillus subtilis. J. Bacteriol. 176:3903-3910.

Licht, A., Preis, S. and S. Brantl. 2005. Implications of CcpN in the regulation of a novel RNA (SR1) in Bacillus subtilis. Mol. Microbiol. 58:189-206.

Licht, M., Golbik, R. and S. Brantl. 2008. Identification of ligands affecting the activity of the transcriptional repressor CcpN from Bacillus subtilis. J. Mol. Biol. 380:17-30.

Lin, M. H., Hsu, T. L., Lin, S. Y., Pan, Y. T., Jan, J. T., Wang, J. T., Khoo, K. H. and S. H. Wu. 2009. Phosphoproteomics of Klebsilla pneumoniae NTUH-K2044 reveals a tight link between tyrosine phosphorylation and virulence. Mol. Cell. Proteomics. 8: 2613-2613.

Lobos, Z. and P. K. Maitra. 1983. Phosphofructokinase mutants of yeast. J. Biol. Chem. 25:1444-1449.

Losick, R., Youngman, P. and P. J. Piggot. 1986. Genetics of endospore formation in Bacillus subtilis. Annu. Rev. Genet. 20:625-669.

Lu, M., Yuri, Y., Sautin, L., Holliday, S. and S. L. Gluck. 2003. The Glycolytic Enzyme Aldolase Mediates Assembly, Expression, and Activity of Vacuolar-H ${ }^{+}$-ATPase. J. Biol. Chem. 279:8732-8739.

Macek, B., Mijakovic, I., Olsen, J. V., Gnad, F., Kumar, C., Jensen, PR. and M. Mann. 2007. The serine/threonine/tyrosine phosphoproteome of the model bacterium Bacillus subtilis. Mol. Cell. Proteomics. 6:697-707.

Macek, B., Gnad, F., Soufi, B., Kumar, C., Olsen, J. V., Mijakovic, I. and M. Mann. 2008. Phosphoproteome analysis of $E$. coli reveals evolutionary conservation of bacterial Ser/Thr/Tyr phosphorylation. Mol. Cell. Proteomics. 7:299-307.

Madec, E., laszkiewicz, A., Iwanicki, A., Obuchowski, M. and S. Séror. 2002. Characterization of a membrane-linked Ser/Thr protein kinase in Bacillus subtilis. Mol. Microbiol. 46:571-586. 
Magill, N. G., Cowan, A. E., Leyva-Vazquez, M. A., Brown, M., Koppel, D. E., and P. Setlow. 1996. Analysis of the relationship between the decrease in $\mathrm{pH}$ and accumulation of 3-phosphoglyceric acid in developing forespores of Bacillus species. J Bacteriol. 178:2204-2210.

Martin-Verstraete, I., Débarbouillé, M., Klier, A. and G. Rapoport. 1994. Interactions of wild-type and truncated LevR of Bacillus subtilis with the upstream activating sequence of the levanase operon. J Mol Biol. 241:178-92.

McCarty, J. S. and G. C. Walker. 1991. DnaK as a thermometer:Threonine-199 is site of autophosphorylation and is critical for ATPase activity. Proc. nat. Acad. Sci. USA. 88:9513-9517.

Merrick, M. J. and R. A. Edwards. 1995. Nitrogen control in bacteria. Microbiol. Rev. 59:604-622.

Mijakovic, I., Poncet, S., Boël, G., Mazé, A., Gillet, S., Jamet, E., Decottigneies, P., Grangasse, C., Doublet, P., Le Maréchal, P. and J. Deutscher. 2003. Transmembrane modulator-dependent bacterial tyrosine kinase activates UDP- glucose dehydrogenases. EMBO J. 22:4709-4718.

Mijakovic, I., Petranovic, D., Macek, B., Cepo, T., Mann, M., Davies, J., Jensen, PR. and D. Vujaklija. 2006. Bacterial single-stranded DNA-binding proteins are phosphorylated on tyrosine. Nucleic Acids Res. 34:1588-1596.

Miller, J. H. 1972. Experiments in molecular genetics, Cold Spring Harbour Laboratorys Press, Cold Spring Harbour, NY.

Mitchel, C. and J. C. Vary. 1989. Proteins that interact with GTP-during sporulation of Bacillus subtilis. J. Bacteriol. 171:2915-2918.

Mittenhuber, G. 2001. Comparative genomics of prokaryotic GTP-binding proteins (the Era, Obg, EngA, ThdF (TrmE), YchF and YihA families) and their relationship to eukaryotic GTP-binding proteins (the DRG, ARF, RAB, RAN, RAS and RHO families). J. Mol. Microbiol. Biotechnol. 3:21-35.

Nakahigashi, K., Toya, Y., Ishii, N., Soga, T., Hasegawa, M., Watanabe, H., Takai, Y., Honma, M., Mori, H., and M. Tomita. 2009. Systematic phoneme analysis 
of Escherichia coli multiple-knockout mutants reveals hidden reactions in central carbon metabolism. Mol. Syst. Biol. 5:306.

Nesterenko, M. V., Tilley, M. and S. J. Upton. 1994. A simple modification of Blum's silver stain method allows for 30 minute detection of proteins in polyacrylamide gels. J Biochem Biophys Methods. 28:239-242.

Oh, Y. K. and E. Freese. 1976. Manganese requirement of phosphoglycerate phosphomutase and its consequences for growth and sporulation of Bacillus subtilis.J. Bacteriol. 127:739-746.

Ohné, M. and B. Rutberg. 1976. Repression of sporulation in Bacillus subtilis by L-malate. J. Bacteriol. 125:453-460.

Olivaraes-Illana, V., Meyer, P., Bechet, E., Gueguen-Chaignon, V., Soulat, D., Lazereg-Riquier, S., Mijakovic, I., Deutscher, J., Cozzone, A. J., Laprévote, O., Morera, S., Grangasse, C. and S. Nessler. 2008. Structural basis for the regulation mechanism of the tyrosine kinase CapB from Staphylococcus aureus. PLoS Biol. 6:e143.

Pailot, A., DÀmbrosius, K., Corbier, C., Talfournier, F. and G. Branlant. 2006. Invariant Thr244 is essential for the efficient acylation step of the nonphosphorylating glyceraldehyde-3-phosphate dehydrogenase from Streptococcus mutans. Biochem. J. 400:521-530.

Pan, Z., Zhu, T., Domagalski, N., Khan, S., Koepsel, R. R., Domach, M. M. and M. M. Ataai. 2006. Regulating expression of pyruvate kinase in Bacillus subtilis for control of growth rate and formation of acidic byproducts. Biotechnol. Prog. 22:1451-1455.

Parkhill, J., Wren, B. W., Mungall, K., Ketley, J. M. et al. 2000. The genome sequence of food-borne pathogen Campylobacter jejuni reveals hypervariable sequences. Nature. 403:665-668.

Pearson, C. L., Loshon, C. A., Pedersen, L. B., Setlow, B. and P. Setlow. 2000. Analysis of the function of a putative 2,3-diphosphoglyceric acid-dependent phosphoglycerate mutase from Bacillus subtilis. J. Bacteriol. 182: 4121-4123. 
Petranovic, D., Michelsen, O., Zahradka, K., Silva, C., Petranovic, M., Ruhdahl Jensen, P. and I. Mijakovic. 2007. Bacillus subtilis strain deficient for the protein-tyrosine kinase PtkA exhibits impaired DNA replication. Mol. Microbiol. 63:1797-1805.

Petranovic, D., Grangeasse, C., Macek, B., Abdillatef, M., Gueguen-Chaignon, V., Nessler, S., Deutscher, J., and I. Mijakovic. 2009. Activation of Bacillus subtilis Ugd by the BY-kinase PtkA proceeds via phosphorylation of its residue tyrosine 70. J. Mol. Microbiol. Biotechnol. 17:83-89.

Pietack. N., Dörte, B., Schmidl, SR., Saier, M., Hecker, M., Commichau, FM. and J. Stülke. 2010. In vitro phosphorylation of key metabolic enzymes from Bacillus subtilis: PrkC phosphorylates enzymes from different branches of basic metabolism. ahead of print.

Piggot, P. J. and D. W. Hilbert. 2004. Sporulation of Bacillus subtilis. Curr. Opin. Microbiol. 7:579-589.

Pilkis, S. J., and T. H. Claus. 1991. Hepatic gluconeogenesis/glycolysis: regulation and structure/function relationships of substrate cycle enzymes. Annu. Rev. Nutr. 11: $465-515$.

Potters, M. B., Solow, B. T., Bischoff, K. M., Graham, D. E., Lower, B. H., Helm, R. and P. J. Kennelly. 2003. Phosphoprotein with phosphoglycerate mutase activity from the archaeon Sulfolobus solfataricus. J. Bacteriol. 185:2112-2121.

Prasad, C., Diesterhaft, M. and E. Freese. 1972. Initiation of spore germination in glycolytic mutants of Bacillus subtilis. J. Bacteriol. 110:321-328.

Preneta, R., Papavinasasundaram, K. G., Cozzone, A. J. and B. Duclos. 2004. Autophosphorylation of the $16 \mathrm{kDa}$ and $70 \mathrm{kDa}$ antigens (Hsp 16.3 and Hsp 70) of Mycobacterium tuberculosis. Microbiol. 150:2135:2141.

Ramakrishnan, C., Dani, V.S. and T. Ramasarma. 2002. A conformational analysis of Walker motif A [GXXXXGKT (S)] in nucleotide-binding and other proteins. Protein Engineering. 10:783-798. 
Ravichandran, A., Sugiyama, N., Tomita, M., Swarup, S. and Ishihama. 2009. Ser/

Thr/Tyr phosphoproteome analysis of pathogenic and non-pathogenic Pseudomonas species. Proteomics. 9:2764-2775.

Reizer, J., Hoischen, C., Titgemeyer, F., Rivolta, C., Rabus, R., Stülke, J., Karamata, D., Saier Jr., M. H. and W. Hillen. 1998. A novel bacterial protein kinase that controls carbon catabolite repression. Mol. Microbiol. 27:1157-1169.

Rigden, D. J., Lamani, E., Mello, L. V., Littlejohn, J. E. and M. J. Jedrzejas. 2003. Insights into the catalytic mechanism of cofactor-independent phosphoglycerate mutase from X-ray crystallography, simulated dynamics and molecular modeling. J. Mol. Biol. 328:909-920.

Sambrook, J., Fritsch, E. F. and T. Maniatis. 1989. Molecular cloning: A laboratory manual. 2. Edition. Cold Spring Harbour, N.Y.: Cold Spring Harbour Laboratory Press.

Sanger. F. S., Nicklen. and A. R. Coulson. 1977. DNA sequencing with chainterminating inhibitors. Proc. Natl. Acad. Sci. U S A. 74:5463-5467.

Sauer, U. and B. J. Eikamanns. 2005. The PEP-pyruvate-oxaloacetate node as the switch point for carbon flux distribution in bacteria. FEMS Microbiol. Rev. 29:765-794.

Schaeffer, P., Millet, J. and J. P. Aubert.1965.Catabolic repression of bacterial sporulation. Proc. Natl. Acad. Sci. U.S.A. 54:704-711.

Schirmer, F., Ehrt, S. and W. Hillen. 1997. Expression, inducer spectrum, domain structure, and function of MopR, the regulator of phenol degradation in Acinetobacter calcoaceticus NCIB8250. J Bacteriol 179:1329-1336.

Shah, I., M., Laaberik, M.-H., Popham, D. L. and J. Dworkin. 2008. A eukaryotic- like Ser/Thr kinase signals bacteria to exit dormancy in response to peptidoglycan fragments. Cell. 135:486-496

Shah, I. M. and J. Dworkin. 2010. Induction and regulation of a secreted peptidoglycan hydrolase by a membrane Ser/Thr kinase that detects muropeptides. Mol. Microbiol. Epub ahead of print. 
Shimazu, K., Takahashi, Y., Uchikawa, Y., Shimazu, Y., Yajima, A., Takashima, E., Aoba, T. and K. Konishi. 2008. Identification of the Streptococcus gordonii glmM gene encoding phosphoglucosamine mutase and its role in bacterial cell morphology, biofilm formation and sensitivity to antibiotics. FEMS Immunol. Med. Microbiol. 53:166-177.

Servant, P., Le Coq, D. and D. Aymerich. 2005. CcpN (YqzB), a novel regulator for CcpA-independent catabolite repression of Bacillus subtilis gluconeogenic genes. Mol. Microbiol. 55:1435-1451.

Singh, K. D., Schmalisch, M. H., Stülke, J. and B. Görke. 2008. Carbon catabolite repression in Bacillus subtilis: quantitative analysis of repression exerted by different carbon sources. J. Bacteriol. 190:7275-7284.

Sood, P., Lerner, C. G., Shimamoto, T., Lu, Q. and M. Inouye. 1994. Characterization of the autophosphorylation of Era, an essential Escherichia coli GTPase. Mol. Microbiol. 12:201-208.

Soufi, B., Gnad, F., Jensen, P. R., Peranovic, D., Mann, M., Mijakovic, I. and B. Macek. 2008. The Ser/Thr/Tyr phosphoproteome of Lactococcus lactis IL1403 reveals multiply phosphorylated proteins. Nucleic Acids Research. 36:6688-6719.

Soufi B, Jers C, Hansen ME, Petranovic D. and I. Mijakovic. 2008. Insights from site specific phosphoproteomics in bacteria. Biochim. Biophys. Acta. 1784:186-192.

Stülke, J. and W. Hillen. 1999. Carbon catabolite repression in bacteria. Curr. Opin. Microbiol. 2:195-201.

Sun, X., Ge, F., Xiao, C. L., Yin, X. F., Ge, R., Zhang, L. H. and Q. Y. He. 2010. Phosphoproteomic analysis reveals the multiple roles of phosphorylation in pathogenic bacterium Streptococcus pneumoniae. J. Proteome Res. 9:275-282.

Suzuki, K., Ito, S., Shimizu-Ibuka, A. and H. Sakai. 2008. Crystal structure of pyruvate kinase from Geobacillus stearothermophilus. J. Biochem. 144:305-312. 
Tanaka, K., Kobayashi, K. and N. Ogasawara. 2003. The Bacillus subtilis YufLM two-component system regulates the expression of the malate transporters MaeN (YufR) and YflS, and is essential for utilization of malate in minimal medium. Microbiology. 149:2317-2329.

Tavares, I. M., Jolly, L., Pompeo, F., Leião, J. H., Fialho, A. M., Sá-Correia, I. and D. Mengin-Lecreulx. 2000. Identification of the Pseudomonas aeruginosa glmM gene, encoding phosphoglucosamine mutase. J. Bacteriol. 182:4453-4457.

Tobisch, S., Zühlke, D., Bernhardt, J., Stülke, J. and M. Hecker. 1999. Role of CcpA in regulation of the central pathways of carbon catabolism in Bacillus subtilis. J. Bacteriol. 181:6996-7004.

Tojo, S., Kumamoto, K., Hirooka, K. and Y. Fujita. 2010. Heavy Involvement of Stringent Transcription Control Depending on the Adenine or Guanine Species of the Transcription Initiation Site in Glucose and Pyruvate Metabolism in Bacillus subtilis. J. Bacteriol. 192:1573-1585.

Thomaides, H. B., Davidson, E. J., Burston, L., Johnson, H., Brown, D. R., Hunt, A. C., Errington, J. and L. Czaplewski. 2007. Essential bacterial functions encodes by gene pairs. J. Bacteriol. 189:591-602.

Tovy, A., Siman Tov, R., Gaentzsch, R., Helm, M., and S. Ankri. 2010. A new nuclear function of the Entamoeba histolytica glycolytic enzyme enolase: the metabolic regulation of cytosine-5 methyltransferase 2 (Dnmt2) activity. PLoS Pathog. 6:e1000775.

Trach. K., Burbulys. D., Strauch. M., Wu. J. J., Dhillon. N., Jonas. R., Hanstein. C., Kallio, P., Perego. M. and T. Bird. 1991. Control of the initiation of sporulation in Bacillus subtilis by a phosphorelay. Res. Microbiol. 142:815-823.

Tännler, S., Fischer, E., Le Coq, D., Doan, T., Jamet, E., Sauer, U. and S. Aymerich. 2008. CcpN controls central carbon metabolism fluxes in Bacillus subtilis. J. Bacteriol. 190:6178-6187. 
Vagner, V., Dervyn, E. and S. D. Ehrlich. 1998. A vector for systematic gene inactivation in Bacillus subtilis. 144:3097-3104.

Voigt, B., Antelmann, H., Albrecht, D., Ehrenreich, A., Maurer, K. H., Evers, S., Gottschalk, G., van Dijl, J. M., Schweder, T. and M. Hecker. 2009. Cell physiology and protein secretion of Bacillus licheniformis compared to Bacillus subtilis. J. Mol. Microbiol. Biotechnol.16:53-68.

Voijek, A. B. and D. G. Fraenkel. Phosphorylation of yeast hexokinase. Eur. J. Biochem. 190:371-375.

Voisin, S., Watson, D. C., Tessier, L., Ding, W., Foote, S., Bhatia, S., Kelly, J. F. and N. M. Young. 2007. The cytoplasmic phosphoproteome of the Gram-negative bacterium Campylobacter jejuni: evidence for modification by unidentified protein kinases. Proteomics 7: 4338-4348.

Wach, A. 1996. PCR-synthesis of marker cassettes with long flanking homology regions for gene disruptions in S. cerevisiae. Yeast. 12:259-265.

Wang, J. Y. and D. E.. Koshland Jr. 1978. Evidence for protein kinase activities in the prokaryote Salmonella typhimurium. J. Biol. Chem. 253:7605-7608.

Wang, S. T., Setlow, B., Conlon, E. M., Lyon, J.L., Imamura, D., Sato, T., Setlow, P., Losick, R., and P. Eichenberger. 2006. The forespore line of gene expression in Bacillus subtilis. J. Mol. Biol. 358:16-37.

Wang, Q., Zhang, Y., Yang, C., Xiong, H., Lin, Y., Yao, J., Li, H., Xie, L., Zhao, W., Yao, Y., Ning, Z. B., Zeng, R., Xiong, Y., Guan, K. L., Zhao, S. and G. P. Zhao. 2010. Acetylation of metabolic enzymes coordinates carbon source utilization and metabolic flux. Science. 375:1004-1007.

Walker, J. E., Saraste, M., Runswick, M. J. and N. J. Gay. 1982. Distantly related sequences in the alpha- and beta-subunits of ATP synthase, myosin, kinases and other ATP-requiring enzymes and a common nucleotide binding fold. EMBO J. 1: 945-951. 
Wei, Y., Guffanti, A. A., Ito, M. and T. A. Krulwich. 2000. Bacillus subtilis YqkI is a novel malic/ $\mathrm{Na}+$-lactate antiporter that enhances growth on malate at low protonmotive force. J. Biol. Chem. 275:30287-30292.

Weinrauch, Y., Msadek, T., Kunst, F. and D. Dubnau. 1991. Sequence and properties of comQ, a new competence regulatory gene of Bacillus subtilis. J Bacteriol 173:5685-5693.

Welsh, K., Trach, K. A., Folger, C. and J. A. Hoch. 1994. Biochemical influence of the essential GTP-binding protein Obg of Bacillus subtilis. America Society for Microbiology. 176:7161-7168.

Wilks, J. C., Kitko, R. D., Cleeton, S. H., Lee, G.E., Ugwu, C. S., Jones, B. D., BonDurant, S. S. and J. L. Slonczewski. 2009. Acid and base stress and transcriptomic responses in Bacillus subtilis. Appl Environ Microbiol. 75:981-990.

Yamamoto, H., Murata, M. and J. Sekiguchi. The CitST two-component system regulates the expression of the $\mathrm{Mg}$-citrate transporter in Bacillus subtilis. Mol. Microbiol. 37:898-912.

Yeats, C., Finn, R.D. and A. Bateman. 2002. The PASTA domain: a betalactam-binding domain. Trends Biochem. Sci. 27:438.

Yoshida, A. 1965. Enzymatic properties of malate dehydrogenase of Bacillus subtilis. J. Biol. Chem. 240:1118-1124.

Zhang, S. and W.G. Haldenwang. 2004. Guanine nucleotides stabilize the binding of Bacillus subtilis Obg to ribosomes. Biochem. Biophy.s Res. Commun. 322:569-569.

Żylicz, M., LeBowitz, J. H., McMacken, R., and C. Georgopoulos. 1983. The DnaK protein of Escherichia coli possesses an ATPase and autophosphorylating activity and is essential in an in vitro DNA replication system. Proc. Natl. Acad. Sci. U S A. 80:6431-6435. 


\section{Appendix}

\subsection{Materials}

\subsubsection{Chemicals}

[ $\left.\alpha-{ }^{32} \mathrm{P}\right]-\mathrm{ATP}(\mathrm{SCP}-207)$

$\left[\gamma-{ }^{32} \mathrm{P}\right]-\mathrm{ATP}$ (SCP-501)

$\left[\gamma-{ }^{32} \mathrm{P}\right]-\mathrm{GTP}(\mathrm{SCP}-402)$

Acrylamide

Adenosine 5'-triphosphate disodium salt solution

Agar

Agarose

Ammonium iron (III) citrate

Ammonium Peroxydisulfate

Antibiotics

Bromphenol blue

Coomassie Brilliant Blue, G250

Desthiobiotin

DL-Dithiothreitol

dNTPs

Ethidium bromide

D-Fructose-1,6-bisphosphate

D-Glucose

Glycerine

Immidazole

Isopropyl B-D-1- thiogalactopyranoside
Hartmann Analytic,

Braunschweig

Hartmann Analytic,

Braunschweig

Hartmann Analytic,

Braunschweig

Roth, Karlsruhe

Sigma, Taufkirchen

Roth, Karlsruhe

Peqlab, Erlangen

Sigma, Taufkirchen

Roth, Karlsruhe

Applichem, Darmstadt

Roth, Karlsruhe

Roth, Karlsruhe

IBA, Göttingen

Sigma, Taufkirchen

Fermentas, Lithuania

Roth, Karlsruhe

Sigma, Taufkirchen

Roth, Karlsruhe

Merck, Darmstadt

Sigma, Taufkirchen

Sigma, Taufkirchen 


\begin{tabular}{ll} 
DL-Malate & Applichem, Darmstadt \\
B-Mercaptoethanol & Roth, Karlsruhe \\
$\mathrm{NaF}$ & Sigma, Taufkirchen \\
$\mathrm{Ni}^{2+}$-nitrilotriacetic acid superflow & Qiagen, Hilden \\
Nutrient Broth & Roth, Karlsruhe \\
$\mathrm{Na}-$ Orthovanadate & Sigma, Taufkirchen \\
Pefabloc & Roth, Karlsruhe \\
Sodium Dodecyl Sulfate & Roth, Karlsruhe \\
Strep-Tactin Sepharose & IBA, Göttingen \\
Tetramethylethylenediamine (TEMED) & Roth, Karlsruhe \\
Tris(hydroxymethyl)aminomethane & Roth, Karlsruhe \\
Yeast extract & Oxoid, Hampshire, U.K. \\
\hline
\end{tabular}

Other chemicals were purchased from Merck, Serva, Sigma or Roth.

\subsubsection{Auxiliary materia}

Dialysis tube

Cuvettes (microlitre, plastic)

Gene amp reaction tubes

Glas pipette

Greiner tubes

Microlitre pipettes

$(2 \mu 1,200 \mu 1,1000 \mu \mathrm{l})$

non-returnable syringe

Poly-Prep Chromatography columns

Centrifuge cups
Roth, Karlsruhe

Greiner, Nürtingen

Applied Biosystems, USA

Ochs, Bovenden

Greiner, Nürtingen

Gilson, Düsseldorf

Becton Dickinson, Heidelberg

Bio-Rad, Munich

Beckmann, Munich 


\subsubsection{Instrumentation}

Steam autoclave

Biofuge fresco

Contamination meter

Frensh pressure cell press

Gel electrophoresis apparatus

Ice maschine

Image eraser

Horizontal shaker VXR basic

Hydro tech vacuum pump

Mini-Protean III System

Orbital shaker G10

Phosphor imagerStorm 860

$\mathrm{pH}$ meter

Refrigerated centrifuge

Scale

Special accuracy weighing machine

Spectral photometer

Standard power pack

Thermocycler

Ultra centrifuge, Sorvall Ultra Pro 80

Ultrasonic device

UV Transilluminator 2000

Vortex

Water-bath incubation system

Water desalination plant
Zirbus technology, Bad Grund

Heraeus Christ, Osterode

Berthold, Bad Wildbad

SLM Aminco, Lorch

PeqLab, Erlangen

Ziegra, Isernhagen

Molecular Dynamics, USA

IKA, Staufen

Bio-Rad, Munich

Bio-Rad, Munich

New Brunswick (Eppendorf), USA

Molecular Dynamics, USA

Knick Calimatic, Berlin

Kendro, Hanau

Sartorius, Göttingen

Sartorius, Göttingen

Amersham, Feiburg

Bio-Rad, Munich

Biometra, Göttingen

Thermo scientific, USA

Dr. Hielscher, Teltow

Bio-Rad, Munich

Bender \& Hobein, Bruchsal

GFL, Burgwedel

Millepore, Schwalbach 


\subsubsection{Commercial systems / software}

$1 \mathrm{~kb}$ DNA ladder

DNeasy Tissue Kit (50)

Nucleospin Plasmid

Qiaquick PCR Purification Kit
NEB Biolabs, Frankfurt / Main

Qiagen, Hilden

Machery-Nagel, Düren

Qiagen, Hilden

\section{Internet programs and software}

http://genolist.pasteur.fr/SubtiList/

http://genolist.pasteur.fr/Colibri/

http://www.ncbi.nlm.nih.gov/

http://tools.neb.com/NEBcutter2/

http://www.expasy.ch/

http://www.ebi.ac.uk/Tools/

clustalw2/index.html

http://www.subtiwiki.uni-

goettingen.de/

http://subtiwiki.uni-goettingen.de/

subtipathways.html
Institute Pasteur, sequence analysis,

Paris Bacillus subtilis

Institute Pasteur, sequence analysis,

Paris Escherichia coli

Natinal Institutes literature enquiry

of Health,

Berthesa, USA

NEB, USA

restriction sites analysis,

DNA

Swiss Institute of protein structures

Bioinformatics

European creation of alignments

Bioinformatics

Institute

University of database for

Göttingen Bacillus subtilis

University of

Göttingen

database for metabolic pathways of Bacillus

subtilis

iWorks

Apple, USA

Microsoft Office 2007

Windows 


\subsection{Oligonucleotides}

Oligonuleotides constructed in this work

\begin{tabular}{|c|c|c|}
\hline Name & Sequence $5^{`} \rightarrow 3^{` \#}$ & Description \\
\hline NP28 & $\begin{array}{l}\text { CTGCGGCATGACATTAATACACCTT } \\
\text { TAACGGCTC }\end{array}$ & $\begin{array}{l}\text { LFH-PCR (prkD), fwd, } \\
\text { up-fragment }\end{array}$ \\
\hline NP29 & $\begin{array}{l}\text { TATCGATACAACAATACTGGAAGCT } \\
\text { GGTCAAGATGAA }\end{array}$ & LFH-PCR ( $p r k D)$, rev, up-fragment \\
\hline NP30 & $\begin{array}{l}\text { TATCTACCTTTACGTATTCGGCATCA } \\
\text { GCTGTCGG }\end{array}$ & $\begin{array}{l}\text { LFH-PCR ( } p r k D) \text {, rev, } \\
\text { down-fragment; sequencing }\end{array}$ \\
\hline NP31 & $\begin{array}{l}\text { GTCAATTTGTTAATTGAACGGACG } \\
\text { ACATATCGTGAACTG }\end{array}$ & $\begin{array}{l}\text { LFH-PCR ( } p r k D), \text { fwd, } \\
\text { up-fragment; sequencing }\end{array}$ \\
\hline NP32 & $\begin{array}{l}\text { CCTATCACCTCAAATGGTTCGCTGC } \\
\text { ACCGCTTCCATTCGCGAGGATCTA }\end{array}$ & $\begin{array}{l}\text { LFH-PCR ( prkD), rev, } \\
\text { down-fragment }\end{array}$ \\
\hline NP33 & $\begin{array}{l}\text { CGAGCGCCTACGAGGAATTTGTAT } \\
\text { CGTTCTTTAGAGGGCGGTCAAATA } \\
\text { GCA }\end{array}$ & $\begin{array}{l}\text { LFH-PCR ( } p r k D), \text { fwd, } \\
\text { down-fragment; sequencing }\end{array}$ \\
\hline NP34 & $\begin{array}{l}\text { ATTGAGGACGATATGACTGTTGTTG } \\
\text { TCGTCCGGAT }\end{array}$ & $\begin{array}{l}\text { LFH-PCR (yabT), fwd, } \\
\text { up-fragment }\end{array}$ \\
\hline NP35 & $\begin{array}{l}\text { ATGACCCGCAGGAGATTGCCGATT } \\
\text { TGCTTAT }\end{array}$ & $\begin{array}{l}\text { LFH-PCR (yabT), fwd, up- } \\
\text { fragment, sequencing }\end{array}$ \\
\hline NP36 & $\begin{array}{l}\text { CTGTAAGAATTGCTCATCTTCCGTC } \\
\text { AGTGCT }\end{array}$ & $\begin{array}{l}\text { LFH-PCR }(y a b T) \text {, rev, down- } \\
\text { fragment }\end{array}$ \\
\hline NP37 & $\begin{array}{l}\text { TCCGCCCAATCGAGAAACTGCTGA } \\
\text { ATGTG }\end{array}$ & $\begin{array}{l}\text { LFH-PCR (yabT), rev, down- } \\
\text { fragment, sequencing }\end{array}$ \\
\hline NP38 & $\begin{array}{l}\text { CCTATCACCTCAAATGGTTCGCTGC } \\
\text { ATGCCAAACTCGTCAAAGCGTCGT }\end{array}$ & LFH-PCR (yabT), rev, up-fragment \\
\hline NP39 & $\begin{array}{l}\text { CGAGCGCCTACGAGGAATTTGTAT } \\
\text { CGTGAATGGTGCAAACTGCAGAGC } \\
\text { CTA }\end{array}$ & $\begin{array}{l}\text { LFH-PCR }(y a b T), \text { fwd, down- } \\
\text { fragment }\end{array}$ \\
\hline NP40 & $\begin{array}{l}\text { AAAGAATTCGTTTCTGTTGCCCATA } \\
\text { TCGGAGACAG }\end{array}$ & prkC-lacZ fusion (EcoRI) fwd \\
\hline NP41 & $\begin{array}{l}\text { AAAGGATCCATTCCCCCGCCGCCT } \\
\text { ATGACGCG }\end{array}$ & prkC-lacZ fusion (BamHI) rev \\
\hline
\end{tabular}




\section{\begin{tabular}{lll}
\hline Name & \multicolumn{1}{c}{ Sequence $\mathbf{5} \rightarrow \mathbf{3}^{`}$} & \multicolumn{1}{c}{ Description } \\
\hline NP42 & AAAGAATTCGAAGACCGAATCAAA & prkD-lacZ fusion (EcoRI) fwd \\
& TCAGGCAGCGGAA & \\
NP43 & AAAGGATCCATACCGAGGCACTCT & prkD-lacZ fusion (BamHI) rev
\end{tabular} TCGATTTTGTATTG}

NP44 AAAGAATTCGTGGAAATGGAAGAG yabT-lacZ fusion (EcoRI) fwd CTTTCTCCGG

NP45 AAAGGATCCACATGTCCATCTGATG yabT-lacZ fusion (BamHI) rev TTTCTGCCAAATACAC

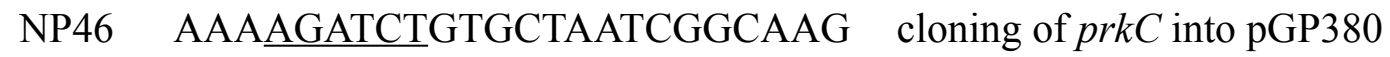
CGGATCAGCG (BglII) fwd

NP47 TTTCTGCAGTCATTATTCATCTTTCG cloning of prkC into pGP380 (PstI) GATACTCAATGGTTTTGTAGC rev

NP48 TTTCTGCAGTCATTACCACTTTTTT cloning of prkCc (kinase domain) CTTTTGCCGTTCTTCTTTGT into pGP380 (PstI) rev

NP49 AAAGGATCCATGGCATTAAAACTT cloning of prkD into pGP380 CTAAAAAAACTGCTATTTGACCGC (BamHI) fwd

NP50 TTTCTGCAGTTATCATGTGACCGAT cloning of prkD into pGP380 (PstI) TGAATGGCCCGGTT rev

NP51 AAA TTGACGAGTTTGGCATGTA (BglII) fwd

NP52 TTTCTGCAGTTATCAGATTAAGAAA cloning of yabT into pGP380 (PstI) AAGATAATATAGGCGAAATAAAGC rev

NP53 AAAGGATCCATGGTCAAGTCATTT cloning of $y x a L$ into pGP380 CGTATGAAAGCTTTGATTG (BamHI) fwd

NP54 TTTCTGCAGCTATCATTTCCCAAAA cloning of yxaL into pGP380 (PstI) GCCATCAGCTTCGTA rev

NP55 P-GGCAAAACAGTTAACCTTAAAT mutagenesis of $p t s H$ (S46C);

GTATTATGGGTGTTATGTCTTTA 5'-phosphate GGT

NP56 GCGTTCATGGCCTCCACCCAGATCT LFH-PCR ( $y m d B)$, fwd, upCATC

fragment

NP57 CGATGACTATATTCGTGAGATGGGT LFH-PCR ( $y m d B$ ), fwd, upGAGCAAACGACA 


\begin{tabular}{|c|c|c|}
\hline Name & Sequence $5^{`} \rightarrow 3^{` \#}$ & Description \\
\hline NP58 & $\begin{array}{l}\text { CCTATCACCTCAAATGGTTCGCTGG } \\
\text { CCCGGTGAACCGACAACATCTCCG }\end{array}$ & $\begin{array}{l}\text { LFH-PCR }(y m d B) \text {, rev, up- } \\
\text { fragment }\end{array}$ \\
\hline NP59 & $\begin{array}{l}\text { CCGAGCGCCTACGAGGAATTTGTA } \\
\text { TCGGACATTGACGATCAAACGAAA } \\
\text { AAAG }\end{array}$ & $\begin{array}{l}\text { LFH-PCR }(y m d B), \text { fwd, } \\
\text { down-fragment }\end{array}$ \\
\hline NP60 & $\begin{array}{l}\text { GCAGACACATACTCTCCCACTTTTA } \\
\text { CACTGCTGACAT }\end{array}$ & $\begin{array}{l}\text { LFH-PCR }(y m d B), \text { rev, down- } \\
\text { fragment }\end{array}$ \\
\hline NP61 & $\begin{array}{l}\text { AGTATTGGTACACACATGAGATTTT } \\
\text { CCTGTTAG }\end{array}$ & $\begin{array}{l}\text { LFH-PCR }(y m d B) \text {, rev, down- } \\
\text { fragment sequencing }\end{array}$ \\
\hline NP62 & $\begin{array}{l}\text { CAGCGAACCATTTGAGGTGATAGG } \\
\text { ATAGCTAGGGTAAGTAAATTGAGTA }\end{array}$ & $\begin{array}{l}\text { Spc-cassette, without terminator } \\
\text { from pGP961 (spec-fwd-kan) }\end{array}$ \\
\hline NP63 & $\begin{array}{l}\text { CGATACAAATTCCTCGTAGGCGCTC } \\
\text { GGCTACTAATTGAGAGAAGTTTCTA } \\
\text { TAGA }\end{array}$ & $\begin{array}{l}\text { Spc-cassette, without terminator } \\
\text { from pGP961 (spec-rev-kan) }\end{array}$ \\
\hline NP64 & $\begin{array}{l}\text { AGCAGGAAGCCATCCGTTATTTCA } \\
\text { GCAATTTGCGG }\end{array}$ & $\begin{array}{l}\text { LFH-PCR ( } p n p A), \text { fwd, } \\
\text { up-fragment }\end{array}$ \\
\hline NP65 & $\begin{array}{l}\text { GAATGGTACAAACGGATTCGGAGC } \\
\text { GAGCGGAA }\end{array}$ & $\begin{array}{l}\text { LFH-PCR }(p n p A), \text { fwd, } \\
\text { up-fragment, sequencing }\end{array}$ \\
\hline NP66 & $\begin{array}{l}\text { CCTATCACCTCAAATGGTTCGCTGT } \\
\text { AAAGACATGTTTTTCTTGTCCCAT }\end{array}$ & LFH-PCR ( $p n p A)$, rev, up-fragment \\
\hline NP67 & $\begin{array}{l}\text { CCGAGCGCCTACGAGGAATTTGTA } \\
\text { TCGGATAAACAAGGACGAGTGAAT } \\
\text { TTAT }\end{array}$ & $\begin{array}{l}\text { LFH-PCR ( } p n p A), \text { fwd, } \\
\text { down-fragment }\end{array}$ \\
\hline NP68 & $\begin{array}{l}\text { GTTCATTAGTCTTGTCGAGCTGCTC } \\
\text { GGAAATTCTTCC }\end{array}$ & $\begin{array}{l}\text { LFH-PCR ( } p n p A), \text { rev, } \\
\text { down-fragment }\end{array}$ \\
\hline NP69 & $\begin{array}{l}\text { GAGCGAACCACTTTGGCTTAACGC } \\
\text { CGATCG }\end{array}$ & $\begin{array}{l}\text { LFH-PCR ( } p n p A) \text {, rev, } \\
\text { down-fragment, sequencing }\end{array}$ \\
\hline NP70 & $\begin{array}{l}\text { AAAGGATCCATGACGAACGAAAGC } \\
\text { TTTAAATCAGGATTTGTATCCATT }\end{array}$ & $\begin{array}{l}\text { cloning of era into pGP } 380 \\
(\text { BamHI) fwd }\end{array}$ \\
\hline NP71 & $\begin{array}{l}\text { TTTCTGCAGTCATTAATATTCGTCCT } \\
\text { CTTTAAAGCCAAAATCGCG }\end{array}$ & $\begin{array}{l}\text { cloning of era into pGP380 (PstI) } \\
\text { rev }\end{array}$ \\
\hline NP72 & $\begin{array}{l}\text { AAAGGATCCATGTTTGTAGATCAG } \\
\text { GTCAAAGTATATGTAAAAGGC }\end{array}$ & $\begin{array}{l}\text { cloning of } o b g \text { into pGP380 } \\
(\text { Bam HI) fwd }\end{array}$ \\
\hline
\end{tabular}




\begin{tabular}{|c|c|c|}
\hline Name & Sequence $5 \rightarrow 3^{` \#}$ & Description \\
\hline NP73 & $\begin{array}{l}\text { TTTCTGCAGTCATTAATCAATAAATT } \\
\text { CAAATTCAAATTCCAGAAGCCTG }\end{array}$ & $\begin{array}{l}\text { cloning of } o b g \text { into pGP380 (PstI) } \\
\text { rev }\end{array}$ \\
\hline NP74 & $\begin{array}{l}\text { AAAGGATCCGTGAAGCAATTAAAA } \\
\text { TGGAGAACTGTAAATCCAGAAGA }\end{array}$ & $\begin{array}{l}\text { cloning of } y d i B \text { into pGP380 } \\
(B a m \mathrm{HI}) \mathrm{fwd}\end{array}$ \\
\hline NP75 & $\begin{array}{l}\text { TTTCTGCAGTCATTAATTGCTAATAT } \\
\text { TGTCATGTCTACTTAACTCCTCAC }\end{array}$ & $\begin{array}{l}\text { cloning of } y d i B \text { into pGP380 (Pst } \mathrm{I}) \\
\text { rev }\end{array}$ \\
\hline NP76 & $\begin{array}{l}\text { AAATCTAGAATGAAAGTCACAAAG } \\
\text { TCAGAAATCGTGATCAGTG }\end{array}$ & $\begin{array}{l}\text { cloning of } y s x C \text { into pGP } 380 \\
(X b a \mathrm{I}) \text { fwd }\end{array}$ \\
\hline NP77 & $\begin{array}{l}\text { TTTCTGCAGTCATTACCGGTTTATCA } \\
\text { TTTTTTTGATCGCTCCC }\end{array}$ & $\begin{array}{l}\text { cloning of } y s x C \text { into pGP380 (Pst I) } \\
\text { rev }\end{array}$ \\
\hline NP78 & $\begin{array}{l}\text { AAAAGATCTATGGGTAAACCTGTC } \\
\text { GTAGCCATTGTCGG }\end{array}$ & $\begin{array}{l}\text { cloning of } y p h C \text { into pGP } 380 \\
\text { (BglII) fwd }\end{array}$ \\
\hline NP79 & $\begin{array}{l}\text { TTTGTCGACTCATTATTTTCTAGCTC } \\
\text { TTGCAAATATTTTGATTGGTGTCC }\end{array}$ & $\begin{array}{l}\text { cloning of } y p h C \text { into pGP380 (SalI) } \\
\text { rev }\end{array}$ \\
\hline NP80 & $\begin{array}{l}\text { AAAGGATCCATGGCTTTAACAGCT } \\
\text { GGAATTGTTGGTTTGC }\end{array}$ & $\begin{array}{l}\text { cloning of yyaF into pGP380 } \\
(\text { BamHI) fwd }\end{array}$ \\
\hline NP81 & $\begin{array}{l}\text { TTTGTCGACTCATTATACATTAAATC } \\
\text { GGAAATGAATAACATCTCCGT }\end{array}$ & $\begin{array}{l}\text { cloning of yyaF into pGP380 (SalI) } \\
\text { rev }\end{array}$ \\
\hline NP82 & $\begin{array}{l}\text { AAAGGATCCATGGCAAGAGAGTTC } \\
\text { TCCTTAGAAAAAACTCGTAATAT }\end{array}$ & $\begin{array}{l}\text { cloning of fus } A \text { into pGP } 380 \\
(B a m \mathrm{HI}) \text { fwd }\end{array}$ \\
\hline NP83 & $\begin{array}{l}\text { TTTCTGCAGTCATTATTCGCCTTTAT } \\
\text { TTTTTTTGATAATTTCTTCTGC }\end{array}$ & $\begin{array}{l}\text { cloning of fus } A \text { into pGP380 (PstI) } \\
\text { rev }\end{array}$ \\
\hline NP84 & $\begin{array}{l}\text { AAAGGATCCATGGCTAAAGAAAAA } \\
\text { TTCGACCGTTCCAAATCACATG }\end{array}$ & $\begin{array}{l}\text { cloning of tufA into pGP } 380 \\
(B a m H I) \text { fwd }\end{array}$ \\
\hline NP85 & $\begin{array}{l}\text { TTTCTGCAGTCATTACTCAGTGATT } \\
\text { GTAGAAACAACGCCTGAAC }\end{array}$ & $\begin{array}{l}\text { cloning of tufA into pGP380 (PstI) } \\
\text { rev }\end{array}$ \\
\hline NP86 & $\begin{array}{l}\text { CATTGACTCAAGGATAACAAGATC } \\
\text { CTTCTC }\end{array}$ & sequencing of fus $A$, check rev \\
\hline NP87 & $\begin{array}{l}\text { GCGGCTGCTGTAGGTCTTAAAGAT } \\
\text { ACA }\end{array}$ & sequencing of $f u s A$, check fwd \\
\hline NP88 & $\begin{array}{l}\text { AAAGGATCCATGAAAGTCACAAAG } \\
\text { TCAGAAATCGTGA }\end{array}$ & $\begin{array}{l}\text { cloning of } y s x C \text { into pWH844 } \\
\text { (BamHI) fwd }\end{array}$ \\
\hline
\end{tabular}




\begin{tabular}{|c|c|c|}
\hline Name & Sequence $5^{`} \rightarrow 3^{` \#}$ & Description \\
\hline NP89 & $\begin{array}{l}\text { AAAGGATCCATGACGCATGTACGC } \\
\text { TTGACTACTC }\end{array}$ & $\begin{array}{l}\text { cloning of pgi into } \mathrm{pWH} 844 \\
(\text { Bam } \mathrm{HI}) \text { fwd }\end{array}$ \\
\hline NP90 & $\begin{array}{l}\text { TTTCTGCAGTCATTAATCTTCCAGA } \\
\text { CGTTTTTCAAGCTC }\end{array}$ & $\begin{array}{l}\text { cloning of pgi into pWH844 (PstI) } \\
\text { rev }\end{array}$ \\
\hline NP91 & $\begin{array}{l}\text { TTTCTGCAGTCATTAGATAGACAGT } \\
\text { TCTTTTGAAAGCTGATACATGTTTT } \\
\text { G }\end{array}$ & $\begin{array}{l}\text { cloning of } p f k A \text { into pWH844 } \\
(B a m \mathrm{HI}) \mathrm{rev}\end{array}$ \\
\hline NP92 & $\begin{array}{l}\text { TTTGTGCACTCATTACTCATATTGAC } \\
\text { CTTCCTCCAATAATTGAACGAATG }\end{array}$ & $\begin{array}{l}\text { cloning of tpiA into pWH844 } \\
(S d u \mathrm{I} \Leftrightarrow B s p 1286 \mathrm{I}) \mathrm{rev}\end{array}$ \\
\hline NP93 & $\begin{array}{l}\text { AAACTGCAGTCATTAAGCTTGGTTT } \\
\text { GAAGAACCAAATTCACGC }\end{array}$ & $\begin{array}{l}\text { cloning of } f b a A \text { into } \mathrm{pWH} 844 \\
(P s t \mathrm{I}) \text { fwd }\end{array}$ \\
\hline NP94 & $\begin{array}{l}\text { AAAGGATCCATGGGACAAGAAAA } \\
\text { ACATGTCTTTACCAT }\end{array}$ & $\begin{array}{l}\text { cloning of pnpA into pWH844 } \\
(B a m \mathrm{HI}) \text { fwd }\end{array}$ \\
\hline NP95 & $\begin{array}{l}\text { TTTCTGCAGTCATTAAGATTGTTGTT } \\
\text { CTTCTTTTTCTTTC }\end{array}$ & $\begin{array}{l}\text { cloning of } p n p A \text { into } \mathrm{pWH} 844 \\
(P s t \mathrm{I})\end{array}$ \\
\hline NP96 & $\begin{array}{l}\text { AAAGGTACCGATGAAACGAATAGG } \\
\text { GGTATTAACGAGCGG }\end{array}$ & $\begin{array}{l}\text { cloning of } f b a A \text { into pGP172 } \\
(K p n I) \text { fwd }\end{array}$ \\
\hline NP97 & $\begin{array}{l}\text { TTTGGATCCTCATTAGATAGACAGTT } \\
\text { CTTTTGAAAGCTGATACATGTTTTG }\end{array}$ & $\begin{array}{l}\text { cloning of } f b a A \text { into pGP172 } \\
(B a m \mathrm{HI}) \mathrm{rev}\end{array}$ \\
\hline NP98 & $\begin{array}{l}\text { P-GAACGTGGCTCGATTAAACTTTG } \\
\text { CTCACGGAGATTTTGAGGAGCA } \\
\text { CGG }\end{array}$ & mutagenesis of $p y k(\mathrm{~S} 36 \mathrm{~A})$ \\
\hline NP99 & $\begin{array}{l}\text { P- CCTGAAGGGCAAATGGGGAAC } \\
\text { GCCGAAGTAGGTCACTTAAATA } \\
\text { TC }\end{array}$ & mutagenesis of $p g m(\mathrm{~S} 36 \mathrm{~A})$ \\
\hline NP100 & $\begin{array}{l}\text { GACCGTGTAGAAAAAGCGTACCGC } \\
\text { GCAATG }\end{array}$ & LFH-PCR (eno), fwd, up-fragment \\
\hline NP101 & $\begin{array}{l}\text { ACGGAGGCGTGCACAGCCATATCA } \\
\text { ATCATT }\end{array}$ & $\begin{array}{l}\text { LFH-PCR (eno), fwd, up-fragment, } \\
\text { sequencing }\end{array}$ \\
\hline NP102 & $\begin{array}{l}\text { CCTATCACCTCAAATGGTTCGCTGT } \\
\text { ACTTCAACTTCAACTGTTGGGTTG }\end{array}$ & LFH-PCR (eno), rev, up-fragment \\
\hline NP103 & $\begin{array}{l}\text { CCGAGCGCCTACGAGGAATTTGTA } \\
\text { TCGTTCTTCGCATCGAAGATCAGTT } \\
\text { GGC }\end{array}$ & $\begin{array}{l}\text { LFH-PCR (eno), fwd, } \\
\text { down-fragment }\end{array}$ \\
\hline
\end{tabular}




\begin{tabular}{|c|c|c|}
\hline Name & Sequence $5{ }^{`} \rightarrow 3^{` \#}$ & Description \\
\hline NP104 & $\begin{array}{l}\text { ACCGGTGTAAGCAGAGTCGCGATT } \\
\text { TGGTCC }\end{array}$ & $\begin{array}{l}\text { LFH-PCR (eno), rev, } \\
\text { down-fragment }\end{array}$ \\
\hline NP105 & $\begin{array}{l}\text { TAGATCGGTATTTTTATAATTGCTGC } \\
\text { TCACTT }\end{array}$ & $\begin{array}{l}\text { LFH-PCR (eno), rev, } \\
\text { down-fragment, sequencing }\end{array}$ \\
\hline NP106 & $\begin{array}{l}\text { AAAGGATCCCTCACTTATTTAA } \boldsymbol{A} \boldsymbol{G} \boldsymbol{G} \\
\boldsymbol{A} \boldsymbol{G} \boldsymbol{G A A A C A A T C A T G T C C A A A A T C G ~} \\
\text { TAAAAATCATCGGTCGT }\end{array}$ & $\begin{array}{l}\text { cloning of eno }(\text { E. coli) into } \\
\text { pBQ200 }\left(\mathrm{RBS}_{\text {gapA }}\right)(\text { Bam HI) fwd }\end{array}$ \\
\hline NP107 & $\begin{array}{l}\text { TTTGTCGACTGATTATGCCTGGCCT } \\
\text { TTGATCTCTTTACG }\end{array}$ & $\begin{array}{l}\text { cloning of eno (E.coli) into } \\
\text { pBQ200 (SalI) rev }\end{array}$ \\
\hline NP108 & $\begin{array}{l}\text { AAAGGATCCCTCACTTATTTAA } \boldsymbol{A} \boldsymbol{G} \boldsymbol{G} \\
\boldsymbol{A} \boldsymbol{G} \boldsymbol{G A A A C A A T C A T G G G C A A G T A T T ~} \\
\text { TTGGAACAGACG }\end{array}$ & $\begin{array}{l}\text { cloning of } g \operatorname{lm} M \text { into pBQ } 200 \\
\left(\mathrm{RBS}_{\text {gapA }}\right)(\text { Bam } \mathrm{HI}) \text { fwd; } \\
\text { Schmidl et al., } 2010\end{array}$ \\
\hline NP109 & $\begin{array}{l}\text { TTTGTCGACCTATCACTCTAATCCCA } \\
\text { TTTCTGACCGG }\end{array}$ & $\begin{array}{l}\text { cloning of glmM into pWH844/ } \\
\text { pBQ200 (SalI) rev; } \\
\text { Schmidl et al., } 2010\end{array}$ \\
\hline NP110 & $\begin{array}{l}\text { GGCTATTCTCCGGAGCAGCCGATT } \\
\text { GTCA }\end{array}$ & $\begin{array}{l}\text { LFH-PCR }(g \operatorname{lm} M) \text {, fwd, } \\
\text { up-fragment; Schmidl et al., } 2010\end{array}$ \\
\hline NP111 & $\begin{array}{l}\text { CAGGAACGGACGACCAAAAGTTTT } \\
\text { CCCG }\end{array}$ & $\begin{array}{l}\text { LFH-PCR ( } g \operatorname{lm} M) \text {, fwd, } \\
\text { up-fragment, sequencing; } \\
\text { Schmidl et al., } 2010\end{array}$ \\
\hline NP112 & $\begin{array}{l}\text { CCTATCACCTCAAATGGTTCGCTGT } \\
\text { AAAGGCCAGCTCAGGTGTAAGCTC }\end{array}$ & $\begin{array}{l}\text { LFH-PCR ( } g l m M) \text {, rev, up- } \\
\text { fragment; Schmidl et al., } 2010\end{array}$ \\
\hline NP113 & $\begin{array}{l}\text { CCGAGCGCCTACGAGGAATTTGTA } \\
\text { TCGAGCGAAGACGAAAGAGCTGT } \\
\text { GCGAT }\end{array}$ & $\begin{array}{l}\text { LFH-PCR }(g \operatorname{lm} M), \text { fwd, } \\
\text { down- fragment; } \\
\text { Schmidl et al., } 2010\end{array}$ \\
\hline NP114 & $\begin{array}{l}\text { CATCGCCATCGCATCAGATGCTACG } \\
\text { ACGT }\end{array}$ & $\begin{array}{l}\text { LFH-PCR ( } g l m M) \text {, rev, down- } \\
\text { fragment; Schmidl et al., } 2010\end{array}$ \\
\hline NP115 & $\begin{array}{l}\text { TATAAGACGCACGTGTAATCACGTC } \\
\text { ACCATC }\end{array}$ & $\begin{array}{l}\text { LFH-PCR }(g \operatorname{lm} M), \text { rev, down - } \\
\text { fragment, sequencing; } \\
\text { Schmidl et al., } 2010\end{array}$ \\
\hline NP116 & $\begin{array}{l}\text { P-GCAGAGGCGGGCGTCATGATTTC } \\
\text { CGCTGCCCATAACCCAGTGCAG } \\
\text { GATAACGGCATCAA }\end{array}$ & $\begin{array}{l}\text { mutagenesis of } g \operatorname{lm} M(\mathrm{~S} 100 \mathrm{~A}) \text {; } \\
\text { Schmidl et al., } 2010\end{array}$ \\
\hline
\end{tabular}

NP117 AAAGGATCCATGGGCAAGTATTTT GGAACAGACG

cloning of glmM into pWH844

(BamHI) fwd; Schmidl et al., 2010 


\section{\begin{tabular}{ccc}
\hline Name & Sequence $\mathbf{5} \rightarrow \mathbf{3}^{`}$ & Description \\
\hline NP118 & P-GATATTTAAGTGACCTACTTCGG & mutagenesis of $p g m($ S62A) rev \\
& CGTTCCCCATTTGCCCTTCAGG &
\end{tabular} \\ NP119 TTTCTGCAGAAGAACGCTCGCACG cloning of pyk into pGP382 rev GCCTTGATAGAC (PstI) (without stop-codon) \\ NP120 AAAGGATCCCTCACTTATTTAAAGG cloning of $p y k$ into pBQ200/ AGGAAACAATCATGAGAAAAACTA pGP382 (BamHI) fwd AAATTGTT}

NP121 GGAGTAGACTTCATCGCACCATCTT sequencing of pyk (from 600b) fwd TC

NP122 GGTAAGGTTTCATAGGGAGGATGG AGATCC

LFH-PCR ( $p y k)$, fwd, up-fragment, sequencing

NP123 GGAATGAACGCAGCAGTTCGCGCA LFH-PCR (pyk), fwd, up-fragment GTAG

NP124 CCTATCACCTCAAATGGTTCGCTGG TACAAACAATTTTAGTTTTTCTCAT TTGGTTCAC

NP125 CCGAGCGCCTACGAGGAATTTGTA TCGGCGTCTGCTCTTATTACAGAAG AAGG

NP126 CTCTTAAAGGTTGAACACGCCGCA ACAATTGC

LFH-PCR (pyk), rev, downfragment

NP127 GCTGTTAGCTGTCACACGATCCGG

LFH-PCR ( $p y k)$, rev, downfragment, sequencing

NP128 AAAGGATCCCTCACTTATTTAA $\boldsymbol{A} \boldsymbol{G} \boldsymbol{G}$ $\boldsymbol{A} \boldsymbol{G G A A A C A A T C A T A T G G C A C A A A A ~}$ AACATTTAAAGTAACT

NP129 P-ATTACAGAAGAAGGCGGTTTGA mutagenesis of $p y k$ (S538A) CTGCCCATGCTGCGGTAGTCGG ATTA

NP130 P-GAAGAAGGCGGTTTGACTAGC GCTGCTGCGGTAGTCGGATTA

NP131 P-GCTGCGGTAGTCGGATTAGCCC mutagenesis of $p y k$ (S546A) TTGGCATCCCGGTTATCGT

NP132 GTACTGGCGAATTTGTTTTAATGTG TTATAC

sequencing of gapB fwd (with NP168, rev) 


\begin{tabular}{|c|c|c|}
\hline Name & Sequence $5^{`} \rightarrow 3^{` \#}$ & Description \\
\hline NP133 & $\begin{array}{l}\text { TTTAAGCTTTCATTACTCGCCGAGT } \\
\text { CCTTCGCT }\end{array}$ & $\begin{array}{l}\text { cloning of } p t s H \text { into } \mathrm{pBQ} 200 \\
\text { (HindIII) rev }\end{array}$ \\
\hline NP134 & $\begin{array}{l}\text { CCTATCACCTCAAATGGTTCGCTGC } \\
\text { CGTTAATACCGACTTTTACTGCCAT }\end{array}$ & LFH-PCR (gapA), rev, up-fragment \\
\hline NP135 & GCGAGCGTGTGCTGAGGGGCGAG & $\begin{array}{l}\text { LFH-PCR (gapA), fwd, } \\
\text { up-fragment }\end{array}$ \\
\hline NP136 & CAGGCTGACAGAACCCATCGGGCG & $\begin{array}{l}\text { LFH-PCR (gap } A) \text {, fwd, } \\
\text { up-fragment, sequencing }\end{array}$ \\
\hline NP137 & $\begin{array}{l}\text { CCGAGCGCCTACGAGGAATTTGTA } \\
\text { TCGCTCTTGGTACGATAACGAAAG } \\
\text { CGGC }\end{array}$ & $\begin{array}{l}\text { LFH-PCR (gapA), fwd, } \\
\text { down-fragment }\end{array}$ \\
\hline NP138 & $\begin{array}{l}\text { ACGAAAGTATAAGCAAGACCTCCG } \\
\text { CCGATG }\end{array}$ & $\begin{array}{l}\text { LFH-PCR (gap } A \text { ), rev, } \\
\text { down-fragment, sequencing }\end{array}$ \\
\hline NP139 & $\begin{array}{l}\text { AAAGGATCCCTCACTTATTTAA } \boldsymbol{A} \boldsymbol{G} \boldsymbol{G} \\
\boldsymbol{A} \boldsymbol{G} \boldsymbol{G A A A C A A T C A T G G C A G T A A A A G ~} \\
\text { TCGGTATTAACG }\end{array}$ & $\begin{array}{l}\text { cloning of gapA into pBQ200 } \\
\left(\mathrm{RBS}_{\text {gap } A}\right)(\text { Bam HI) fwd }\end{array}$ \\
\hline NP140 & $\begin{array}{l}\text { AAAGGATCCCTCACTTATTTAA } \boldsymbol{A} \boldsymbol{G} \boldsymbol{G} \\
\boldsymbol{A} \boldsymbol{G} \boldsymbol{G A A A C A A T C A T G C C T T T A G T T T C ~} \\
\text { TATGACGGAAATGTTGAATAC }\end{array}$ & $\begin{array}{l}\text { cloning of } f b a A \text { into pBQ200 } \\
\left(\mathrm{RBS}_{\text {gap } A}\right)(B a m \mathrm{HI}) \text { fwd }\end{array}$ \\
\hline NP141 & $\begin{array}{l}\text { CTGTGCCCGTCCCTGAGCAAAACA } \\
\text { TCAG }\end{array}$ & $\begin{array}{l}\text { LFH-PCR }(f b a A), \text { fwd, } \\
\text { up-fragment, sequencing }\end{array}$ \\
\hline NP142 & $\begin{array}{l}\text { GACAGATGGGAAGGGTTCTTTGCT } \\
\text { TTCGG }\end{array}$ & $\begin{array}{l}\text { LFH-PCR }(f b a A), \text { fwd, } \\
\text { up-fragment }\end{array}$ \\
\hline NP143 & $\begin{array}{l}\text { CCTATCACCTCAAATGGTTCGCTGC } \\
\text { ATTTCCGTCATAGAAACTAAAGGC } \\
\text { AT }\end{array}$ & LFH-PCR $(f b a A)$, rev, up-fragment \\
\hline NP144 & $\begin{array}{l}\text { CCGAGCGCCTACGAGGAATTTGTA } \\
\text { TCGCCTTGGACCAGCTCGTGAAGC } \\
\text { GATC }\end{array}$ & $\begin{array}{l}\text { LFH-PCR }(f b a A), \text { fwd, } \\
\text { down-fragment }\end{array}$ \\
\hline NP145 & $\begin{array}{l}\text { CGGCTCGAGAGACATCGTCGTCAT } \\
\text { CCGGC }\end{array}$ & $\begin{array}{l}\text { LFH-PCR ( } f b a A) \text {, rev, } \\
\text { down-fragment, sequencing }\end{array}$ \\
\hline NP146 & $\begin{array}{l}\text { CAATGATTCCTTCTCTGTAAAGCGG } \\
\text { CGTCAG }\end{array}$ & $\begin{array}{l}\text { LFH-PCR }(f b a A), \text { rev, } \\
\text { down-fragment }\end{array}$ \\
\hline NP147 & $\begin{array}{l}\text { CCGAGCGCCTACGAGGAATTTGTA } \\
\text { TCGCTTGCACCAACGTTATTAGACC } \\
\text { TTC }\end{array}$ & $\begin{array}{l}\text { LFH-PCR }(p g m), \text { fwd, } \\
\text { down-fragment }\end{array}$ \\
\hline
\end{tabular}




\begin{tabular}{|c|c|c|}
\hline Name & Sequence $5^{`} \rightarrow 3^{` \#}$ & Description \\
\hline NP148 & $\begin{array}{l}\text { CCAAGACGCTCAGTAAGAAGCTTG } \\
\text { TGGCC }\end{array}$ & $\begin{array}{l}\text { LFH-PCR ( } p g m) \text {, rev, } \\
\text { down-fragment, sequencing }\end{array}$ \\
\hline NP149 & $\begin{array}{l}\text { GGGTATTTAGAAACAAGCTCTTCAT } \\
\text { ACCAGTC }\end{array}$ & $\begin{array}{l}\text { LFH-PCR }(p g m), \text { rev, } \\
\text { down-fragment }\end{array}$ \\
\hline NP150 & $\begin{array}{l}\text { GGAAACCGCTTTTCCAAGTACATC } \\
\text { AAGCTC }\end{array}$ & $\begin{array}{l}\text { LFH-PCR (gap } A) \text {, rev, } \\
\text { down-fragment }\end{array}$ \\
\hline NP151 & $\begin{array}{l}\text { GAAGCCGTGGGACCGGGTTCAAAT } \\
\text { CGC }\end{array}$ & $\begin{array}{l}\text { LFH-PCR ( } p f k A), \text { fwd, } \\
\text { up-fragment, sequencing }\end{array}$ \\
\hline NP152 & $\begin{array}{l}\text { AATGTCACGGAGACAGAGCGTACG } \\
\text { GGGA }\end{array}$ & $\begin{array}{l}\text { LFH-PCR ( } p f k A), \text { fwd, up- } \\
\text { fragment }\end{array}$ \\
\hline NP153 & $\begin{array}{l}\text { CCTATCACCTCAAATGGTTCGCTGC } \\
\text { CGCTCGTTAATACCCCTATTCGTTT } \\
\text { CAT }\end{array}$ & LFH-PCR ( $p f k A)$, rev, up-fragment \\
\hline NP154 & $\begin{array}{l}\text { CCGAGCGCCTACGAGGAATTTGTA } \\
\text { TCGGCTTGTAGACCATGATATTATA } \\
\text { GAAATACTTG }\end{array}$ & $\begin{array}{l}\text { LFH-PCR }(p f k A), \text { fwd, } \\
\text { down-fragment }\end{array}$ \\
\hline NP155 & GCTTCCGCACGAGTCGGACGCGGG & $\begin{array}{l}\text { LFH-PCR }(p f k A), \text { rev, } \\
\text { down-fragment }\end{array}$ \\
\hline NP156 & $\begin{array}{l}\text { CGGGTAACTTCCGGCAGCAGTTTC } \\
\text { ACCAG }\end{array}$ & $\begin{array}{l}\text { LFH-PCR ( } p f k A) \text {, rev, } \\
\text { down-fragment, sequencing }\end{array}$ \\
\hline NP157 & $\begin{array}{l}\text { AAAGGATCCCTCACTTATTTAA } \boldsymbol{A} \boldsymbol{G} \boldsymbol{G} \\
\boldsymbol{A} \boldsymbol{G} \boldsymbol{G A A A C A A T C A T G A A A C G A A T A G ~} \\
\text { GGGTATTAACGAGCGG }\end{array}$ & $\begin{array}{l}\text { cloning of } p f k A \text { into } \mathrm{pBQ} 200 \\
\left(\mathrm{RBS}_{\text {gap } A}\right)(\text { Bam } \mathrm{HI}) \text { fwd }\end{array}$ \\
\hline NP158 & $\begin{array}{l}\text { AAAGGATCCCTCACTTATTTAA } \boldsymbol{A} \boldsymbol{G} \boldsymbol{G} \\
\boldsymbol{A} \boldsymbol{G} \boldsymbol{G A A A C A A T C A T G C C A T A C A T T G T ~} \\
\text { TGATGTTTATGCACGCGAAG }\end{array}$ & $\begin{array}{l}\text { cloning of eno into pBQ200 } \\
\left(\mathrm{RBS}_{\text {gapA }}\right)(\text { Bam } \mathrm{HI}) \text { fwd }\end{array}$ \\
\hline NP159 & GCGGTTGCTGTGTGATCGG & sequencing of $c c p N$, fwd \\
\hline NP160 & GCCGTTTCACCGACGGAATCCG & sequencing of $c c p N$, rev \\
\hline NP161 & $\begin{array}{l}\text { ATTATAATACAAACTTCACAAAGAT } \\
\text { GCTA }\end{array}$ & sequencing of $y q f L$, rev \\
\hline NP162 & $\begin{array}{l}\text { GCGGTTGCTGCCATCGTATTACCGG } \\
\text { CA }\end{array}$ & $\begin{array}{l}\text { LFH-PCR (gapB), fwd, } \\
\text { up-fragment, sequencing }\end{array}$ \\
\hline NP163 & $\begin{array}{l}\text { GAGGTCAATGAAGTTAATATAGGTG } \\
\text { CCCCAAATG }\end{array}$ & $\begin{array}{l}\text { LFH-PCR (gapB), fwd, } \\
\text { up-fragment }\end{array}$ \\
\hline NP164 & $\begin{array}{l}\text { CCTATCACCTCAAATGGTTCGCTGC } \\
\text { GTTGATCGCTACTTTTACCTTCAT }\end{array}$ & LFH-PCR (gapB), rev,up-fragment \\
\hline
\end{tabular}




\begin{tabular}{|c|c|c|}
\hline Name & Sequence $5 \mathbf{5}^{`} \mathbf{3}^{` \#}$ & Description \\
\hline NP165 & $\begin{array}{l}\text { CCGAGCGCCTACGAGGAATTTGTA } \\
\text { TCGGAATGGGGCTACTCCTGCAGA } \\
\text { GTTG }\end{array}$ & $\begin{array}{l}\text { LFH-PCR (gapB), fwd, } \\
\text { down-fragment }\end{array}$ \\
\hline NP166 & $\begin{array}{l}\text { AATCGACTTTCCGTCATCCACAGG } \\
\text { CCG }\end{array}$ & $\begin{array}{l}\text { LFH-PCR (gapB), rev, } \\
\text { down-fragment }\end{array}$ \\
\hline NP167 & $\begin{array}{l}\text { CACAACGATGAGCGGGGTTTCCTC } \\
\text { CAC }\end{array}$ & $\begin{array}{l}\text { LFH-PCR ( } \operatorname{gap} B) \text {, rev, } \\
\text { down-fragment sequencing }\end{array}$ \\
\hline NP168 & $\begin{array}{l}\text { CTGTGTTTAAGTCTAATTTGCAAGG } \\
\text { TGCG }\end{array}$ & $\begin{array}{l}\text { sequencing of gapB rev } \\
\text { (with NP132 rev) }\end{array}$ \\
\hline $\begin{array}{l}\text { cat- } \\
\text { fwd } \\
(\text { kan) }\end{array}$ & $\begin{array}{l}\text { CAGCGAACCATTTGAGGTGATAGG } \\
\text { CGGCAATAGTTACCCTTATTATCAA } \\
\text { G }\end{array}$ & $\begin{array}{l}\text { construction of mutants by LFH- } \\
\text { PCR }\end{array}$ \\
\hline $\begin{array}{l}\text { cat-rev } \\
\text { (kan) }\end{array}$ & $\begin{array}{l}\text { CGATACAAATTCCTCGTAGGCGCTC } \\
\text { GGCCAGCGTGGACCGGCGAGGCTA } \\
\text { GTTACCC }\end{array}$ & $\begin{array}{l}\text { construction of mutants by LFH- } \\
\text { PCR }\end{array}$ \\
\hline $\begin{array}{l}\text { cat- } \\
\text { check } \\
\text { fwd }\end{array}$ & ССТTCTACСCATTATTACAGCAGG & sequencing of mutants; LFH-PCR \\
\hline $\begin{array}{l}\text { cat- } \\
\text { check } \\
\text { rev }\end{array}$ & $\begin{array}{l}\text { GTCTGCTTTCTTCATTAGAATCAAT } \\
\text { CC }\end{array}$ & sequencing of mutants; LFH-PCR \\
\hline $\begin{array}{l}\text { mls- } \\
\text { fwd } \\
\text { (kan) }\end{array}$ & $\begin{array}{l}\text { CAGCGAACCATTTGAGGTGATAGG } \\
\text { GATCCTTTAACTCTGGCAACCCTC }\end{array}$ & $\begin{array}{l}\text { construction of mutants by LFH- } \\
\text { PCR }\end{array}$ \\
\hline $\begin{array}{l}\text { mls- } \\
\text { rev } \\
\text { (kan) }\end{array}$ & $\begin{array}{l}\text { CGATACAAATTCCTCGTAGGCGCTC } \\
\text { GGGCCGACTGCGCAAAAGACATAA } \\
\text { TCG }\end{array}$ & $\begin{array}{l}\text { construction of mutants by LFH- } \\
\text { PCR }\end{array}$ \\
\hline $\begin{array}{l}\text { mls- } \\
\text { check } \\
\text { rev }\end{array}$ & GTTTTGGTCGTAGAGCACACGG & sequencing of mutants; LFH-PCR \\
\hline $\begin{array}{l}\text { mls- } \\
\text { check } \\
\text { fwd }\end{array}$ & CСТTAAAACATGCAGGAATTGACG & sequencing of mutants; LFH-PCR \\
\hline $\begin{array}{l}\text { spec- } \\
\text { fwd } \\
(\mathrm{kan})\end{array}$ & $\begin{array}{l}\text { CAGCGAACCATTTGAGGTGATAGG } \\
\text { GACTGGCTCGCTAATAACGTAACG } \\
\text { TGACTGGCAAGAG }\end{array}$ & $\begin{array}{l}\text { construction of mutants by LFH- } \\
\text { PCR }\end{array}$ \\
\hline
\end{tabular}




\begin{tabular}{lll}
\hline Name & \multicolumn{1}{c}{ Sequence $\mathbf{5} \rightarrow \mathbf{3}^{` \#}$} & \multicolumn{1}{c}{ Description } \\
\hline spec- & CGATACAAATTCCTCGTAGGCGCTC & construction of mutants by LFH- \\
rev & GGCGTAGCGAGGGCAAGGGTTTAT & PCR \\
$(\mathrm{kan})$ & TGTTTTCTAAAATCTG & \\
& & \\
spec & GTTATCTTGGAGAGAATATTGAATG & sequencing of mutants; LFH-PCR \\
check & GAC & \\
fwd & & \\
spec & CGTATGTATTCAAATATATCCTCCTC & sequencing of mutants; LFH-PCR \\
check & AC & \\
rev & & \\
\hline
\end{tabular}

\# restriction sites are underlined, introduced mutations are bold, promoters are italic,

$P$ indicates 5'-phosphorylation;

stop-codons are italic and underlined

LFH-PCR: long flanking homology PCR

\section{Oligonucleotides used in this work}

\begin{tabular}{|c|c|c|}
\hline Name & Sequence $5{ }^{`} \rightarrow 3^{`}$ & Reference \\
\hline$\overline{\text { EW1 }}$ & $\begin{array}{l}\text { AAAGGATCCATGAAACGAATAGGGGTATTAACGA } \\
\text { GCGG }\end{array}$ & $\begin{array}{l}\text { Commichau } \\
\text { et al., } 2009\end{array}$ \\
\hline EW2 & $\begin{array}{l}\text { TTTGTCGACTCATTAGATAGACAGTTCTTTTGAAA } \\
\text { GCTGAT }\end{array}$ & $\begin{array}{l}\text { Commichau } \\
\text { et al., } 2009\end{array}$ \\
\hline EW3 & $\begin{array}{l}\text { AAAGGATCCATGCCTTTAGTTTCTATGACGGAAAT } \\
\text { GTTGAATAC }\end{array}$ & $\begin{array}{l}\text { Commichau } \\
\text { et al., } 2009\end{array}$ \\
\hline EW4 & $\begin{array}{l}\text { TTTGTCGACTCATTAAGCTTGGTTTGAAGAACCAA } \\
\text { ATTCACGC }\end{array}$ & $\begin{array}{l}\text { Commichau } \\
\text { et al., } 2009\end{array}$ \\
\hline EW5 & $\begin{array}{l}\text { AAAGGATCCATGAGAAAACCAATTATCGCCGGTA } \\
\text { ACTGG }\end{array}$ & $\begin{array}{l}\text { Commichau } \\
\text { et al., } 2009\end{array}$ \\
\hline EW8 & $\begin{array}{l}\text { TTTGTCGACTCATTAAAGACCTTTTTTTGCGATGTA } \\
\text { AGCTGCAAGGTC }\end{array}$ & $\begin{array}{l}\text { Commichau } \\
\text { et al., } 2009\end{array}$ \\
\hline EW9 & $\begin{array}{l}\text { AAAGGATCCATGAATAAAAAAACTCTCAAAGACA } \\
\text { TCGACGTAAAAGGC }\end{array}$ & $\begin{array}{l}\text { Commichau } \\
\text { et al., } 2009\end{array}$ \\
\hline EW12 & $\begin{array}{l}\text { TTTGTCGACTCATTATTTTTGAATTAAAGATGTTCC } \\
\text { TGTCATTTC }\end{array}$ & $\begin{array}{l}\text { Commichau } \\
\text { et al., } 2009\end{array}$ \\
\hline EW14 & $\begin{array}{l}\text { TTTGTCGACTCATTACTTGTTTAAGTTGTAGAAAGA } \\
\text { GTTGATACCGTGG }\end{array}$ & $\begin{array}{l}\text { Commichau } \\
\text { et al., } 2009\end{array}$ \\
\hline MA4 & $\begin{array}{l}\text { AAAGGATCCCTCACTTATTTAA } \boldsymbol{A} \boldsymbol{G} \boldsymbol{G} \boldsymbol{A} \boldsymbol{G} \boldsymbol{G} \text { AAACAAT } \\
\text { CATGAGTAAAAAACCAGCTGCACTC }\end{array}$ & Arnold, 2009 \\
\hline
\end{tabular}




\subsection{Plasmids}

\section{Plasmids constructed in this work}

\begin{tabular}{|c|c|c|}
\hline Name & Construction & Reference \\
\hline pGP390 & pGP380 + prkD gene (NP49-NP50) via BamHI/PstI & - \\
\hline pGP391 & pGP380 (BamHI / PstI $)+y a b T(\mathrm{NP} 51 / \mathrm{NP} 52)$ via BglII/PstI & - \\
\hline pGP392 & pGP380 + yxaL (NP53/NP54) via BamHI / Pst I & - \\
\hline pGP393 & $\mathrm{pWH} 844+p f k A($ EW1-NP91) via BamHI / PstI & - \\
\hline pGP394 & $\begin{array}{l}\mathrm{pWH} 844(\text { BamHI / PstI })+t p i A(\mathrm{EW} 5 / \mathrm{NP} 92) \text { via } \\
\text { BamHI/SduI }\end{array}$ & - \\
\hline pGP395 & $\mathrm{pWH} 844+f b a A(\mathrm{EW} 3 / \mathrm{NP} 93)$ via BamHI/Pst & - \\
\hline pGP396 & $\begin{array}{l}\text { pWH844 + pgm (S62A), (pgmfwd/pgmrev M:NP99) via } \\
\text { BamHI/SalI }\end{array}$ & - \\
\hline pGP397 & $\begin{array}{l}\text { pWH844 + pyk (S36A) (pykfwd/pykrev/M:NP98) via } \\
\text { BamHI/PstI }\end{array}$ & - \\
\hline pGP398 & pWH844 + pgi (NP89/NP90) via BamHI/PstI & - \\
\hline pGP399 & pBQ200 + eno (E. coli); (NP106/NP107) via BamHI/SalI & - \\
\hline pGP400 & $\mathrm{pBQ} 200+g \operatorname{lm} M(\mathrm{NP} 108 / \mathrm{NP} 109)$ via BamHI/SalI & $\begin{array}{l}\text { Schmidl } \\
\text { et al., } 2010\end{array}$ \\
\hline pGP826 & $\begin{array}{l}\text { pWH844 + ptsH (NP27/SH83) via BamHI/HindIII } \\
(\text { HPr-S12A) }\end{array}$ & - \\
\hline pGP827 & $\begin{array}{l}\text { pWH844 + ptsH1 (NP27/SH83) via BamHI / HindIII } \\
\text { (from pGP371) (HPr-S12A/S46A) }\end{array}$ & - \\
\hline pGP828 & pGP184 $\mathrm{Cm}^{\mathrm{R}}($ EcoRI $) \rightarrow$ pGP821 $($ prkD $)(M f e \mathrm{I})$ & - \\
\hline pGP829 & pAC7 + prkC-lacZ fusion (NP40/NP41) via EcoRI/BamHI & - \\
\hline pGP830 & $\mathrm{pAC} 7+$ prkD-lacZ fusion (NP42/NP43) via EcoRI/BamHI & - \\
\hline pGP831 & $\mathrm{pAC} 7+y a b T-l a c Z$ fusion (NP44/NP45) via EcoRI/BamHI & - \\
\hline pGP832 & pGP380 + prkC (NP46/NP47) via BglII/PstI & - \\
\hline pGP833 & pGP380 + ydiB (NP74/NP75) via BamHI/PstI & - \\
\hline pGP834 & pGP380 + ysxC (NP76/NP77) via XbaI/PstI & - \\
\hline
\end{tabular}




\begin{tabular}{|c|c|c|}
\hline Name & Construction & Reference \\
\hline pGP835 & pGP380 + obg (NP72/NP73) via BamHI/PstI & - \\
\hline pGP836 & pGP380 + yyaF (NP80/NP81) via BamHI/SalI & - \\
\hline pGP837 & pGP380 + era (NP70/NP71)via BamHI/PstI & - \\
\hline pGP838 & pWH844 + pnpA (NP94/NP95) via BamHI/PstI & - \\
\hline pGP839 & pGP380 + tufA (NP84/NP85) via BamHI/PstI & - \\
\hline pGP840 & pGP380 + fusA (NP82/NP83) via BamHI/PstI & - \\
\hline pGP841 & pWH844 + ydiB (gel extraction, pGP833) via BamHI/PstI & - \\
\hline pGP842 & pWH844 + ysxC (NP88/NP77) via BamHI/PstI & - \\
\hline pGP843 & pWH844 + obg (gel extraction, pGP835) via BamHI/PstI & - \\
\hline pGP844 & pWH844 + yyaF (gel extraction, pGP836) via BamHI/SalI & - \\
\hline pGP845 & pWH844 + era (gel extraction, pGP837) via BamHI/PstI & - \\
\hline pGP846 & pWH844 + yphC (NP78/NP79) via BamHI/SalI & - \\
\hline pGP847 & pWH844 + tufA (gel extractionGP839) via BamHI/PstI & - \\
\hline pGP848 & pWH844 + fusA (gel extraction, pGP840) via BamHI/PstI & - \\
\hline pGP849 & $\begin{array}{l}\text { pGP380 + prkC-kinase domain, (NP46/NP48) via } \\
\text { BglII/PstI }\end{array}$ & - \\
\hline pGP1401 & pWH844 + glmM (NP117/NP109) via BamHI/SalI & $\begin{array}{l}\text { Schmidl } \\
\text { et al., } 2010\end{array}$ \\
\hline pGP1402 & $\begin{array}{l}\text { pBlueskript KS }(+)+g \operatorname{lm} M(\mathrm{GlmM} / \mathrm{S} 100 \mathrm{~A}) \\
(\mathrm{NP} 108 / \mathrm{NP} 109 \text { /M:NP116) via BamHI/SalI }\end{array}$ & - \\
\hline pGP1403 & $\begin{array}{l}\text { pBQ200 + glmM }(\mathrm{GlmM} / \mathrm{S} 100 \mathrm{~A}) \text { (gel extraction, pGP1402) } \\
\text { via } B a m \mathrm{HI} / \text { SalI }\end{array}$ & $\begin{array}{l}\text { Schmidl } \\
\text { et al., } 2010\end{array}$ \\
\hline pGP1404 & $\begin{array}{l}\text { pBlueskript KS }(+)+g \operatorname{lm} M(\mathrm{GlmM} / \mathrm{S} 100 \mathrm{~A}) \\
(\mathrm{NP} 117 / \mathrm{NP} 109 / \mathrm{M}: \mathrm{NP} 116) \text { via BamHI/SalI }\end{array}$ & - \\
\hline pGP1405 & $\begin{array}{l}\text { pWH844 }+g \operatorname{lm} M(\mathrm{GlmM} / \mathrm{S} 100 \mathrm{~A}) \\
(\text { gel extraction, } \mathrm{pGP} 1404 \text { via BamHI/SalI }\end{array}$ & $\begin{array}{l}\text { Schmidl } \\
\text { et al., } 2010\end{array}$ \\
\hline pGP1406 & $\begin{array}{l}\text { pWH844 + prkC-kinase domain (NP46/NP48) via } \\
\text { BglII/PstI }\end{array}$ & - \\
\hline
\end{tabular}




\begin{tabular}{|c|c|c|}
\hline Name & Construction & Reference \\
\hline pGP1407 & pWH844 + prkD (NP49/NP50) via BamHI/PstI & - \\
\hline pGP1408 & $\mathrm{pWH} 844+y a b T(\mathrm{NP51/NP52)}$ via BglII/PstI & - \\
\hline pGP1409 & pGP380 + pyk (pykfwd/pykrev) via BamHI/PstI & - \\
\hline pGP1410 & pGP382 + pyk (NP119/NP120) via BamHI/PstI & - \\
\hline pGP1411 & pBQ200 + pyk (NP120/pykrev) via BamHI/PstI & - \\
\hline pGP1412 & $\begin{array}{l}\text { pGP380 + pyk (Pyk/S36A) (pykfwd/pykrev/ (M:NP98)) via } \\
\text { BamHI/SalI }\end{array}$ & - \\
\hline pGP1413 & $\begin{array}{l}\text { pGP382 + pyk (Pyk/S36A) (NP119/NP120/(M:NP98)) via } \\
\text { BamHI/PstI; }\end{array}$ & - \\
\hline pGP1414 & $\begin{array}{l}\text { pBQ200 + pyk (Pyk/S36A) (NP120/pykrev(M:NP98)) via } \\
\text { BamHI/PstI }\end{array}$ & - \\
\hline pGP1415 & pBQ200 + ptsH (NP128/NP133) via BamHI/HindIII & - \\
\hline pGP1416 & $\begin{array}{l}\mathrm{pBQ} 200+p t s H(\mathrm{HPr} / \mathrm{H} 15 \mathrm{~A})(\mathrm{NP} 128 / \mathrm{NP} 133 \text { from QB5250) } \\
\text { via Bam HI/HindIII }\end{array}$ & - \\
\hline pGP1417 & $\begin{array}{l}\mathrm{pBQ} 200+p t s H(\mathrm{NP} 128 / \mathrm{NP} 133 \text { from pGP826) via } \\
\text { Bam HI/HindIII }\end{array}$ & - \\
\hline pGP1418 & $\begin{array}{l}\text { pWH844 + tpiA }(\mathrm{Tpi} / \mathrm{S} 213 \mathrm{~A})(\text { BamHI/SalI })(\mathrm{EW} 5 / \mathrm{NP} 92 \\
\text { from pGP1512) via BamHI/SduI }\end{array}$ & - \\
\hline pGP1419 & $\begin{array}{l}\mathrm{pWH} 844+p g k(\mathrm{Pgk} / \mathrm{S} 183 \mathrm{~A})(\mathrm{EW} 9 / \mathrm{EW} 10 \text { from pG1514) } \\
\text { via BamHI/SalI }\end{array}$ & - \\
\hline pGP1420 & $\begin{array}{l}\text { pWH } 844+p g k(\mathrm{Pgk} / \mathrm{T} 299 \mathrm{~A})(\mathrm{EW} 9 / \mathrm{EW} 10 \text { from pG1515) } \\
\text { via BamHI/SalI }\end{array}$ & - \\
\hline pGP1421 & $\begin{array}{l}\text { pWH844 + pgk (Pgk/S183A / T299A) (EW9/EW10 from } \\
\text { pGP1516) BamHI/SalI }\end{array}$ & - \\
\hline pGP1422 & pBQ200 +.pfk (NP157/EW2) via BamHI/SalI & - \\
\hline pGP1423 & $\mathrm{pBQ} 200+f b a A(\mathrm{NP} 140 / \mathrm{EW} 4)$ via BamHI/SalI & - \\
\hline pGP1424 & $\mathrm{pBQ} 200+$ gapA $(\mathrm{NP} 139 / \mathrm{EW} 8)$ via BamHI/SalI & - \\
\hline pGP1425 & pBQ200 + pgm (MA4/EW 12) via BamHI/SalI & - \\
\hline pGP1426 & pBQ200 + eno (NP158/EW14) via BamHI/SalI & - \\
\hline pGP1427\# & $\begin{array}{l}\mathrm{pWH} 844+p y k(\mathrm{Pyk} / \mathrm{S} 538 \mathrm{~A})(\mathrm{M} 13 \mathrm{puc} \mathrm{fwd} / \mathrm{M} 13 \mathrm{puc} \mathrm{rev} / \\
(\mathrm{M}: \mathrm{NP} 129) \text { from } \mathrm{pGP} 1410) \text { via BamHI/Pst }\end{array}$ & - \\
\hline
\end{tabular}




\begin{tabular}{clc}
\hline Name & \multicolumn{1}{c}{ Construction } & Reference \\
\hline pGP1428\# & $\begin{array}{l}\text { pWH844 + pyk (Pyk/H539A) (M13 puc fwd/M13 puc rev/ } \\
\text { (M:NP130) from pGP1410) via BamHI/Pst }\end{array}$ & - \\
pGP1429\# & $\begin{array}{l}\text { pWH844 + pyk (Pyk/S546A) } \\
\text { (M13 puc fwd/M13 puc rev/(M:NP131) from pGP1410) via }\end{array}$ & - \\
& BamHI/Pst
\end{tabular}

\section{Plasmids used in this work}

\begin{tabular}{|c|c|c|c|}
\hline Plasmid & Resistance & Description & Referenz \\
\hline $\mathrm{pAC7}$ & $\begin{array}{l}\text { ampicillin/ } \\
\text { chloram- } \\
\text { phenicol }\end{array}$ & construction of LacZ-fusion & Weinrauch et al., 1991 \\
\hline pAG2 & ampicillin & $\begin{array}{l}\text { overexpression of } \mathrm{His}_{6}-\mathrm{HPr} \text { in } E \text {. } \\
\text { coli }\end{array}$ & Galinier et al., 1997 \\
\hline $\begin{array}{l}\text { pBlue- } \\
\text { skript } \\
\text { KS (+) }\end{array}$ & ampicillin & cloning & Stratagene, USA \\
\hline pDG646 & ampicillin & PCR template for ery-cassette & $\begin{array}{c}\text { Guérout-Fleury et al., } \\
1995\end{array}$ \\
\hline
\end{tabular}




\begin{tabular}{|c|c|c|c|}
\hline Plasmid & Resistance & Description & Referenz \\
\hline pDG780 & ampicillin & PCR template for kan-cassette & $\begin{array}{c}\text { Guérout-Fleury et al., } \\
1995\end{array}$ \\
\hline pDG1726 & ampicillin & PCR template for spec-cassette & $\begin{array}{c}\text { Guérout-Fleury et al., } \\
1995\end{array}$ \\
\hline pGEM-cat & ampicillin & PCR template for cat-cassette & $\begin{array}{c}\text { Guérout-Fleury et al., } \\
1995\end{array}$ \\
\hline pBQ200 & $\begin{array}{l}\text { ampicillin/ } \\
\text { erythromycin }\end{array}$ & expression in $B$. subtilis & $\begin{array}{c}\text { Martin-Verstraete et } \\
\text { al., } 1994\end{array}$ \\
\hline pGP371 & ampicillin & ptsH1 in pWH844 & Halbedel, 2006 \\
\hline pGP380 & $\begin{array}{l}\text { ampicillin/ } \\
\text { erythromycin }\end{array}$ & $\begin{array}{l}\text { expression in B. subtilis with } \\
\text { N-terminal Strep-tag }\end{array}$ & Herzberg et al., 2007 \\
\hline pGP382 & $\begin{array}{l}\text { ampicillin/ } \\
\text { erythromycin }\end{array}$ & $\begin{array}{l}\text { expression in B. subtilis with } \\
\text { N-terminal Strep-tag }\end{array}$ & Herzberg et al., 2007 \\
\hline pGP821 & ampicillin & construction of $p r k D$ mutant & Pietack, 2007 \\
\hline pGP826 & ampicillin & $\begin{array}{l}\text { ptsH }(\mathrm{HPr} \mathrm{S} 12 \mathrm{~A}) \text { in pWH844 } \\
\text { (expression with N-terminal His6- } \\
\text { tag in } E . \text { coli) }\end{array}$ & Pietack, 2007 \\
\hline pGP1100 & ampicillin & $\begin{array}{l}\text { pyk in pWH844 (expression with } \\
\text { N-terminal His6-tag in E. coli) }\end{array}$ & Schilling, 2007 \\
\hline pGP1101 & ampicillin & $\begin{array}{l}\text { pgm in pWH844 (expression with } \\
\text { N-terminal His6-tag in E. coli) }\end{array}$ & Schilling, 2007 \\
\hline pGP1102 & ampicillin & $\begin{array}{l}p g k \text { in pWH844 (expression with } \\
\text { N-terminal His6-tag in E. coli) }\end{array}$ & Schilling, 2007 \\
\hline pGP1500 & $\begin{array}{l}\text { ampicillin/ } \\
\text { erythromycin }\end{array}$ & $\begin{array}{l}\text { pgm/eno in } \mathrm{pBQ} 200 \text { (expression in } \\
\text { B. subtilis) }\end{array}$ & Arnold, 2009 \\
\hline pGP1501 & $\begin{array}{l}\text { ampicillin/ } \\
\text { erythromycin }\end{array}$ & $\begin{array}{l}\text { pgm }(\mathrm{S} 62 \mathrm{~A}) / \text { eno in } \mathrm{pBQ} 200 \\
(\text { expression in B. subtilis) }\end{array}$ & Arnold, 2009 \\
\hline pGP1511 & $\begin{array}{l}\text { ampicillin/ } \\
\text { erythromycin }\end{array}$ & $\begin{array}{l}\text { tpiA in } \mathrm{pBQ} 200 \text { (expression in } \\
\text { B. subtilis) }\end{array}$ & Arnold, 2009 \\
\hline pGP1512 & $\begin{array}{l}\text { ampicillin/ } \\
\text { erythromycin }\end{array}$ & $\begin{array}{l}\text { tpiA }(\mathrm{S} 213 \mathrm{~A}) \text { in } \mathrm{pBQ} 200 \\
\text { (expression in B. subtilis) }\end{array}$ & Arnold, 2009 \\
\hline pGP1513 & $\begin{array}{l}\text { ampicillin/ } \\
\text { erythromycin }\end{array}$ & $\begin{array}{l}p g k \text { in } \mathrm{pBQ} 200 \text { (expression in } \\
\text { B. subtilis) }\end{array}$ & Arnold, 2009 \\
\hline pGP1514 & $\begin{array}{l}\text { ampicillin/ } \\
\text { erythromycin }\end{array}$ & $\begin{array}{l}\text { pgk }(\mathrm{S} 183 \mathrm{~A}) \text { in } \mathrm{pBQ} 200 \text { (expression } \\
\text { in B. subtilis) }\end{array}$ & Arnold, 2009 \\
\hline
\end{tabular}




\begin{tabular}{cllc}
\hline Plasmid & Resistance & \multicolumn{1}{c}{ Description } & Referenz \\
\hline pGP1515 & $\begin{array}{l}\text { ampicillin/ } \\
\text { erythromycin }\end{array}$ & $\begin{array}{l}p g k(\mathrm{~S} 183 \mathrm{~A} / \mathrm{T} 299 \mathrm{~A}) \text { in } \mathrm{pBQ} 200 \\
\text { (expression in } \text { B. subtilis) }\end{array}$ & Arnold, 2009 \\
pGP1516 & $\begin{array}{l}\text { ampicillin/ } \\
\text { erythromycin }\end{array}$ & $\begin{array}{l}p g k(\mathrm{~S} 183 \mathrm{~A} / \mathrm{T} 299 \mathrm{~A}) \text { in } \mathrm{pBQ} 200 \\
\text { (expression in } \text { B. subtilis })\end{array}$ & Arnold, 2009 \\
pWH844 & ampicillin & overexpression vector & Schirmer et al., 1997
\end{tabular}

\subsection{Strains}

\section{Strains constructed in this work}

\begin{tabular}{|c|c|c|c|}
\hline Strain & Genotype & Construction $^{\mathrm{a}}$ & Reference \\
\hline GP576 & $\operatorname{trp} C 2 \Delta p r k C::$ spec & $\mathrm{LFH} \rightarrow 168$ & \\
\hline GP577 & $\operatorname{trp} C 2 \Delta y a b T:: m l s$ & $\mathrm{LFH} \rightarrow 168$ & \\
\hline GP578 & $\operatorname{trp} C 2 \Delta p r k D:: k a n$ & $\mathrm{LFH} \rightarrow 168$ & \\
\hline GP579 & $\operatorname{trp} C 2 \Delta p r k C:: s p e c \Delta y a b T:: k a n$ & $\mathrm{LFH} \rightarrow \mathrm{GP} 576$ & \\
\hline GP580 & $\operatorname{trp} C 2 \Delta p r k C:: s p e c \Delta p r k D:: k a n$ & GP578 $\rightarrow$ GP576 & \\
\hline GP581 & $\operatorname{trp} C 2 \Delta p r k C:: s p e c \Delta p r k D:: k a n$ & GP577 $\rightarrow$ GP578 & \\
\hline GP582 & $\begin{array}{l}\triangle y a b T:: \text { erm } \\
\text { trpC2 } \Delta \text { prkC::spec } \Delta p r k D:: k a n\end{array}$ & TMB293 $\rightarrow$ GP581 & \\
\hline GP583 & $\begin{array}{l}\triangle y a b T:: m l s \text { DliaF::cat } \\
\text { trpC2 } \Delta y m d B:: s p e c\end{array}$ & $\mathrm{LFH} \rightarrow 168$ & \\
\hline GP584 & $\operatorname{trp} C 2 \triangle p n p A:: k a n$ & $\mathrm{LFH} \rightarrow 168$ & Lehnik-Habrink \\
\hline GP585 & $\operatorname{trpC} 2$ amyE::(yabT-lacZ kan) & pGP831 $\rightarrow 168$ & $\begin{array}{c}\text { et al., subm. } \\
\text { - }\end{array}$ \\
\hline GP586 & $\operatorname{trpC} 2$ amyE::(prkC-lacZ kan) & pGP829 $\rightarrow 168$ & - \\
\hline GP587 & $\operatorname{trpC} 2$ amyE::(prkD-lacZ kan) & pGP830 $\rightarrow 168$ & - \\
\hline GP588 & $\begin{array}{l}\operatorname{trp} C 2 \Delta g \operatorname{lm} M:: \text { spec; complemented } \\
\text { with pGP400 }\end{array}$ & $\mathrm{LFH} \rightarrow 168$ & $\begin{array}{l}\text { Schmidl } \\
\text { et al., } 2010\end{array}$ \\
\hline
\end{tabular}




\begin{tabular}{|c|c|c|c|}
\hline Strain & Genotype & Construction ${ }^{a}$ & Reference \\
\hline GP589 & $\operatorname{trpC2} \Delta p y k:: c a t$ & $\mathrm{LFH} \rightarrow 168$ & - \\
\hline GP590* & $\operatorname{trp} C 2 \Delta p f k A:: c a t$ & $\mathrm{LFH} \rightarrow 168$ & - \\
\hline \multirow[t]{2}{*}{ GP591* } & $\operatorname{trpC} 2 \Delta f b a A:: c a t$ & $\mathrm{LFH} \rightarrow 168$ & - \\
\hline & & $0,5 \%$ glucose & \\
\hline \multirow[t]{2}{*}{ GP592* } & $\operatorname{trp} C 2 \Delta$ gapA::cat & $\begin{array}{l}0,5 \% \text { malate; } \mathrm{pH} \leq 7 \\
\mathrm{LFH} \rightarrow 168\end{array}$ & - \\
\hline & & $0,5 \%$ glucose & \\
\hline \multirow[t]{2}{*}{ GP593* } & $\operatorname{trp} C 2 \Delta p g m:: c a t$ & $\begin{array}{l}0,5 \% \text { malate; } \mathrm{pH} \leq 7 \\
\mathrm{LFH} \rightarrow 168\end{array}$ & - \\
\hline & & $0,5 \%$ glucose & \\
\hline \multirow[t]{2}{*}{ GP594* } & $\operatorname{trp} C 2 \Delta$ eno::cat & $\begin{array}{l}0,5 \% \text { malate; } \mathrm{pH} \leq 7 \\
\mathrm{LFH} \rightarrow 168\end{array}$ & - \\
\hline & & $0,5 \%$ glucose & \\
\hline \multirow[t]{2}{*}{ GP595* } & trpC2 $\Delta p f k:: e r m$ & $\begin{array}{l}0,5 \% \text { malate; } \mathrm{pH} \leq 7 \\
\mathrm{LFH}->168\end{array}$ & - \\
\hline & & $0,5 \%$ glucose & \\
\hline \multirow[t]{2}{*}{ GP596* } & $\operatorname{trp} C 2 \triangle f b a A:: \mathrm{erm}$ & $\begin{array}{l}0,5 \% \text { malate; } \mathrm{pH} \leq 7 \\
\mathrm{LFH}->168\end{array}$ & - \\
\hline & & $0,5 \%$ glucose & \\
\hline \multirow[t]{2}{*}{ GP597* } & $\operatorname{trp} C 2 \Delta$ gapA::erm & $\begin{array}{l}0,5 \% \text { malate; } \mathrm{pH} \leq 7 \\
\mathrm{LFH} \rightarrow 168\end{array}$ & - \\
\hline & & $0,5 \%$ glucose & \\
\hline \multirow[t]{2}{*}{ GP598* } & $\operatorname{trp} C 2 \Delta p g m:: e r m$ & $\begin{array}{l}0,5 \% \text { malate; } \mathrm{pH} \leq 7 \\
\mathrm{LFH} \rightarrow 168\end{array}$ & - \\
\hline & & $0,5 \%$ glucose & \\
\hline \multirow[t]{2}{*}{ GP599* } & trpC2 $\triangle$ eno::erm & $\begin{array}{l}0,5 \% \text { malate; } \mathrm{pH} \leq 7 \\
\mathrm{LFH} \rightarrow 168\end{array}$ & - \\
\hline & & $0,5 \%$ glucose & \\
\hline GP600 & trpC2 $\triangle p y k:: e r m$ & $\begin{array}{l}0,5 \% \text { malate; } \mathrm{pH} \leq 7 \\
\mathrm{LFH} \rightarrow 168\end{array}$ & - \\
\hline GP701 & $\operatorname{trpC2} \triangle$ gapB::spec & $\mathrm{LFH} \rightarrow 168$ & - \\
\hline GP702 & $\operatorname{trp} C 2 \Delta g a p B::$ spec $\Delta m g s A:: t e t$ & GP701 $\rightarrow$ GP67 & - \\
\hline \multirow[t]{3}{*}{ GP703* } & $\operatorname{trp} C 2 \Delta$ gapA::cat $\triangle$ gapB::spec & GP592 $\rightarrow$ GP701 & - \\
\hline & & $0,5 \%$ glucose & \\
\hline & & $0,5 \%$ malate; $\mathrm{pH} \leq 7$ & \\
\hline
\end{tabular}




\begin{tabular}{|c|c|c|c|}
\hline Strain & Genotype & Construction $^{a}$ & Reference \\
\hline \multirow[t]{2}{*}{ GP704* } & $\operatorname{trpC} \Delta \Delta$ pfk::erm $\Delta($ pgm eno $):: c a t$ & GP698 $\rightarrow$ GP595 & - \\
\hline & & $0,5 \%$ glucose & \\
\hline \multirow[t]{2}{*}{ GP705* } & $\operatorname{trp} C 2 \Delta g a p A:: c a t \quad \Delta m g s A:: t e t$ & $\begin{array}{l}0,5 \% \text { malate; } \mathrm{pH} \leq 7 \\
\text { GP592 } \rightarrow \text { GP67 }\end{array}$ & - \\
\hline & & $0,5 \%$ glucose & \\
\hline \multirow[t]{2}{*}{ GP706* } & $\operatorname{trp} C 2 \Delta$ gapA::erm $\Delta c c p N:: c a t$ & $\begin{array}{l}0,5 \% \text { malate; } \mathrm{pH} \leq 7 \\
\text { GP592 } \rightarrow \text { DB104 }\end{array}$ & - \\
\hline & & $0,5 \%$ glucose & \\
\hline \multirow[t]{2}{*}{ GP707* } & trpC2 $\triangle p g k:: e r m$ & $\begin{array}{l}0,5 \% \text { malate; } \mathrm{pH} \leq 7 \\
\mathrm{LFH} \rightarrow 168\end{array}$ & - \\
\hline & & $0,5 \%$ glucose & \\
\hline \multirow[t]{2}{*}{ GP708* } & $\operatorname{trp} C 2 \Delta(p f k A$ pyk $):: s p e c$ & $\begin{array}{l}0,5 \% \text { malate; } \mathrm{pH} \leq 7 \\
\mathrm{LFH} \rightarrow 168\end{array}$ & - \\
\hline & & $0,5 \%$ glucose & \\
\hline \multirow[t]{2}{*}{ GP709* } & $\operatorname{trp} C 2 \Delta($ tpiA pgm $):: s p e c$ & $\begin{array}{l}0,5 \% \text { malate; } \mathrm{pH} \leq 7 \\
\mathrm{LFH} \rightarrow 168\end{array}$ & - \\
\hline & & $0,5 \%$ glucose & \\
\hline \multirow[t]{2}{*}{ GP710* } & $\operatorname{trpC} 2 \Delta(p g k$ tpiA $)::$ spec & $\begin{array}{l}0,5 \% \text { malate } ; \mathrm{pH} \leq 7 \\
\mathrm{LFH} \rightarrow 168\end{array}$ & - \\
\hline & & $0,5 \%$ glucose & \\
\hline \multirow[t]{2}{*}{ GP711* } & $\operatorname{trp} C 2 \Delta($ pgk tpiA pgm eno)::spec & $\begin{array}{l}0,5 \% \text { malate; } \mathrm{pH} \leq 7 \\
\mathrm{LFH} \rightarrow 168\end{array}$ & - \\
\hline & & $0,5 \%$ glucose & \\
\hline \multirow[t]{2}{*}{ GP712* } & $\operatorname{trp} C 2 \Delta f b a A:: c a t \Delta p f k:: e r m$ & $\begin{array}{l}0,5 \% \text { malate; } \mathrm{pH} \leq 7 \\
\text { GP591 } \rightarrow \text { GP595 }\end{array}$ & - \\
\hline & & $0,5 \%$ glucose & \\
\hline \multirow[t]{3}{*}{ GP713* } & $\operatorname{trp} C 2 \Delta g a p B::$ spec $\Delta p g k:: e r m$ & $\begin{array}{l}0,5 \% \text { malate; } \mathrm{pH} \leq 7 \\
\text { GP707 } \rightarrow \text { GP701 }\end{array}$ & - \\
\hline & & $0,5 \%$ glucose & \\
\hline & & $0,5 \%$ malate; $\mathrm{pH} \leq 7$ & \\
\hline
\end{tabular}

a Arrows indicate construction by transformation.

* strains are unable to sporulate, genomic DNA is saved. Transformants require supplementation with glucose and malate. $\mathrm{pH}$ value of the media must be keept below 7 . 
Strains used in this work

\begin{tabular}{|c|c|c|}
\hline Strain & Genotype & Reference \\
\hline \multicolumn{3}{|l|}{ Escherichia coli } \\
\hline DH5 $\alpha$ & $\begin{array}{l}\text { recAl endA1 gyrA96 thi hsdR17rK- } \\
\mathrm{mK}+\text { relA1 supE44 } \Phi 80 \Delta \text { lacZ } \Delta M 15 \\
\Delta(\text { lacZYA-argF }) \mathrm{U} 169\end{array}$ & Sambrook et al., 1989 \\
\hline \multicolumn{3}{|l|}{ Bacillus subtilis } \\
\hline 168 & $\operatorname{trpC2}$ & Laboratory collection \\
\hline DB104 & $c c p N::$ cat & Licht et al., 2005 \\
\hline GP67 & $\operatorname{trp} C 2 \Delta m g_{s} A:: t e t$ & Landmann, Promo \\
\hline GP698 & $\operatorname{trp} C 2 \Delta($ pgm-eno $):: c a t$ & Arnold, 2009 \\
\hline GP699 & $\operatorname{trp} C 2 \Delta p g k:: c a t$ & Arnold, 2009 \\
\hline GP700 & $\operatorname{trp} C 2 \Delta t p i A:: c a t$ & Arnold, 2009 \\
\hline GP909 & $\operatorname{trpC2}$ amyE::(hag-lacZ cat) & Dietmaier, Promo \\
\hline TMB293 & $\Delta l i a F:: c a t$ & Mascher, unpublished \\
\hline E. coli stock 147 & Taq-polymerase & Nadicom \\
\hline QB5223 & $\operatorname{trpC2} p t s H 1$ & Martin-Verstraete et al.,1995 \\
\hline
\end{tabular}




\subsection{Construction of mutants}

\section{Mutants of glycolytic genes}
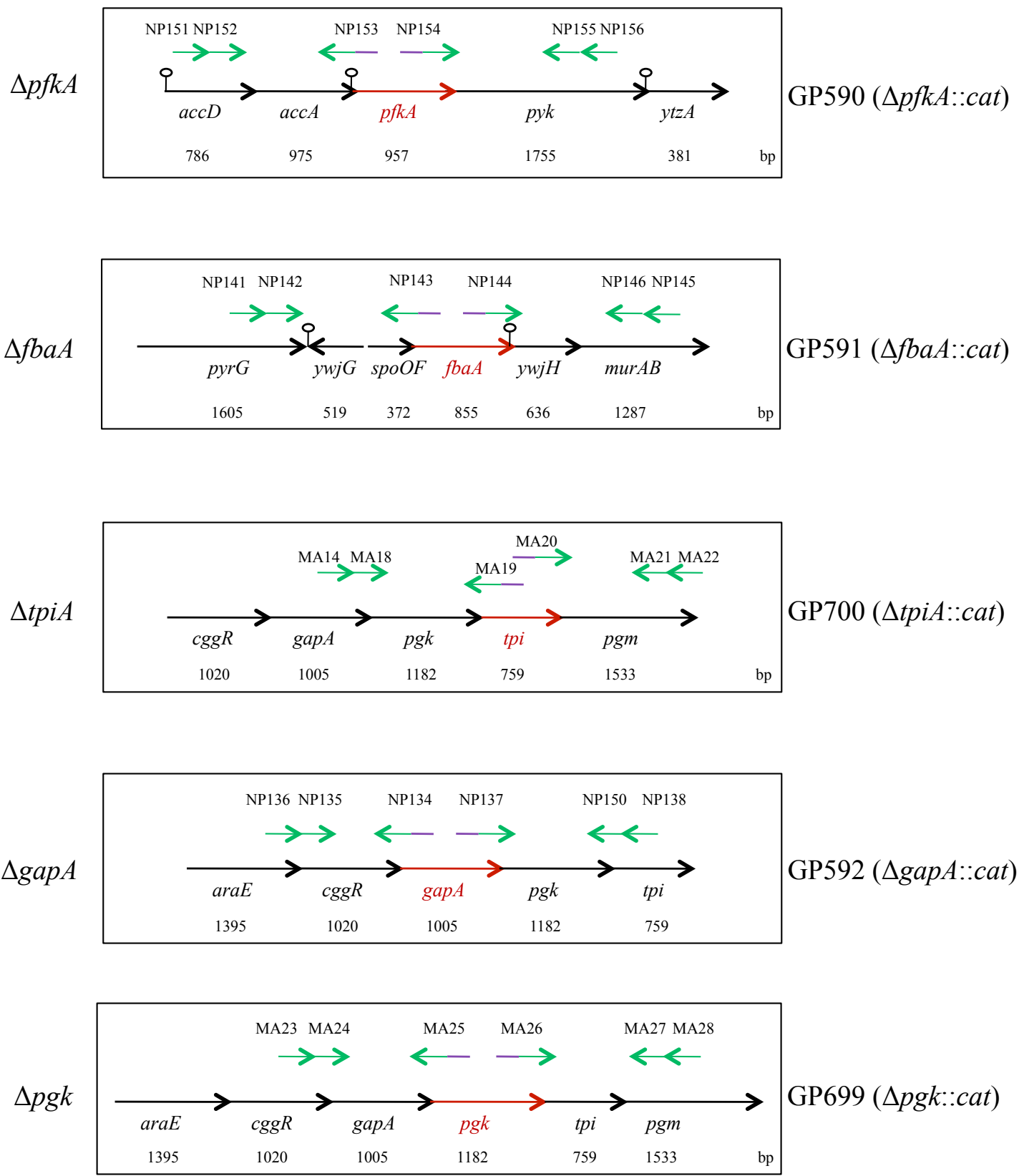
Appendix
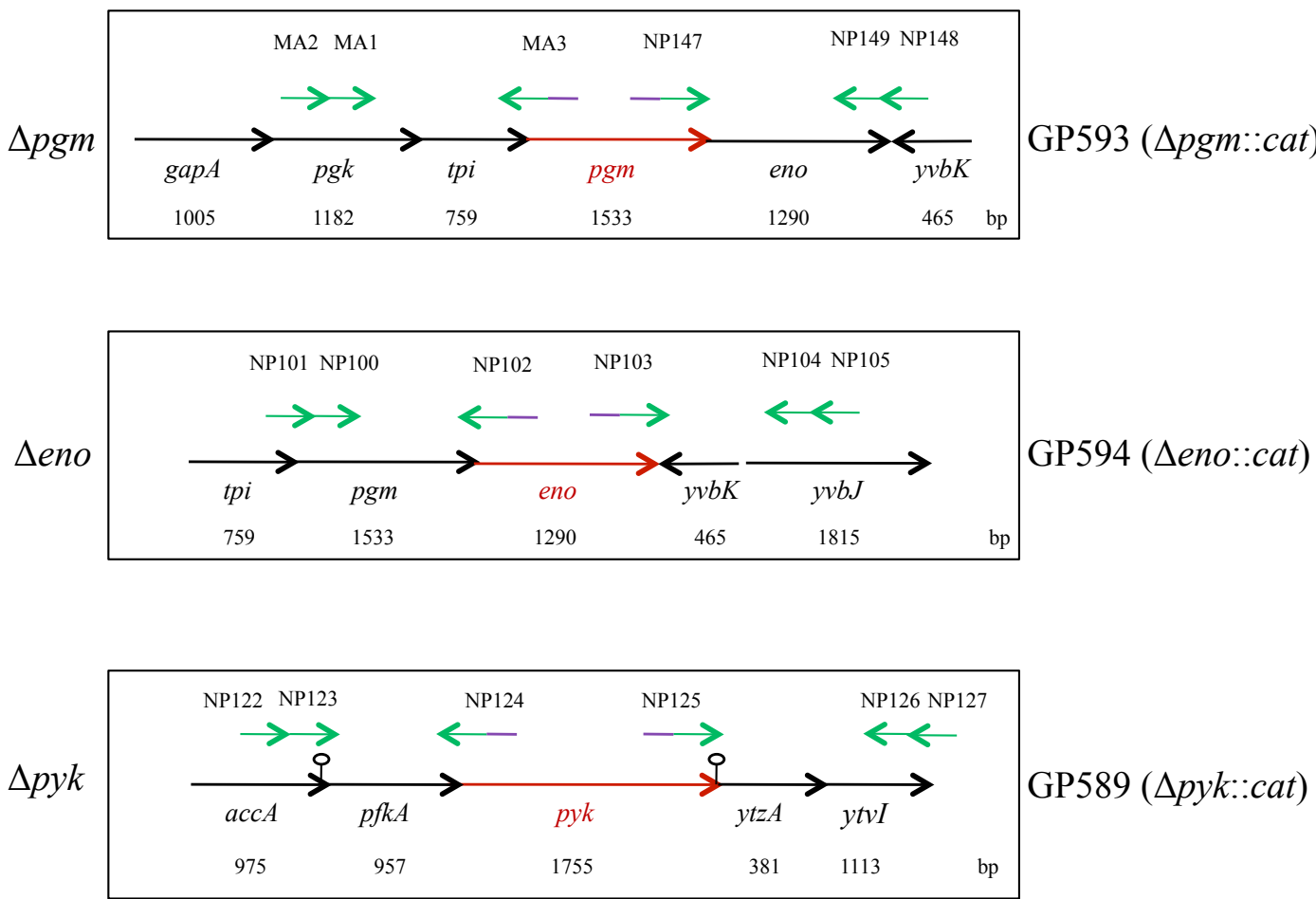

Additional mutants
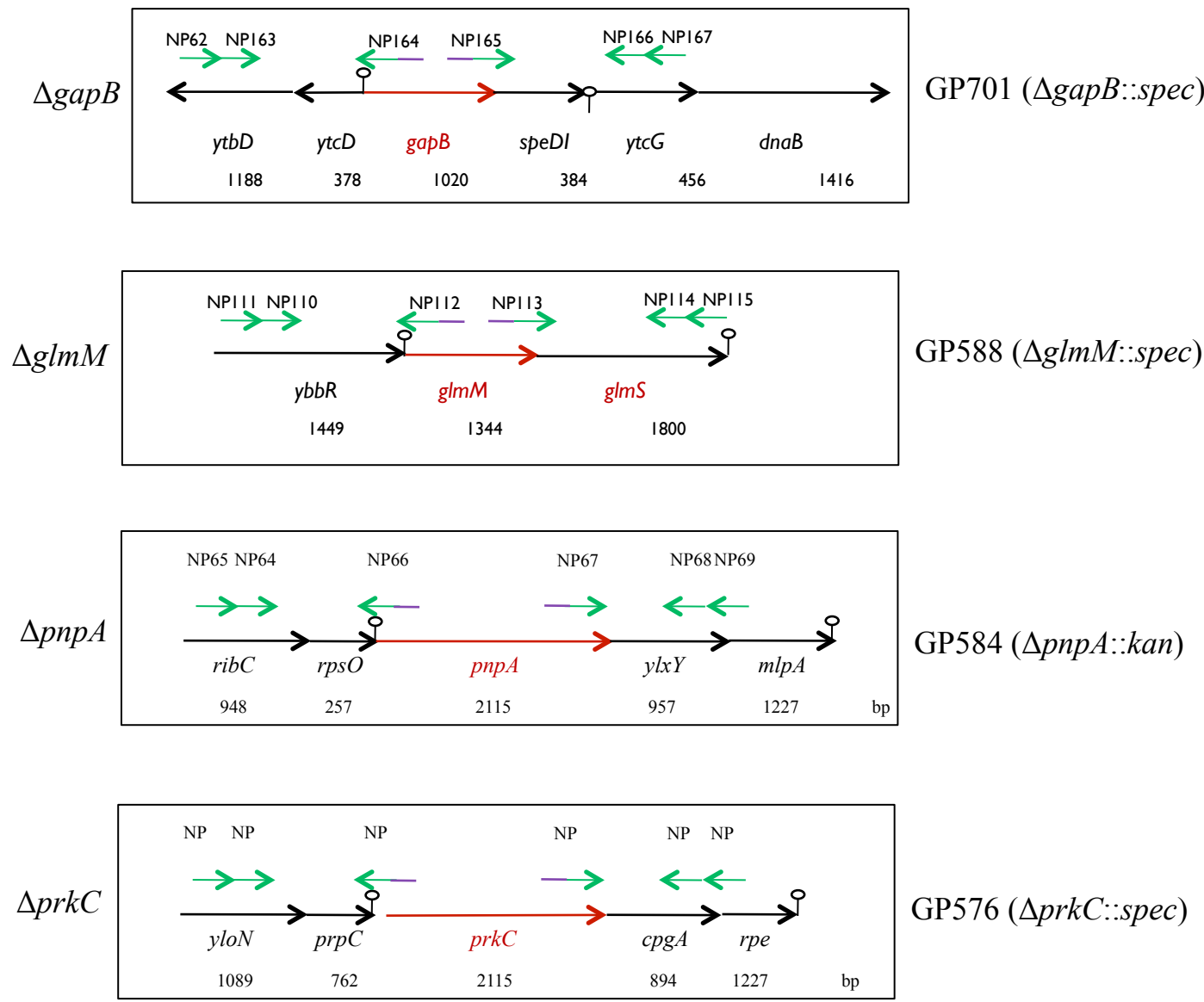

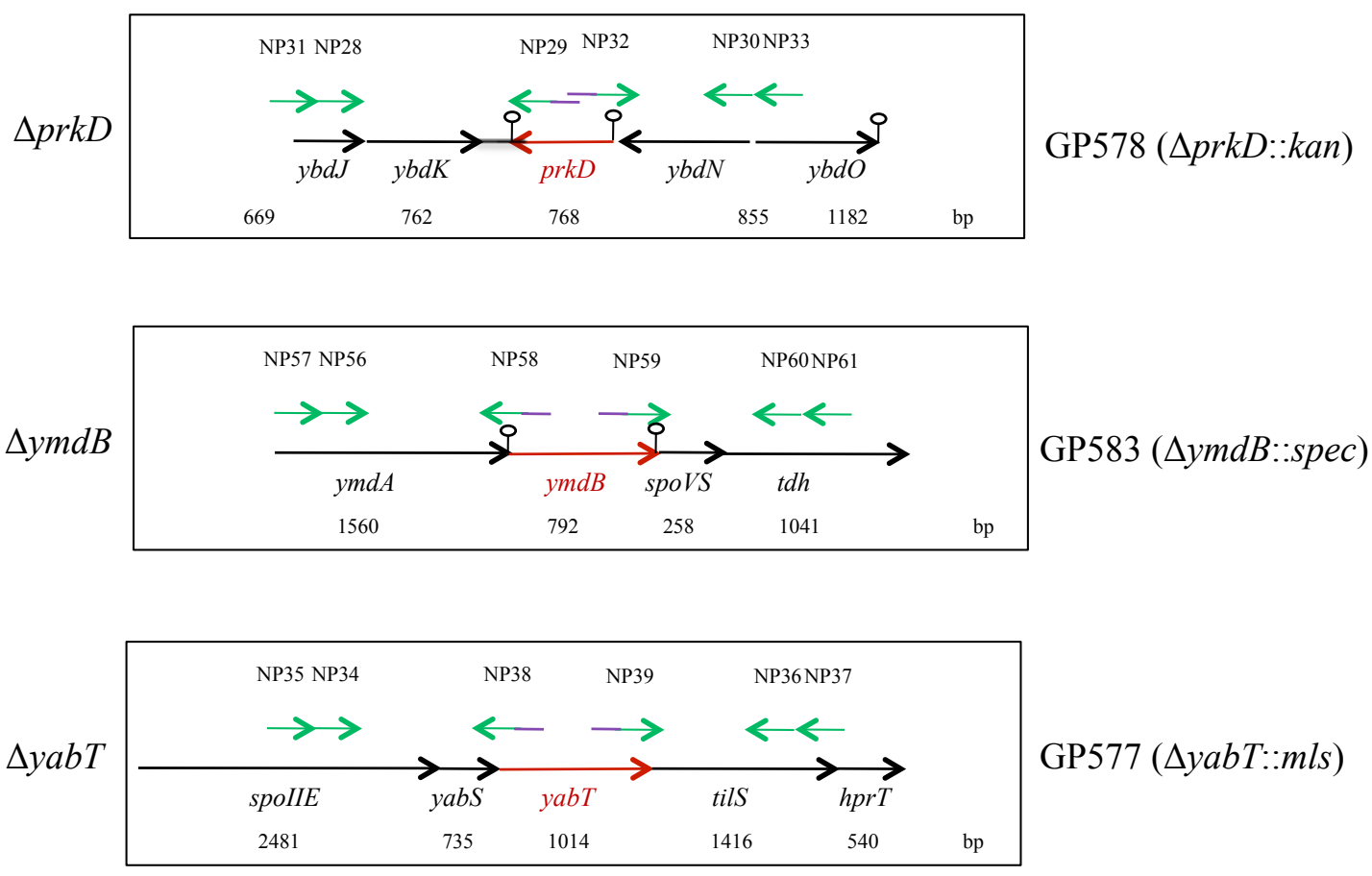


\section{Danksagung}

An erste Stelle danke ich Prof. Dr. Jörg Stülke für die Möglichkeit die vorliegende Arbeit in seiner Abteilung anfertigen zu dürfen und für die wertvolle Unterstützung.

Des Weiteren möchte ich Prof. Dr. Ralf Ficner, sowie Dr. Ingo Heilmann für die Übernahme des Korreferats danken. In diesem Zusammenhang möchte ich mich auch bei der GGNB für die Unterstützung und Förderung bedanken.

Prof. Dr. Michael Hecker, Dr. Dörte Becher und Katrin Gronau gebührt Dank für die professionelle Durchführung von Phosphoproteomenanalyse, sowie für die Identifizierung von Phosphorylierungsorten.

Christina Herzberg, hat mich insbesondere in den letzten Wochen in denen wir zusammen gearbeitet haben, mit viel Enthusiasmus und fachlicher Expertise unterstützt, dafür ein herzliches Dankeschön!

Bei meinem Freund und Kollegen Martin Lehnik-Habrink möchte ich mich für die schöne Zeit bedanken. Im gleichen Maße möchte ich Katrin Gunka und Dr. Fabian M. Commichau für die Diskussionsbereitschaft und Ratschläge danken. Arne Schmeisky, ja was soll ich jetzt sagen, ob als Anhänger von B-Movies oder Freund des Gärungsstoffwechsel,...,es hat auf jeden Fall immer Spaß gemacht! Meinen Büronachbarn Fabian Rothe (Frothe) und Frederik Meyer (Freddy) gilt Dank für die abwechslungsreichen, lustigen Einlagen. Auch möchte ich Christine Diethmaier dafür danken, dass sie, wie alle andere, die musikalische „Auswahl“ ausgehalten hat. SPICE, The Incredibles; Hinnerk Eilers, hat für mich den wissenschaftlichen Wahnsinn personifiziert, Danke dafür. Auch möchte ich PD Dr. Boris Görke, Jens J. Landmann und Denise Lüttmann für interessante Gespräche und Diskussionen danken. Jens danke ich auch für seine immer freundliche und geradlinige Art, sowie seine Beharrlichkeit. Des Weiteren möchte ich hier den Häuptling der IT-Abteilung, Lope Andres Flórez Weidinger, und Sebastian R. Schmidl erwähnen.

Bei meinen Praktikanten/innen: Martin Arnold, Martje Weidmann, Mandy Hannemann, Christian Schulz und Robert Hertel möchte ich mich für die tatkräftige Unterstützung 
bedanken. Außerdem danke ich meinem leider einzigen Diplomanden Martin „Arni“ Arnold für seine stets besonnene Art ;)

All denen, die mich in der Zeit dieser Arbeit begleitet haben und die hier nicht genannt wurden, möchte ich natürlich ebenfalls danken.

Ein besonderer Dank gilt meinen Eltern und Schwestern, die mir stets moralischen Rückhalt und Unterstützung geboten haben, Vielen Dank! 


\section{Curriculum vitae}

\section{Personal Information}

$\begin{array}{ll}\text { Name: } & \text { Nico Pietack } \\ \text { Date of birth: } & \text { July } 28^{\text {th }}, 1981 \\ \text { Place of birth: } & \text { Frankfurt (Oder), Germany } \\ \text { Parents: } & \text { Olaf Pietack and Gabriele Pietack, born Hannemann } \\ \text { Siblings: } & \text { Vanessa Pietack, Mandy Pietack } \\ \text { Nationality: } & \text { German }\end{array}$

\section{School Education}

$1988-1991$

Allgemeine polytechnische Oberschule Fürstenwalde

$1991-1994$

Theodor-Fontane Grundschule Fürstenwalde

$1994-2001$

Geschwister-Scholl-Gymnasium Fürstenwalde

$06 / 2001$

General university qualification (Abitur)

\section{Military service}

$2001-2002$

basic military service in Strausberg

\section{Scientific education}

$10 / 2002-04 / 2007$

study of biology, University of Göttingen

diploma thesis in the group of Prof. Dr. Jörg Stülke,

University of Göttingen

thesis title:

"Protein phosphorylation in Bacillus subtilis"

05/2007 - 05/2010 PhD project:

"Investigation of glycolysis in Bacillus subtilis"

Dept. of General Microbiology (Prof. Dr. Jörg Stülke)

University of Göttingen

Göttingen, 19.03.2010 